\title{
AVALIAÇÃO E IMPLEMENTAÇÃO DE UM SISTEMA DE ESTIMULAÇÃO ELÉTRICA NEURO-MUSCULAR PARA REABILITAÇÃO DOS MEMBROS SUPERIORES DE TETRAPLÉGICOS
}

\section{Alessandra Rossi Paolillo}

Dissertação apresentada ao Programa de PósGraduação Interunidades em Bioengenharia - Escola de Engenharia de São Carlos / Faculdade de Medicina de Ribeirão Preto / Instituto de Química de São Carlos - da Universidade de São Paulo, para obtenção do Título de Mestre em Bioengenharia.

Orientador: Prof. Dr. Alberto Cliquet Jr. 


\section{FOLHA DE APROVAÇÃO}

Tese defendida e aprovada em

pela comissão julgadora:

(Assinatura)

(Nome/Instituição)

(Assinatura)

(Nome/Instituição)

(Assinatura)

(Nome/Instituição)

(Assinatura)

(Nome/Instituição)

(Assinatura)

(Nome/Instituição) 


\section{DEDICATÓRIA}

Aos meus filhos Lucas e Marina,

que este trabalho seja um exemplo em suas vidas.

um exemplo de:

\section{LIMITES \\ DEDICAÇÃO \\ PERSEVERANÇA}

SUPERAÇÃO DE DIFICULDADES

Em fim, de ALEGRIA E ESPERANÇA ...

É IMPORTANTE SABER RECOMEÇAR SEMPRE ! 


\section{AGRADECIMENTOS}

A TODA minha família, em especial os meus pais, Marta e Nicola, pela minha vida, dedicação infinita e estímulos ao estudo.

Ao meu orientador Prof. Dr. Alberto Cliquet Jr. pela oportunidade e privilégio de ser sua aluna. Pelo exemplo de pessoa e profissional. Pela confiança e encaminhamento profissional.

Ao Prof. Dr. Luiz Eduardo Barreto Martins pela amizade e apoio científico para realização deste trabalho.

A minha irmã, Fernanda, pelo acompanhamento em todo trabalho, inclusive nas longas e longas madrugadas, nas viagens e viagens para Campinas, ...

Pelos pacientes e seus familiares, o que sem eles não seria possível a realização deste trabalho. Além da lição de vida ...

Ao Programa Interunidades Bioengenharia e ao Departamento de Engenharia Elétrica da USP, São Carlos. Ao Prof. Dr. José Carlos Pereira, Janete e Melaine pela organização burocrática do mestrado. A todos os Professores e Técnicos de Laboratório pelo incentivo aos estudos. Pela amizade e apoio de Rosane, Xaraba, José Carlos, Marisa, Denise, Jussara, Cida, Áurea, Kely e Valdir.

Ao Departamento de Ortopedia e Traumatologia da FCM/UNICAMP.

Ao Renato Varoto e Gustavo Freitas de Lima, alunos de Iniciação Científica, pela significativa colaboração no Projeto das Órteses.

Aos amigos do Departamento de Educação Física da UFSCar pelo estímulo para realização deste trabalho, em especial a Prof ${ }^{\mathrm{a}}$. Dr ${ }^{\mathrm{a}}$. Paula Hentschel Lobo da Costa, Prof ${ }^{\mathrm{a}}$. Ms. Selva Barreto, Prof ${ }^{\mathrm{a}}$. Dr ${ }^{\mathrm{a}}$. Ana Cláudia Duarte e Prof ${ }^{\mathrm{a}}$. Dr ${ }^{\mathrm{a}}$. Ana Dâmaso pela amizade e longas conversas nos momentos difíceis.

A todos, todos, sem exceção, a todos os meus amigos do LABCIBER (USPSão Carlos) e do Laboratório de Biomecânica e Reabilitação do Aparelho Locomotor (UNICAMP), pela amizade, colaboração e grandes momentos de convivência.

Ao Daniel Pavani, colega de mestrado, pela grande colaboração nesta pesquisa, principalmente com o uso do Mat Lab e a amiga Marcela Sene por todo suporte! financeiro.

A FAPESP (Processo $n^{\circ}$ 96/12198-2) e CAPES pelo apoio e suporte financeiro. 


\section{RESUMO}

Os objetivos desta pesquisa consistiram em contribuir para o projeto das órteses, realizar a análise cinemática do movimento de flexão/extensão do cotovelo, além de avaliar qualitativamente a independência na execução de Atividades de Vida Diária e o ganho neurológico decorrente de um período de 6 meses de Estimulação Elétrica Neuro-Muscular (EENM). Participaram desta pesquisa oito tetraplégicos e um sujeito saudável. As órteses foram projetadas e os primeiros protótipos desenvolvidos. As avaliações cinemáticas foram realizadas durante dez tentativas do movimento de flexão/extensão do cotovelo em diferentes atividades. As avaliações qualitativas foram realizadas com os Protocolos ASIA e FIM. As órteses mostraram eficácia e funcionalidade. A avaliação cinemática mostrou que durante os movimentos com EENM houve repetibilidade, mudança no tipo de onda (de pico para retangular) e aumento do tempo de execução da atividade, comparado ao movimento voluntário. Com preensão de objeto e adição de cargas, houve alteração no padrão cinemático do movimento para a maioria dos pacientes, que indica insegurança em relação a preensão, fraqueza muscular, bem como, perturbação e incoordenação do movimento; em outros casos, houve aumento da amplitude de onda e predominância do tipo em rampa durante a EENM, o que possivelmente indica ação sinergista. Os resultados dos protocolos ASIA e FIM mostraram ganho neurológico e aumento no índice de independência funcional, para a maioria dos pacientes, decorrentes dos efeitos terapêuticos da EENM. 


\begin{abstract}
The objectves of this research consisted of contributing for the orthosis project, to asses the knematics of the elbow flexion and extension, besides the qualitative evaluations of the independence to perform activities of daily living and neurological improvements due to a period of six months of Neuromuscular Electrical Stimulation (NMES). Eight tetraplegics and one healthy subject participated in this study. The orthosis was projected and the first prototypes were developed. The kinematic assessment consisted of ten trials of elbow flexion and extension in different activities. The qualitative evaluations were accomplished with the ASIA and FIM Protocols. The orthosis showed effectiveness and functionality. The kinematics analysis showed that during movements with NMES there was repeatability, change in the wave form (peak to rectangular) and increase in time of performed trials, compared to the voluntary movement. With prehension of object and addition of loads, there was alteration in the kinematics pattern of the movement for most of the patients, which indicates insecurity during the prehension, muscular weakness, as well as perturbation and movement incoordination. On the others cases, there were higher wave amplitudes and wave forms mostly in ramp during NMES, which possibly indicates synergist action. The results of the ASIA e FIM Protocols showed neurological improvements and also in the index of functional independence for most of the patients due to the therapeutic effects of NMES.
\end{abstract}




\section{LISTA DE FIGURAS}

FIGURA 1 - Coluna cervical (a), torácica (b) e lombo-sacral (c)...........................27

FIGURA 2 - Órtese estática para punho..............................................................33

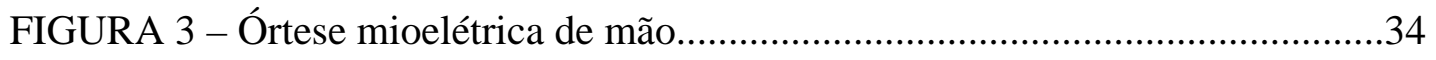

FIGURA 4 - Órtese mioelétrica de punho e mão para portadores de lesão no plexo

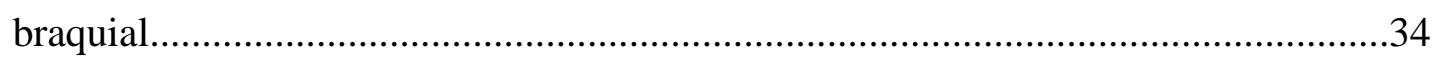

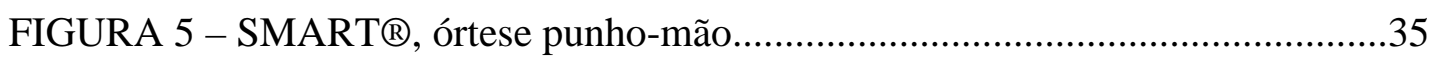

FIGURA 6 - Órtese mecânica para cotovelo...........................................................35

FIGURA 7 - HAG, órtese para membro superior..................................................36

FIGURA 8 - Pacientes com lesão medular cervical incompleta realizando a marcha assistida por EENM (a) e utilizando o sistema híbrido para marcha (b).....................38

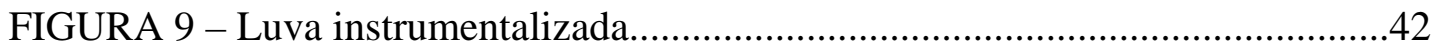

FIGURA 10 - Sistema de controle por eletroencefalograma..................................42

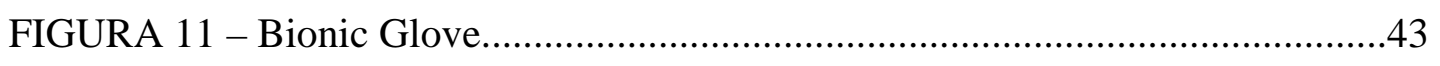

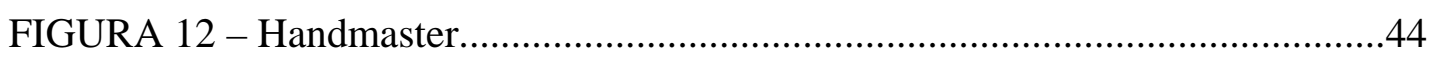

FIGURA 13 - Neuropróteses propostas pela equipe de Popovic..............................46

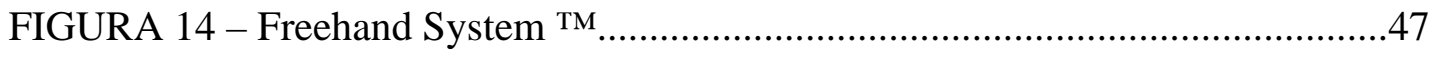

FIGURA 15 - Procedimento experimental sem preensão (a) e com preensão (b).....61

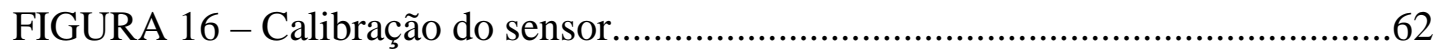

FIGURA 17 - Planificação (a) e primeiro protótipo da órtese de punho (b).............66

FIGURA18 - Diagrama de blocos da órtese robótica de cotovelo............................66

FIGURA19 - Projeto virtual (a) e primeiro protótipo da órtese robótica para cotovelo (b)...

FIGURA 20 - Medida Angular vs. Tempo durante o movimento de flexão e extensão do cotovelo do paciente 1: sem preensão e sem EENM (a); sem preensão e com EENM (b); com preensão e adição de cargas sem EENM (c); com preensão e adição de cargas com EENM. .76

FIGURA 21 - Medida Angular vs. Tempo durante o movimento de flexão e extensão do cotovelo do paciente 2: sem preensão e sem EENM (a); sem preensão e com EENM (b); com preensão e adição de cargas sem EENM (c); com preensão e adição de cargas com EENM .77 
FIGURA 22 - Medida Angular vs. Tempo durante o movimento de flexão e extensão do cotovelo do paciente 3: sem preensão e sem EENM (a); sem preensão e com EENM (b); com preensão e adição de cargas sem EENM (c); com preensão e adição de cargas com EENM .78 FIGURA 23 - Medida Angular vs. Tempo durante o movimento de flexão e extensão do cotovelo do paciente 4: sem preensão e sem EENM (a); sem preensão e com EENM (b); com preensão e adição de cargas sem EENM (c); com preensão e adição de cargas com EENM .79 FIGURA 24 - Medida Angular vs. Tempo durante o movimento de flexão e extensão do cotovelo do paciente 5: sem preensão e sem EENM (a); sem preensão e com EENM (b); com preensão e adição de cargas sem EENM (c); com preensão e adição de cargas com EENM.

FIGURA 25 - Medida Angular vs. Tempo durante o movimento de flexão e extensão do cotovelo do paciente 6: sem preensão e sem EENM (a); sem preensão e com EENM (b); com preensão e adição de cargas sem EENM (c); com preensão e adição de cargas com EENM

FIGURA 26 - Medida Angular vs. Tempo durante o movimento de flexão e extensão do cotovelo do paciente 7: sem preensão e sem EENM (a); sem preensão e com EENM (b); com preensão e adição de cargas sem EENM (c); com preensão e adição de cargas com EENM.

FIGURA 27 - Medida Angular vs. Tempo durante o movimento de flexão e extensão do cotovelo do paciente 8: sem preensão e sem EENM (a); sem preensão e com EENM (b); com preensão e adição de cargas sem EENM (c); com preensão e adição de cargas com EENM

FIGURA 28 - Medida Angular vs. Tempo durante o movimento de flexão e extensão do cotovelo do sujeito saudável: sem preensão e sem EENM (a); com preensão e adição de cargas sem EENM (b).

FIGURA 29 - Calibração do Sistema Qualisys (a) e procedimento experimental (b)......

FIGURA 30 - Variação angular vs. tempo durante a flexão e extensão do cotovelo do paciente 1 sem Estimulação Elétrica (a) e com EENM (b), utilizando o Sistema Qualisys. 120 
FIGURA 31 - Restauração da preensão em pinça durante as atividades

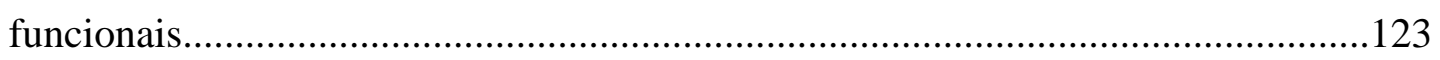

FIGURA 32 - Restauração da preensão em disco durante as aticvidades

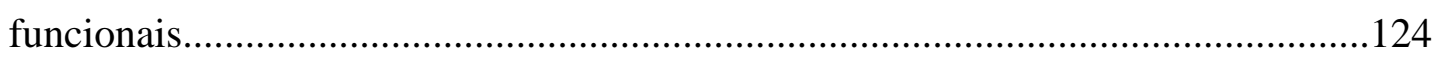

FIGURA 33 - Restauração da preensão lateral durante o ato de escovar os

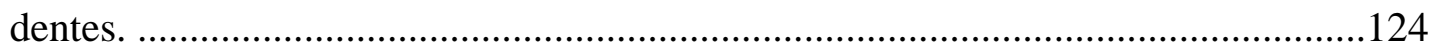

FIGURA 34 - Restauração da preensão palmar durante as atividades funcionais..125 FIGURA 35 - Procedimento experimental em neurofisiologia (a) e atividade muscular do grupo flexor do punho esquerdo do paciente 4 sem e com a EENM (b)... 


\section{LISTA DE TABELAS}

TABELA 1 - Classificação da capacidade motora remanescente dos membros superiores de tetraplégicos de acordo com o nível de lesão. .29

TABELA 2 - Perfil dos pacientes tetraplégicos participantes da pesquisa. .58

TABELA 3 - Medidas angulares da flexão e extensão do cotovelo dos pacientes 1, 2, 3 e 4 . .85

TABELA 4 - Medidas angulares da flexão e extensão do cotovelo dos pacientes 5, 6,

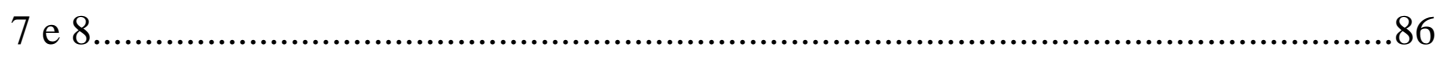

TABELA 5 - Medidas angulares da flexão e extensão voluntária do cotovelo do

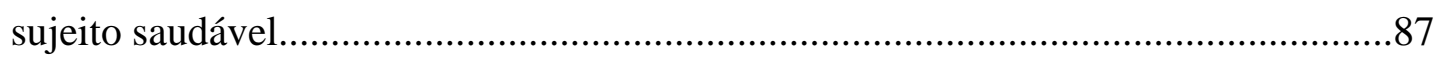

TABELA 6 - Protocolo ASIA e FIM (índice motor, sensorial e de independência

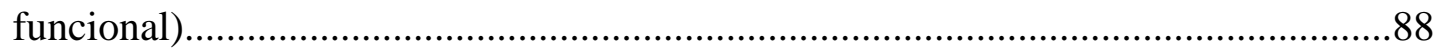

TABELA 7 - Protocolo ASIA (nível neurológico).................................................89 


\section{ABREVIAÇÕES E SIGLAS}

Além das abreviações e siglas, também são apresentadas algumas expressões técnicas utilizadas.

- AVDs: Atividades de Vida Diária

- ASIA: Escala de Deficiência da American Spinal Injury Association

- BGS: Belgrade Grasping System

- CPG: Gerador de Padrão Central

- Dermátomos: área da pele inervada por axônios sensitivos dentro de cada nervo segmentar (raiz)

- EENM: Estimulação Elétrica neuro-Muscular

- EMG: Eletromiografia

- FIM: Functional Independence Measure

- FSR: Sensores de força

- H-reflexo: Reflexo de Hoffmann

- HAG: Órtese Híbrida de braço

- H.O. Órtese de mão

- IBGE: Instituto Brasileiro de Geografia e Estatística

- LEDs: Emissores Luminosos na faixa de infravermelho

- MCV: Unidade de Captura de Movimento

- Miótomos: grupo de fibras musculares inervadas pelos axônios motores dentro de cada nervo segmentar (raiz)

- RNA: Redes Neurais Artificiais

- SMA: Shape Memory Alloy

- SNC: Sistema Nervoso Central

- SNS: Sistema Nervoso Simpático

- W.H.O.: Órtese de punho-mão

- 3-D: Tridimensional 


\section{SUMÁRIO}

\section{PREFÁCIO}

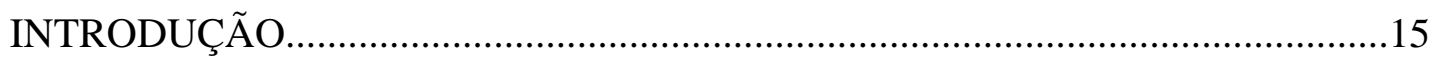

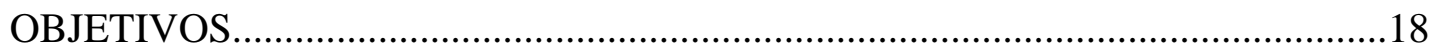

CAPÍTULO 1.........................................................................................19

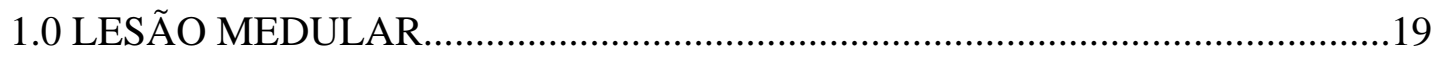

1.1 EPIDEMIOLOGIA E DEMOGRAFIA............................................................19

1.2 LESÃO MEDULAR AGUDA E CRÔNICA ………………………………......21

1.2.1 FISIOPATOLOGIA DA LESÃO MEDULAR......................................22

1.2.2 SEQÜELAS DA LESÃO MEDULAR..................................................23

1.3 O PRINCÍPIO DA REABILITAÇÃO DE LESADOS MEDULARES................25

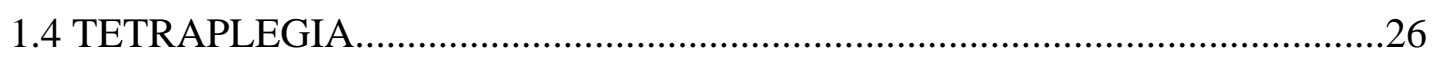

1.4.1 REABILITAÇÃO DE MEMBROS SUPERIORES DE

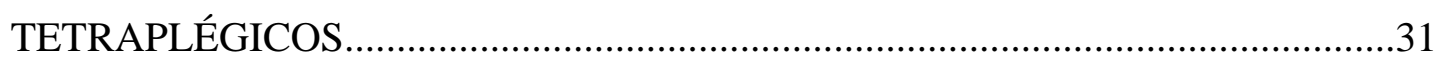

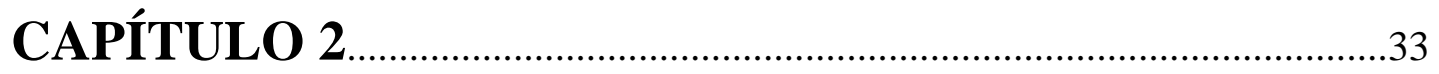

2.0 ÓRTESE, PRÓTESE E NEUROPRÓTESE......................................................33

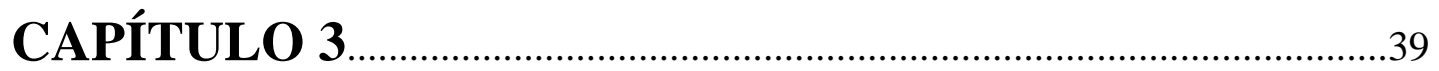

3.0 ESTIMULAÇÃO ELÉTRICA NEURO-MUSCULAR........................................39

3.1 NEUROPRÓTESES PARA MEMBROS SUPERIORES....................................41

3.2 EFEITOS TERAPÊUTICOS DA ESTIMULAÇÃO ELÉTRICA NEURO-

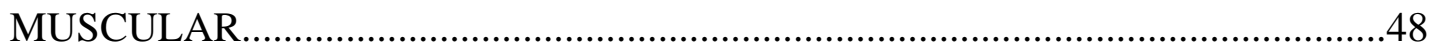

3.2.1 PLASTICIDADE NEURAL...............................................................49 


\section{CAPÍTULO 4}

4.0 ASPECTOS BIOMECÂNICOS APLICADOS À REABILITAÇÃO DE MEMBROS SUPERIORES

CAPÍTULO 5 .57

5.0 MATERIAIS E MÉTODOS . .57

5.1 RECURSOS HUMANOS . .57

5.2 METODOLOGIA. . .58

5.2.1 ÓRTESES INSTRUMENTALIZADAS PARA MEMBROS SUPERIORES. . .59

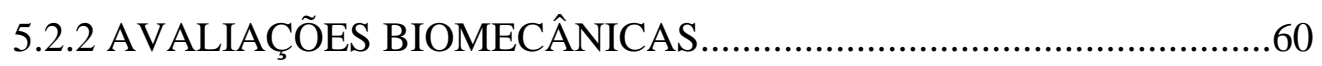

5.2.3 AVALIAÇÕES QUALITATIVAS......................................................63

5.3 ANÁLISE DOS DADOS...............................................................................64

CAPÍTULO 6 .65

6.0 RESULTADOS E DISCUSSÃO. .65

6.1 ÓRTESES INSTRUMENTALIZADAS PARA MEMBROS SUPERIORES. . .65

6. 2 AVALIAÇÕES QUANTITATIVAS E QUALITATIVAS...................................67

6.2.1 ESTUDOS DE CASO. .67

6.2.2 RESULTADOS COM OS VALORES BRUTOS DOS PACIENTES TETRAPLÉGICOS E DO SUJEITO SAUDÁVEL......................................................76

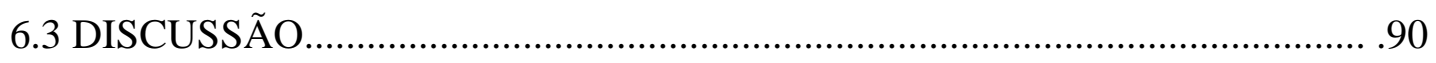

CONSIDERAÇÕES FINAIS............................................................103

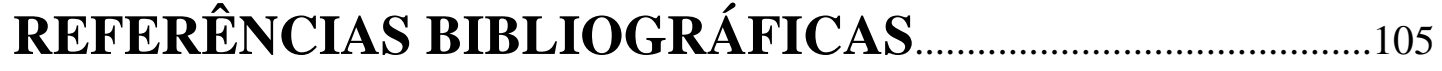


APÊNDICE A - o eStUdo PILOTO COM O SISTEMA QUALISYS

APÊNDICE B - RESTAURAÇÃO DE PREENSÕES, MOVIMENTOS DE ALCANCE E DESLOCAMENTO DO MEMBRO SUPERIOR NO ESPAÇO DURANTE ATIVIDADES DE VIDA DIÁRIA

APÊNDICE C - REFLEXOS INTERMEMBROS EM TETRAPLEGIA

ANEXO A - TERMO DE CONSENTIMENTO PÓS - INFORMAÇÃO

ANEXO B - PROTOCOLOS ASIA E FIM 


\section{INTRODUÇÃO}

O desenvolvimento tecnológico resultante da II Guerra mundial refletiu nos avanços das Ciências Médicas e da Reabilitação, para a recuperação dos feridos. Com o conseqüente aumento do número de deficientes físicos surgiu a necessidade de profissionais especializados e de técnicas específicas para intervenção terapêutica. A Terapia Ocupacional, que até então tinha sua atuação predominantemente na área de saúde mental, passa a contribuir para a reabilitação física.

Os portadores de deficiências físicas, em especial os portadores de lesão medular, são geralmente jovens que têm o auge de suas vidas profissionais e pessoais abruptamente interrompidas e modificadas, devido às seqüelas adquiridas em decorrência de acidentes ou patologias. Sendo necessário o trabalho em equipes multidisciplinares, visando a implementação e o aprimoramento das técnicas de reabilitação, para que possam atingir o bem-estar bio-psico-social, consistindo em desafios para a Engenharia de Reabilitação atual.

Indivíduos que possuem pouco ou nenhum controle voluntário sobre os movimentos dos membros superiores, devido a uma lesão que comprometa suas funções, apresentam impedimentos ou dificuldades na realização de atividades simples do cotidiano, o que gera perda de independência e diminuição da qualidade de vida.

Os métodos de reabilitação convencionais apresentam limitações no que se refere à recuperação dos movimentos de indivíduos com lesão medular, sendo motivo de frustração para pacientes, seus familiares e terapeutas. 
As limitações referentes à recuperação e/ou restauração dos movimentos de indivíduos portadores de lesão medular têm como solução o desenvolvimento científico-tecnológico e seus produtos, daí a importância das Neuropróteses e das órteses robóticas.

As Neuropróteses através de Estimulação Elétrica Neuro-Muscular (EENM) são usadas para restaurar e/ou recuperar as funções sensório-motoras perdidas em portadores de lesão neurológica (KEITH, 2001). Esta técnica consiste na ativação artificial dos músculos esqueléticos, através de formas de pulsos aplicados no ponto motor ou diretamente no nervo, gerando seletivamente potenciais de ação, produzindo contração muscular (BHADRA, KILGORE e PECKHAM, 2001).

A Estimulação Elétrica Neuro-Muscular possibilita a recuperação sensóriomotora, devido aos efeitos terapêuticos, como aumento da força e volume muscular, redução da espasticidade e rigidez, melhora da circulação sangüínea e plasticidade neural (DALY et al., 1996); (HANDA, 1997); (MELA, VELTININK \& HUIJING, 2001); (SKÖLD et al., 2002).

Os sistemas de estimulação privilegiam os movimentos de mão, pois dependendo do nível de lesão medular, os tetraplégicos preservam os movimentos de ombro e cotovelo. Entretanto, o estágio de funcionalidade dos membros superiores de indivíduos tetraplégicos depende do nível em que ocorreu a lesão, necessitando ou não do auxílio de órteses mecânicas para melhor execução dos movimentos desejados.

Quando a resposta muscular à estimulação é insuficiente devido a denervação periférica, atrofia por desuso, além de outras causas, o sistema mecânico tem a finalidade de substituir ou aumentar a função muscular (NATHAN, 1989); (WIERZBICKA \& WIEGNER, 1996).

As órteses robóticas são um importante coadjuvante da Estimulação Elétrica, potencializando o ganho de função em portadores de lesão neurológica, em especial os tetraplégicos. Quando usados simultaneamente, são denominados Sistema Híbrido.

A avaliação cinemática do membro superior de tetraplégicos, em especial do movimento de alcance, é importante para viabilizar a implementação da neuroprótese de mão (CLIQUET, Jr, \& CASTRO, 2000 a); (CLIQUET, Jr, \& CASTRO, 2000 b), 
bem como para avaliar a necessidade do uso do Sistema Híbrido, além da obtenção de parâmetros para o desenvolvimento de órteses robóticas.

Portanto, para a reabilitação de membros superiores dos portadores de tetraplegia é importante privilegiar tanto a preensão quanto à função de deslocamento do membro superior no espaço, para que o ato de alcançar, pegar e largar objetos facilite as atividades de vida diária, possibilitando a recuperação sensório-motora e melhora da qualidade de vida, com conseqüente aumento da independência, redução do custo com cuidadores, além de poupar os familiares quando exercem esta função. 


\section{OBJETIVO GERAL}

Avaliar os benefícios de um programa de seis meses de EENM sobre a reabilitação de pacientes tetraplégicos e implementar um sistema de Estimulação Elétrica Neuro-Muscular para a reabilitação dos membros superiores de portadores de tetraplegia.

\section{OBJETIVOS ESPECÍFICOS}

1. Contribuir para o projeto e desenvolvimento de órteses instrumentalizadas para membros superiores.

2. Realizar as medidas angulares da flexão/extensão do cotovelo para contribuir com estratégias para o controle de órtese e neuroprótese para o movimento de alcance.

3. Avaliar o aumento da independência na execução de Atividades de Vida Diária e o ganho neurológico decorrentes do programa de EENM durante seis meses de tratamento. 


\section{CAPÍtUlo 1}

\subsection{LESÃO MEDULAR}

A incidência de lesão medular tem aumentado em vários países, gerando grande impacto social e econômico, envolvendo não só o paciente - que apresenta perda da função motora e sensorial abaixo do nível da lesão - mas também sua família e a sociedade. Devido à severidade das seqüelas adquiridas, torna-se necessária a atuação de equipes multidisciplinares, visando a reabilitação e o bem estar geral do indivíduo.

\subsection{EPIDEMIOLOGIA E DEMOGRAFIA}

Dados estatísticos americanos revelam que existem entre 183.000 e 230.000 portadores de lesão medular naquele país, não incluindo aqueles que vieram a óbito no local do acidente. A estimativa é de aproximadamente 11.000 novos casos a cada ano. As principais causas citadas de lesão medular traumática foram: acidentes automobilísticos, violência, quedas, esportes e atividades de lazer, principalmente o mergulho (BELANGER \& LEVI, 2000); (SEKHON \& FEHLING, 2001); (www.spinalcord.uab.edu).

Dos portadores de lesão medular americanos, 82\% são homens e 18\% mulheres, sendo a faixa etária mais atingida a de 16 a 30 anos. Do total dos americanos portadores de lesão medular, 21.3\% possuem paraplegia incompleta, 27.3\% paraplegia completa, $29.5 \%$ tetraplegia incompleta e $18.5 \%$ tetraplegia 
completa. Estima-se que o custo do tratamento desses pacientes nos Estados Unidos, seja entre \$ 168.627 e \$ 572.178 para o primeiro ano após a lesão e, entre \$ 11.817 e \$ 102.491 para os anos seguintes (www.spinalcord.uab.edu).

Os custos mais elevados estão relacionados ao nível de lesão, sendo o maior custo associado aos pacientes tetraplégicos, dependentes da ventilação artificial (BELANGER \& LEVI, 2000). As despesas iniciais são com o hospital, modificações nas residências, processo de reabilitação, equipamentos para adaptações e perda da produtividade (SEKHON \& FEHLING, 2001).

No Brasil, segundo a pesquisa do Instituto Brasileiro de Geografia e Estatística - IBGE (www.ibge.gov.br), os dados obtidos no CENSO de 1991 indicam que, do total da população residente (157.070.163 habitantes totalizando área urbana e rural), foram considerados deficientes físicos: os portadores de cegueira, surdez, deficiência mental, falta de membros ou parte deles, hemiplegia (208.572), paraplegia (201.592) e tetraplegia (46.998).

Entretanto, observa-se falha nos conceitos de deficiência física e mental, incluídos na mesma categoria. No CENSO de 2000 já houve a reparação parcial destes conceitos, mas mesmo assim, continuam obscuros os dados relativos ao número de portadores de hemiplegia, paraplegia e tetraplegia, que estão englobados na mesma categoria, totalizando 955.287 , sendo $55.21 \%$ homens e $44.78 \%$ mulheres.

De acordo com os dados do IBGE, a região Sudeste apresenta-se com maior concentração de portadores de hemiplegia, paraplegia e tetraplegia tanto no ano de 1991 (197.853) quanto em 2000 (411.547), seguidos pelas regiões: Nordeste, Sul, Centro-Oeste e Norte. Entretanto, os dados sobre a etiologia das deficiências não foram registrados.

Segundo os registros da Rede Sarah de Hospitais do Aparelho Locomotor (www.sarah.br), desde de 1995, as principais causas de internações de pacientes com lesão medular foram decorrentes de acidentes de trânsito e vítimas de disparos de arma de fogo, constituindo atos de violência social.

Os pacientes foram caracterizados como sendo a maioria adultos jovens, do sexo masculino (75.9\%), solteiros (51\%), com escolaridade até o ensino fundamental 
(54.3\%), residentes em área urbana (90.7\%) e pertencentes a faixa etária entre 15 e 39 anos.

Do total de pacientes internados nesta instituição, 44\% apresentaram lesão medular (paraplegia, 61.6\% e tetraplegia, 38.4\%), sendo a etiologia predominante, acidentes de trânsito (38.3\%), seguido por arma de fogo (34.2\%), queda (13.8\%), mergulho $(8.8 \%)$ e outras causas $(4.9 \%)$.

Portanto, existe a necessidade da criação de programas preventivos que encorajem crianças e adultos a modificarem os comportamentos de riscos, visando a redução da incidência de lesão medular.

Além das lesões medulares traumáticas, podem ocorrer as não-traumáticas, que podem ser geradas por vários fatores, como as neoplasias (neurofibroma, meningeoma, ependimoma, astrocitoma, glioblastoma e um grupo misto, incluindo lesões freqüentes e raras, como cistos dermoides e epidermoides, cistos epidurais (lipomas e hemangiomas), os acidentes vasculares ou hérnias de disco e ainda as infecções causadas por vírus e bactérias (ISELI et al., 1999); (YOCK, 1995).

\subsection{LESÃO MEDULAR AGUDA E CRÔNICA}

A medula espinhal é o principal condutor de informações sensoriais e motoras entre o Sistema Nervoso Central e Periférico, sua lesão pode resultar em tetraplegia e paraplegia.

Tetraplegia é o termo que descreve a diminuição ou perda da função motora e/ou sensorial dos segmentos cervicais, devido a lesão dos elementos neurais dentro do canal medular, resultando em redução da função dos membros superiores, tronco, membros inferiores e órgãos pélvicos. Porém, não inclui lesões do plexo braquial ou dos nervos periféricos fora do canal vertebral (BARROS FILHO et al., 1994); (BURNS \& DITUNNO, 2001).

Paraplegia é o termo que descreve a diminuição ou perda da função motora e/ou sensorial dos segmentos torácicos, lombares ou sacrais, secundários a lesões nos elementos neurais dentro do canal vertebral. A paraplegia deixa íntegro os membros 
superiores, porém pode comprometer o tronco, os membros inferiores e os órgãos pélvicos. Este termo também é usado para descrever lesões da cauda eqüina e cone medular, porém não inclui as lesões do plexo lombo-sacral ou lesões de nervos periféricos fora do canal vertebral (BARROS FILHO et al., 1994); (BURNS \& DITUNNO, 2001).

A lesão medular completa é definida pela ausência da função sensorial e motora no segmento sacral mais inferior. A lesão incompleta é definida pela presença da função sensorial e/ou motora no segmento sacral mais inferior. O termo zona de preservação parcial é aplicado somente para lesões completas, refere-se aos dermátomos e miótomos caudais para o nível de lesão neurológico que mantém inervação parcial. O termo choque espinhal refere-se ao período de ausência até a presença de reflexos após a lesão (BARROS FILHO et al., 1994); (BURNS \& DITUNNO, 2001).

\subsubsection{FISIOPATOLOGIA DA LESÃO MEDULAR}

No momento do trauma, se as forças externas forem de magnitude suficiente para sobrepor a resistência das estruturas ósteoligamentares da coluna, a energia será transmitida para a medula espinhal, criando a primeira lesão. Estas forças podem resultar em contusão, hemorragias, rompimento ou laceração da medula espinhal. O processo de lesão secundária segue a lesão primária e inclui interrupção da microcirculação, perda da autorregulação, edema, anóxia, isquemia e alterações específicas do metabolismo das células, podendo causar morte celular, que agravará o quadro clínico (BELANGER \& LEVI, 2000); (SEKHON \& FEHLING, 2001).

Durante a fase aguda, para minimizar e prevenir a lesão secundária é utilizado procedimento padrão de imobilização espinhal no local do acidente, que consiste na colocação do colar cervical, transporte adequado, atendimento especializado e rápido. Entretanto, a imobilização imprópria pode causar deslocamento da fratura e comprometimento da função medular, convertendo uma lesão com bom prognóstico em uma mais severa (KELLY \& BECKER, 2001).

O tratamento médico com esteróides (metilpredinisolona) deverá ser iniciado nas primeiras oito horas após a lesão e também previne/reduz a lesão secundária 
(LANKHORST et al., 2000); (POYNTON et al., 1997); (TAOKA \& OKAJIMA, 1998). O tratamento cirúrgico em pacientes lesados medulares consiste em posicionar a medula espinhal e os nervos em uma condição ideal para recuperação, devendo ser acompanhado da descompressão das estruturas neurológicas ou correção das deformidades ósseas (BELANGER \& LEVI, 2000).

Já na fase crônica, os avanços consistem no tratamento cirúrgico da siringomielia, das deformidades pós-traumáticas tardias e controle da dor. As demais seqüelas podem ser prevenidas, minimizadas ou revertidas, através de métodos de reabilitação convencionais e não convencionais (BURNS \& DITUNNO, 2001); (RAPADO, 1996).

\subsubsection{SEQÜELAS DA LESÃO MEDULAR}

Além das disfunções sensório-motoras que acometem os portadores de lesão medular, tratadas através de técnicas de reabilitação, existem outras seqüelas que comprometem o estado de saúde geral destes indivíduos.

A siringomielia pós-traumática é caracterizada por acúmulo de líquido céfaloraquidiano na medula e conseqüente dilatação do canal central. A incidência de siringomielia depende do nível de lesão e de sua severidade, sendo que os sintomas incluem perda motora progressiva e sensorial dissociada (propriocepção preservada com perda da sensibilidade a dor e temperatura). O fator inicial pode ser decorrente do aumento da resistência do fluxo deste fluído, causado por fibrose, compressão, deformidade espinhal e esforço físico, podendo aumentar o nível da lesão (ASANO et al., 1996); (BELANGER \& LEVI, 2000).

A espasticidade é uma desordem motora caracterizada pelo aumento do tônus muscular dependente da velocidade, durante o reflexo de estiramento, em indivíduos com lesão no neurônio motor superior. Isto ocorre devido a ruptura da transmissão de informações entre o córtex cerebral e o neurônio motor inferior, com subseqüente redução no efeito de modulação dos centros mais altos sobre a unidade motora (FENG \& MAK, 1997); (MUSA, 1986). A espasticidade pode resultar em dor, distúrbios posturais e contraturas permanentes. Quando a espasticidade é de moderada à severa, a fisioterapia, os procedimentos cirúrgicos-ortopédicos e drogas 
antiespásticas, como o bloqueador neural com álcool ou fenol e o baclofen podem apresentar limitações. Entretanto, a aplicação de toxina botulínica demonstra ser um tratamento promissor indicado por estudos (DUNE, HEYE \& DUNE, 1995). Outros medicamentos utilizados são o diazepan, dantrolene sodium e clonidine (BELANGER \& LEVI, 2000). A hidroterapia (PAGLIARO \& ZAMPARO, 1999) e a Estimulação Elétrica Neuromuscular, também são indicadas para o tratamento desta seqüela.

O tratamento da dor após a lesão medular pode ser frustrante, mas agentes inovadores, como terapias que previnem a lesão secundária e as novas classes de analgésicos, previnem a dor neuropática abaixo do nível de lesão (BURNS, 2001).

Outras seqüelas são as úlceras de pressão e a ossificação heterotópica, que freqüentemente ocorre em grandes articulações, causando dor, calor, inchaço e contratura (DEC, SPARROW \& McKEAG, 2000), (SEKHON et al., 2001). A osteopenia/osteoporose, pode gerar fraturas ósseas em portadores de lesão medular (BLOOMFIELD, 1997); (CARVALHO, CARVALHO \& CLIQUET Jr., 2001).

Também ocorrem redução da massa, volume e força muscular, redução de enzimas oxidativas, predominância de fibras rápidas em comparação com as lentas e mudanças neuromusculares, como alterações no recrutamento de unidades motoras (EDGERTON et al., 2000).

A descentralização do Sistema Nervoso Simpático, causa a disfunção autonômica, que interfere nas ocorrências fisiológicas das funções urogenital, gastrointestinal, termorregulatória, cardiovascular, pulmonar, metabólica e hormonal. Em indivíduos com nível de lesão medular acima de T6, geralmente ocorre hiporreflexia ou hiperreflexia do Sistema Nervoso Simpático (SNS).

A disreflexia autonômica (hiperreflexia do SNS) é desencadeada por estímulo nociceptivo ou viceral abaixo do nível de lesão que induz a hipertensão, bradicardia, piloereção e suor acima do nível de lesão (KARLSSON et al., 1998); (ROGERS, 2002).

A insuficiência da resposta termorregulatória ocorre devido a perda ou deficiência da resposta vasomotora e sudorípara, que reduz a capacidade de tetraplégicos e paraplégicos tolerarem temperaturas extremas (DEC, SPARROW \& McKEAG, 2000). 
A ausência da bomba muscular/respiratória e redução do tônus vascular nos músculos paralisados, geram estasis venosa nos membros inferiores, dificultando o retorno venoso e diminuindo a eficiência cardíaca, podendo conduzir a hipotensão durante o ortostatismo ou exercícios com os membros superiores (GLASER et al., 2002); (HOPMAN et al., 1998).

Ocorre ainda a redução das dimensões cardíacas (HUONKER et al., 1998), e diminuição da capacidade respiratória (BAYDUR, ADKINS \& MILIC-EMILI, 2001). Nos portadores de lesões cervicais altas, ainda há necessidade da utilização de terapia com ventilação artificial (BÜHREN, POTULSKI \& JAKSCHE, 1999).

Devido às freqüentes infecções urinárias, podem ocorrer cálculo e disfunção renal. Outra complicação pode ser devido a ausência do reflexo de tosse e/ou acúmulo de secreções, além do prolongado período de permanência na cama, que aumenta o risco em adquirir pneumonia (SEKHON \& FEHLING, 2001).

Estas seqüelas conduzem a diminuição da qualidade de vida de portadores de lesão medular, afetando em maior extensão os tetraplégicos, que apresentam maior insatisfação e sofrimento mental, devido à redução da funcionalidade física, acessibilidade, amizade, função social, ocupação, sexualidade, atividades de lazer e aumento da estigmatização, dependência e despesa financeira (BÉNONY et al., 2002); (MANNS \& CHAD, 2001); (van der SLUIS et al., 1998).

Entretanto, desde o final da Segunda Guerra Mundial, o Canadian Department of Veterans Affairs, por exemplo, tinham como principais metas a reabilitação e reinserção social dos indivíduos portadores de lesão medular, favorecendo a acessibilidade e o retorno às atividades profissionais, educacionais e de lazer, juntamente com a criação de associações para defenderem os direitos dos deficientes físicos (TREMBLAY, 1996).

\subsection{O PRINCÍPIO DA REABILITAÇÃO DE LESADOS MEDULARES}

Segundo Tremblay (1996), os métodos de tratamento para lesados medulares durante a Primeira Guerra Mundial não apresentavam sucesso. Nas primeiras 
semanas após a lesão, 80\% dos indivíduos morriam devido as infecções renais, pulmonares e nas úlceras de pressão, por estarem acamados. Os que sobrevivessem permaneceriam como “inválidos”, necessitando de cuidados em casa ou no Hospital. Na década de 1930, alguns médicos começaram a questionar a crença de que não havia tratamento efetivo para os lesados medulares e que a morte apresentava-se como solução natural.

Após a Segunda Guerra Mundial, o Governo do Canadá foi um dos primeiros a oferecer programas de reabilitação para os veteranos lesados medulares, liderado pelo neurocirurgião Dr. Harry Botterell, que reduziu a taxa de mortalidade, visando a independência e o retorno da participação destes indivíduos à sociedade. Estes programas de reabilitação providenciaram cadeira de rodas, carros adaptados e muletas canadenses para o treinamento da marcha, melhorando a mobilidade e independência, tirando-os da condição de confinamento no leito de hospitais e nas “colônias de paraplégicos”, o que reduziu significativamente as taxas de mortalidade. Portanto, o desenvolvimento tecnológico favoreceu a melhora da qualidade de vida dos portadores de lesão medular, com repercussão na Inglaterra e nos Estados Unidos (TREMBLAY, 1996).

Com o advento das drogas antibióticas, dos avanços das técnicas cirúrgicas, de diagnóstico por imagens e da reabilitação, os indivíduos portadores de lesão medular podem ter uma expectativa de vida próxima ao normal. Entretanto, segundo Dai (2001), os fatores que influenciam a expectativa de vida são: o nível, extensão e idade em que ocorreu a lesão. Geralmente, quanto menor a idade na época da lesão, nível mais baixo e menor extensão, melhor será o prognóstico.

Entretanto, os portadores de tetraplegia podem apresentar maior número de seqüelas que comprometam suas funções, de acordo com o nível de lesão.

\subsection{TETRAPLEGIA}

Os padrões de lesão medular são melhores elucidados pela análise da anatomia da coluna vertebral. A coluna vertebral cervical é, freqüentemente, a 
porção mais lesada da medula, devido em grande parte a sua flexibilidade e exposição (SAVITSKY \& VOTEY, 1997).

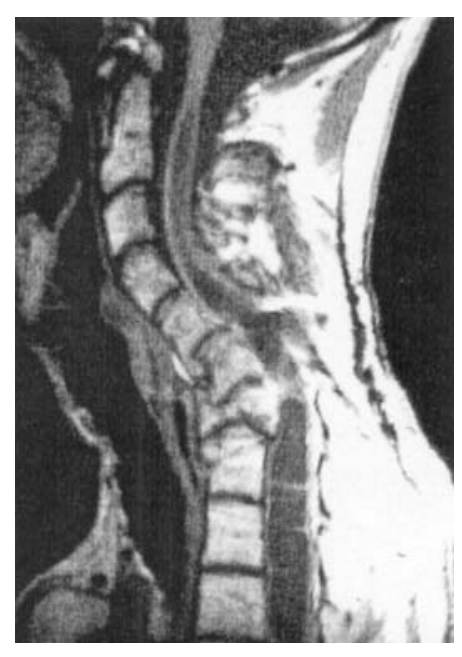

(a)

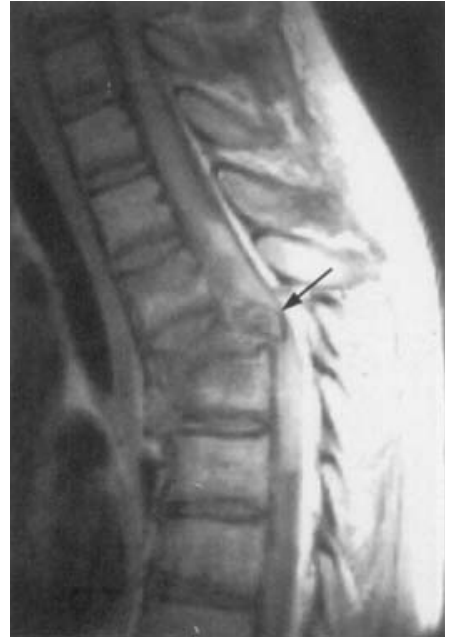

(b)

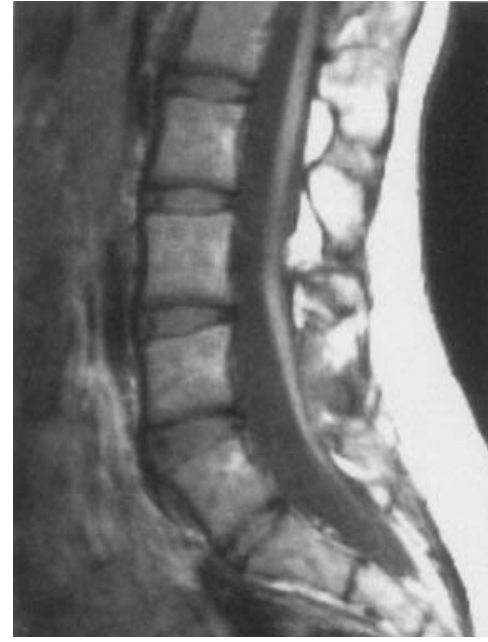

(c)

FIGURA 1 - Coluna cervical (a), torácica (b) e lombo-sacral (c).

As fraturas da primeira vértebra ou Atlas são raras. As fraturas do Axis ou C2 são produzidas por hiperextensão da cabeça, num acidente de carro ou durante o enforcamento, associada ao deslocamento de C2 sobre C3. As lesões mais comuns ocorrem no restante da coluna cervical. As lesões por flexão, freqüentemente produzem fraturas por compressão anterior e as fraturas por compressão grave, com deslocamento posterior da coluna superior, podem gerar um característico fragmento triangular do corpo vertebral, conhecida como "fratura em gota", decorrente do mergulho em águas rasas. A “lesão em chicote” é causada por uma súbita desaceleração do corpo, resultante de uma parada brusca do automóvel ou quando se é atingido atrás por um outro veículo em movimento, podendo provocar variados graus de lesão, devido a flexão, seguida de hiperextensão do pescoço. As fraturas dos processos espinhosos de C7 a T1 podem ocorrer em conseqüência de uma lesão de rotação, denominada “fratura do escavador” (YOCK, 1995). 
Na fase aguda, o socorro adequado e o atendimento clínico especializado, bem como a combinação de cirurgia e corticoesteroides é importante para a reabilitação dos tetraplégicos na fase crônica.

No estudo de Poynton et al. (1997) foi realizado o procedimento cirúrgico (que variou de acordo com a necessidade), juntamente com aplicação de metilpredinisolona em portadores de lesão medular cervical e tóraco-lombar. Os resultados mostram que os tetraplégicos completos e incompletos apresentaram maior recuperação neurológica comparado aos paraplégicos. Os tetraplégicos incompletos apresentaram maior recuperação motora, enquanto, o grupo de portadores de tetraplegia completa com fraturas ósseas e retropulsão ou lesões nãoesqueléticas, apresentou melhor prognóstico, comparado àqueles que sofreram subluxação e deslocamento da coluna cervical.

A partir destas condutas, pode-se evitar ou minimizar a lesão secundária, conduzindo a um prognóstico favorável para marcha, principalmente os indivíduos com tetraplegia incompleta (BAJD et al., 1999).

Entretanto, os tetraplégicos mais acometidos não têm a possibilidade de realizar o treinamento da marcha com o auxílio de andadores e muletas, devido ao comprometimento dos membros superiores (BURNS \& DITUNNO, 2001). Sendo uma alternativa para a marcha assistida, o Sistema de Suspensão Corpórea (LEROUX, FUNG \& BARBEAU, 1999).

Portanto, indivíduos que possuem pouco ou nenhum controle voluntário sobre os movimentos dos membros superiores, apresentam impedimentos ou dificuldades na realização de atividades simples do cotidiano, o que gera perda de independência e diminuição da qualidade de vida. De acordo com o nível de lesão, os tetraplégicos apresentam seqüelas típicas nos membros superiores.

Os indivíduos que sofreram lesão medular ao nível C4, geralmente apresentam controle escapular, mas não de todo braço. Uma lesão em C5 pode resultar em limitação do controle do ombro e flexão do cotovelo, embora estejam ausentes a extensão do cotovelo, punho e mão, bem como, ausência de sensibilidade abaixo do antebraço. Os portadores de lesão cervical C6 possuem mínima extensão de punho, acompanhada de sensibilidade parcial que se estende distalmente para a 
mão. Em lesão ao nível C7-T1 os pacientes têm preservado algum controle dos dedos, acompanhado de sensibilidade parcial da mão (STEIN, PECKHAM \& POPOVIC, 1992).

TABELA 1 - Classificação da capacidade motora remanescente dos membros superiores de tetraplégicos de acordo com o nível de lesão.

\begin{tabular}{cc}
\hline Nível de Lesão & $\begin{array}{c}\text { Capacidade Motora Remanescente dos } \\
\text { Membros Superiores }\end{array}$ \\
\hline C4 & $\begin{array}{c}\text { Controle Escapular e de Ombro } \\
+\end{array}$ \\
C5 & $\begin{array}{c}\text { Controle dos Flexores do Cotovelo } \\
+\end{array}$ \\
C6 & Controle Parcial dos Extensores de Punho \\
+ \\
C7 e T1
\end{tabular} $\begin{gathered}+ \\
\end{gathered}$

Burns e Ditunno (2001), descrevem o nível de independência e funcionalidade dos indivíduos tetraplégicos, de acordo com o nível de lesão, obtendo a seguinte classificação:

Os pacientes com lesão em C1-C3 são dependentes de ventilação mecânica. Nas lesões entre C1 e C4, os tetraplégicos são dependentes nas Atividades de Vida Diária (AVDs), transferências e mobilidade na cama, mas podem usar cadeira de rodas motorizadas, com mecanismos de adaptação.

Os pacientes C5 que possuem flexão do cotovelo ativa, podem realizar algumas atividades simples do cotidiano, através de equipamentos adaptados, entretanto, são parcialmente dependentes nas AVDs que apresentam maior complexidade e nas transferências. Também não são capazes de rolar, permanecer na posição sentada (cama) e realizar a propulsão em cadeira de rodas, embora possam utilizar as motorizadas com controle manual (joy-stick).

Os tetraplégicos com lesão em C6 podem apresentar inervação da musculatura do manguito rotador e estabilidade de ombro. Possuem extensão ativa do punho, acompanhada pela flexão passiva dos dedos e oposição do segundo dedo 
com o polegar, devido a limitação do comprimento dos tendões dos flexores dos dedos, o que permite pegar objetos. Enquanto o ato de soltar objetos é obtido a partir da flexão do punho. Esta preensão passiva, refere-se a preensão em tenodese, que pode ser desenvolvida através de sessões de terapia ocupacional, visando o treinamento da preensão, com manipulação de objetos, além da utilização de órteses para tornar este movimento mais funcional. Ainda, muitos destes pacientes necessitam de auxílio para a realização das AVDs, mobilidade na cama e transferências. Estes pacientes realizam propulsão de cadeira de rodas a curta distância, através de adaptação, com colocação de pinos no aro das rodas.

Os portadores de tetraplegia em C7 podem aumentar a força muscular do tríceps para extensão completa do cotovelo, permitindo o alívio de pressão na posição sentada. Podem rolar, sentar na cama e mover-se na posição sentada. Realizam também, transferência de maneira independente, necessitando de auxílio para a realização das atividades de higiene e vestir/despir roupas. As atividades de comer podem ser realizadas independentemente, exceto o ato de cortar o alimento. A propulsão em cadeira de rodas de maneira independente é possível para longas distâncias, em superfícies lisas.

Os pacientes com lesão entre C8 e T1 ganham progressivamente maior função da musculatura intrínseca da mão, possibilitando o aumento da força de preensão e destreza, ainda, podem ser independentes para a realização de transferências e mobilidade na cama. Os que apresentam lesão abaixo da oitava vértebra cervical podem ser independentes nas AVDs.

Entretanto, com o processo de reabilitação, os portadores de lesão medular podem apresentar recuperação sensório-motora, diminuindo o nível de lesão neurológica, no qual as seqüelas são minimizadas e cada paciente passa a apresentar um quadro clínico individual, tornando difícil a compartimentalização das características de acordo com o nível de lesão. 


\subsubsection{REABILITAÇÃO DE MEMBROS SUPERIORES DE TETRAPLÉGICOS}

Com o objetivo de restaurar e recuperar a função perdida dos membros superiores de tetraplégicos e melhorar sua independência e qualidade de vida, existem várias técnicas de tratamento, como as cirurgias de transferência de tendão, utilização de órteses, terapias convencionais e não-convencionais (BHADRA et al., 2001).

A cirurgia de transferência de tendão tem como objetivo a restauração da função utilizando a transferência do sistema músculo-tendão intacto para a musculatura denervada, visando obter movimentos simples, como a extensão de cotovelo, pronação do antebraço e preensão lateral. A transferência do deltóide para o tríceps gera a extensão do cotovelo. Os pacientes com extensão ativa do punho podem usar o efeito tenodese para preensão de objetos, entretanto, se as mãos não forem capazes de realizar a pronação, a gravidade não poderá ser utilizada para facilitar o ato de soltar o objeto, então, a pronação gerada pela conversão do bíceps em pronador do antebraço e a transferência do braquioradial para o extensor do carpo favorecem os movimentos simples de preensão (FREEHAFER, 1998); (GREENWALD et al., 2002). Uma das desvantagens desta técnica é a perda de força muscular no local da transferência de tendão, além de ser um procedimento invasivo e que requer cuidados no período de recuperação.

Outro procedimento cirúrgico realizado é a artrodese das articulações que são utilizadas para a estabilização, por exemplo na articulação interfalangeana do polegar. As inserções tendinosas dos músculos podem ficar em anastomose, ou seja, os tendões são unidos, criando uma unidade muscular para mover simultaneamente todos os dedos. Isto permite apenas o movimento sincrônico dos dedos. É importante condicionar o músculo que será transferido antes do procedimento cirúrgico, pois o músculo hipotrofiado e rígido interfere na relação entre comprimento e tensão muscular, diminuindo a eficiência funcional (STEIN, PECKHAM \& POPOVIC, 1992). 
O sucesso do tratamento cirúrgico depende da seleção adequada do paciente, ou seja, com 12 a 18 meses após a lesão, espasticidade controlada, presença de sensibilidade na mão, força muscular adequada e quadro psicológico estável, além dos cuidados pós-cirúrgicos, como a realização de exercícios e uso contínuo dos membros superiores para prevenção de deformidades (FREEHAFER, 1998); (GREENWALD et al., 2002).

Várias são as abordagens para reabilitação física convencional, por exemplo a neurodesenvolvimentista, que utiliza as técnicas de Rood, Bobath e Brunnstron.

A técnica de Rood, consiste em estímulos sensoriais para evocar respostas motoras, enquanto a de Bobath, utiliza a normalização do tônus e a inibição dos padrões anormais de postura e movimento. A técnica de Brunnstrom utiliza os reflexos tônicos, as reações associadas e os estímulos proprioceptivos e esteroceptivos, visando desenvolver tensão muscular para obtenção do movimento. Portanto, a reabilitação convencional prioriza restaurar ou manter a variação de movimento e a força muscular, através da movimentação passiva/ativa e do exercício resistido, favorecendo a autonomia do paciente (TROMBLY, 1989).

Os métodos de reabilitação convencionais apresentam limitações referentes à recuperação e/ou restauração dos movimentos de indivíduos portadores de lesão medular, tendo como solução o desenvolvimento científico-tecnológico e seus produtos, daí a importância da utilização de órteses mecânicas e da Estimulação Elétrica Neuro-Muscular, considerada uma terapia não convencional, que fornece meios alternativos para a reabilitação das funções motoras perdidas, consistindo em desafios para a Engenharia de Reabilitação atual. Portanto, é de grande importância o trabalho em equipes multidisciplinares, visando a avaliação, implementação e aprimoramento deste sistema. 


\section{CAPÍtUlO 2}

\section{0 ÓRTESE, PRÓTESE E NEUROPRÓTESE}

As órteses, próteses e neuropróteses são comumente utilizadas na reabilitação de portadores de deficiência física. Esta tecnologia assistida visa diminuir o impacto das perdas funcionais decorrentes de traumas ou patologias, beneficiando especialmente os indivíduos tetraplégicos, ampliando os recursos terapêuticos utilizados.

As órteses podem ser classificadas em estáticas, que não possuem partes móveis e favorecem o posicionamento adequado e em dinâmicas, cujas partes móveis são utilizadas para restaurar os movimentos, podendo ser acionadas por polias, molas, elásticos, motores, dispositivos a gás, movimento voluntário, Estimulação Elétrica Neuro-Muscular e sinal mioelétrico (RAHMAN et al., 2000); (TROMBLY, 1989).

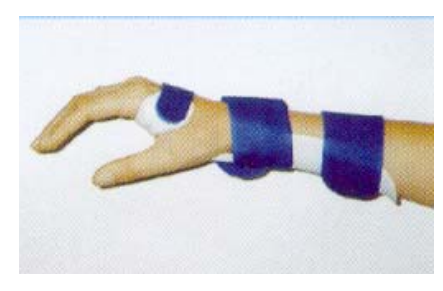

FIGURA 2 - Órtese estática para punho.

Nos últimos anos, o movimento funcional dos membros superiores de portadores de lesão neurológica e o aspecto cosmético das órteses dinâmicas vêm sendo investigados por vários autores. 
Benjuya e Kenney (1990 a), desenvolveram uma órtese mioelétrica de mão (HO - Hand Orthosis), que restaura a preensão tridigital ou de força para portadores de lesão medular com nível C5-C6. Foram utilizados motor miniaturizado DC, circuitos eletrônicos, bateria e feedback visual da força de preensão através de LEDs. O sinal mioelétrico pode ser obtido dos extensores/flexores do punho ou bíceps/tríceps, desde que não estejam denervados.

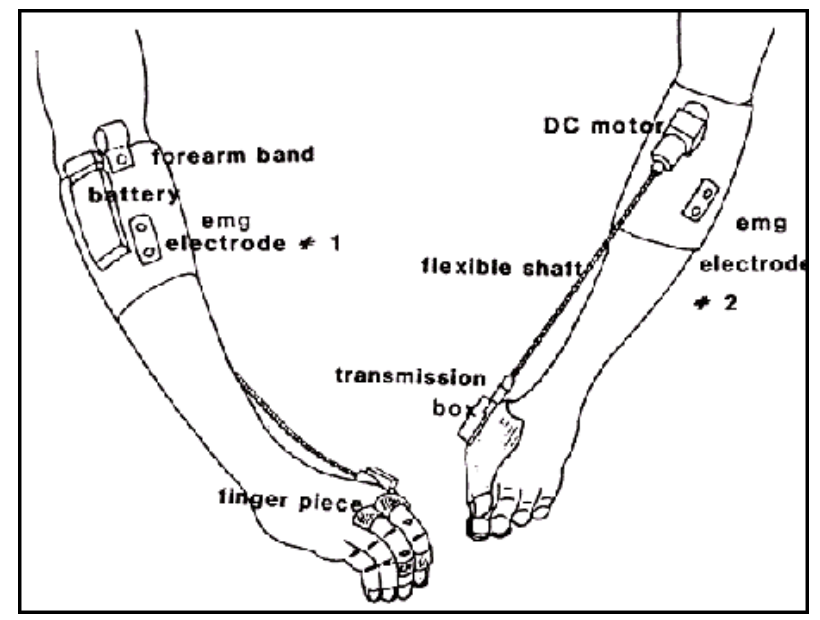

FIGURA 3 - Órtese mioelétrica de mão.

Outra órtese mioelétrica para punho e mão (WHO) foi proposta por Slack e Berbrayer (1992), com a finalidade de restaurar o movimento de pinça de força para indivíduos com lesão no plexo braquial unilateral. Foram utilizados circuitos eletrônicos, baterias, atuadores lineares e sinal mioelétrico do antebraço.

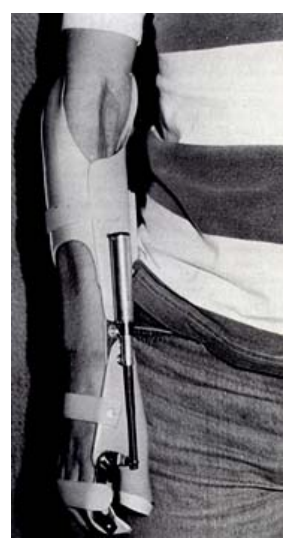

FIGURA 4 - Órtese mioelétrica de punho e mão para portadores de lesão no plexo braquial. 
Makaran et al. (1993), desenvolveram e avaliaram a SMART (WHO - Wrist Hand Orthosis), uma órtese de punho-mão para indivíduos com lesão medular na quinta vértebra cervical, utilizando Shape Memory Alloy (SMA), circuitos eletrônicos, transdutores de pressão, bateria e molas para abrir e fechar a mão, permitindo o ato de pegar objetos maiores (por exemplo: copo), através da preensão tridigital.

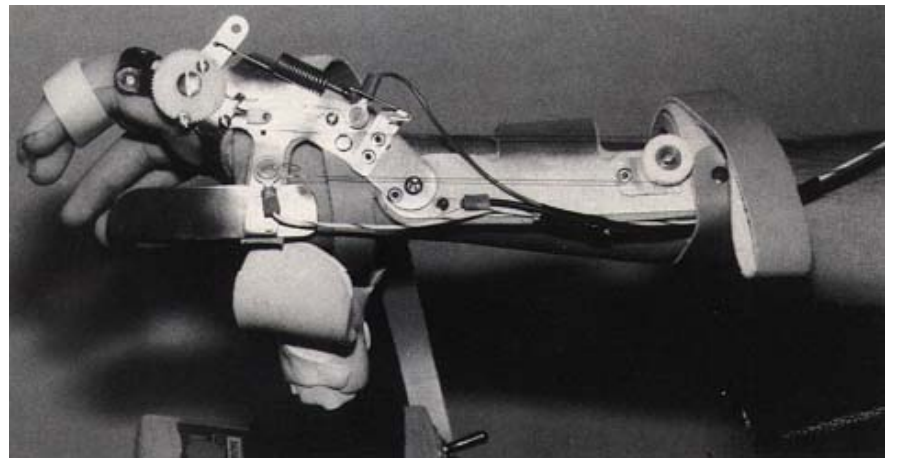

FIGURA 5 - SMART®, órtese punho-mão.

Wierzbicka e Wiegner (1996) avaliaram o protótipo de uma órtese para cotovelo que gera movimento funcional de alcance em lesados medulares nível C5C6 com função do bíceps preservada, mas com pouco/nenhum controle do tríceps ou que perderam a habilidade de pronação. O protótipo consiste de quatro envoltórios fabricados com lâminas de fibra de carbono, em forma de C, que fixam duas juntas medialmente e lateralmente à articulação do cotovelo. Cada junta tem uma mola incorporada, estas juntas são movidas ao redor do eixo.

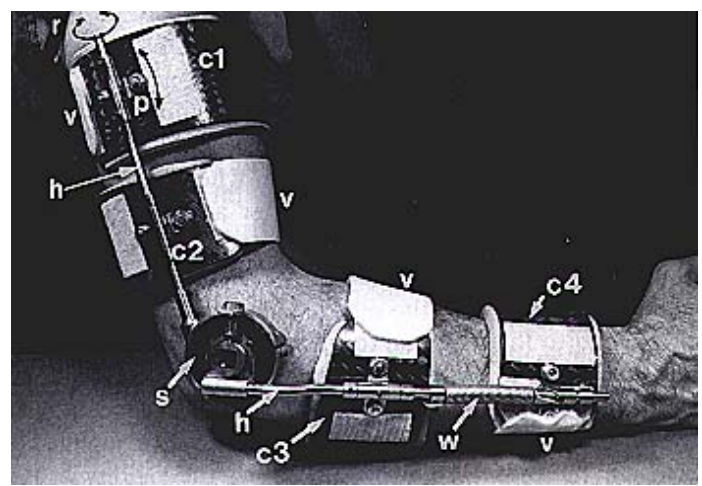

FIGURA 6 - Órtese mecânica para cotovelo. 
Benjuya e Kenney (1990 b), apresentaram a órtese para o membro superior (HAG - Hibrid Arm Orthosis), que restaura os movimentos de abdução do ombro, flexão do cotovelo, prono-supinação do antebraço e pinça de força em pacientes C3C4. A abdução do ombro e a flexão do cotovelo são acionadas pela elevação do ombro contralateral, utilizando cabos e molas. Botões sensíveis a pressão de ar, fixados no descanso para cabeça da cadeira de rodas, são utilizados para acionar os motores DC miniaturizados, para prono-supinação e preensão. Ainda, foram utilizados circuitos eletrônicos e bateria da própria cadeira motorizada.

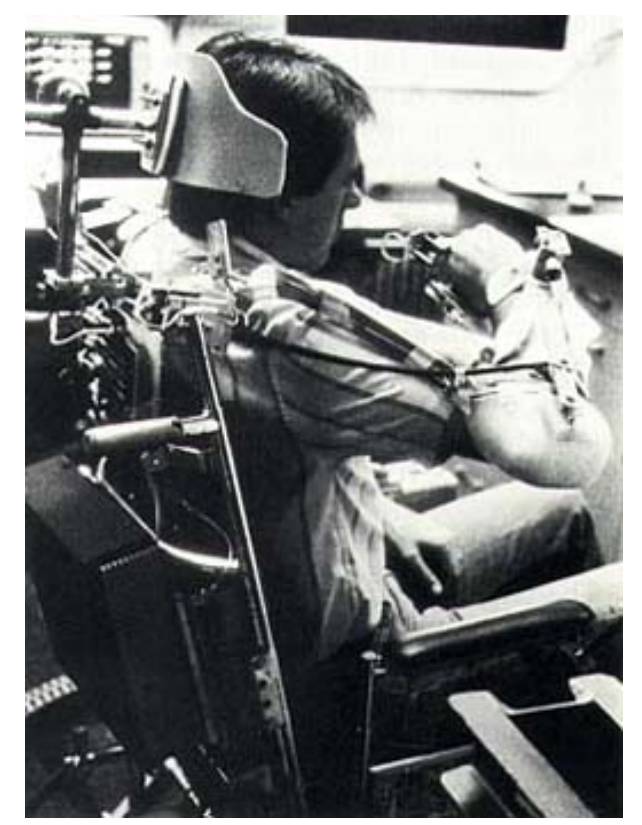

FIGURA 7 - HAG, órtese para membro superior.

Portanto, as órteses robóticas são resultados dos esforços dos profissionais da Engenharia de Reabilitação, que visam a restauração do movimento do membro comprometido, que de outra maneira não seria possível realizá-lo.

Outra opção de reabilitação para membros superiores é a terapia assistida por robôs.

Os indivíduos portadores de lesão neurológica podem interagir com o robô passivamente ou ativamente. A mão e o punho, em posição neutra, são fixados no braço robótico e a terapia consiste em movimentos rotacionais e de flexão/extensão das articulações do ombro e cotovelo. O movimento é inicialmente passivo, 
conforme o paciente ganha função motora, o robô requer iniciação voluntária da atividade. O braço robótico aplica precisos graus de força, velocidade, duração e repetição do movimento com padrão esteriotipado. Durante as sessões, os indivíduos podem observar seu próprio desempenho, por monitor de vídeo. Os dados sobre a força e qualidade do movimento são informados verbalmente pelo robô. Portanto, o sistema oferece ao paciente feedback visual, auditivo e tátil, além de apresentar uma grande reprodutibilidade nas sessões e terapia intensiva para reabilitação sensóriomotora (AISEN et al., 1997); (VOLPE et al., 2000).

As próteses são utilizadas para complementar a ausência de membros superiores e/ou inferiores ou parte destes, podendo ser estética, funcional ou ambas. As próteses ativas podem ser acionadas por força própria, sinal mioelétrico e força externa elétrica ou pneumática. O modelo de prótese varia de acordo com o nível e o tipo de amputação (TROMBLY, 1989). As próteses estão em constante evolução e atualmente está sendo desenvolvida, pela equipe de Alberto Cliquet Jr., uma prótese de mão antropomórfica e multifuncional, com feedback de força, deslizamento e temperatura.

As Neuropróteses por Estimulação Elétrica Neuro-Muscular podem ser usadas para restaurar e recuperar as funções sensório-motoras perdidas em portadores de lesão neurológica (KEITH, 2001). Esta técnica consiste na ativação artificial dos músculos esqueléticos, através de formas discretas de pulsos aplicados no ponto motor ou diretamente no nervo, gerando seletivamente potenciais de ação, produzindo contração muscular (BHADRA et al., 2001), o que possibilita seqüências de movimentos de membros superiores e inferiores, tais como, ficar em pé, caminhar, subir e descer escada, dar passos para o lado e para trás, deslocar o membro superior no espaço para alcançar, pegar e soltar objetos.

Quando a resposta muscular à estimulação é insuficiente devido a denervação periférica, atrofia por desuso, além de outras causas, o sistema mecânico tem a finalidade de substituir ou aumentar a função muscular (NATHAN, 1989); (WIERZBICKA \& WIEGNER, 1996). Então, as órteses mecânicas são um 
importante coadjuvante da Estimulação Elétrica, potencializando o ganho de função em portadores de lesão neurológica, em especial os tetraplégicos. Quando usados simultaneamente, são denominados Sistema Híbrido.
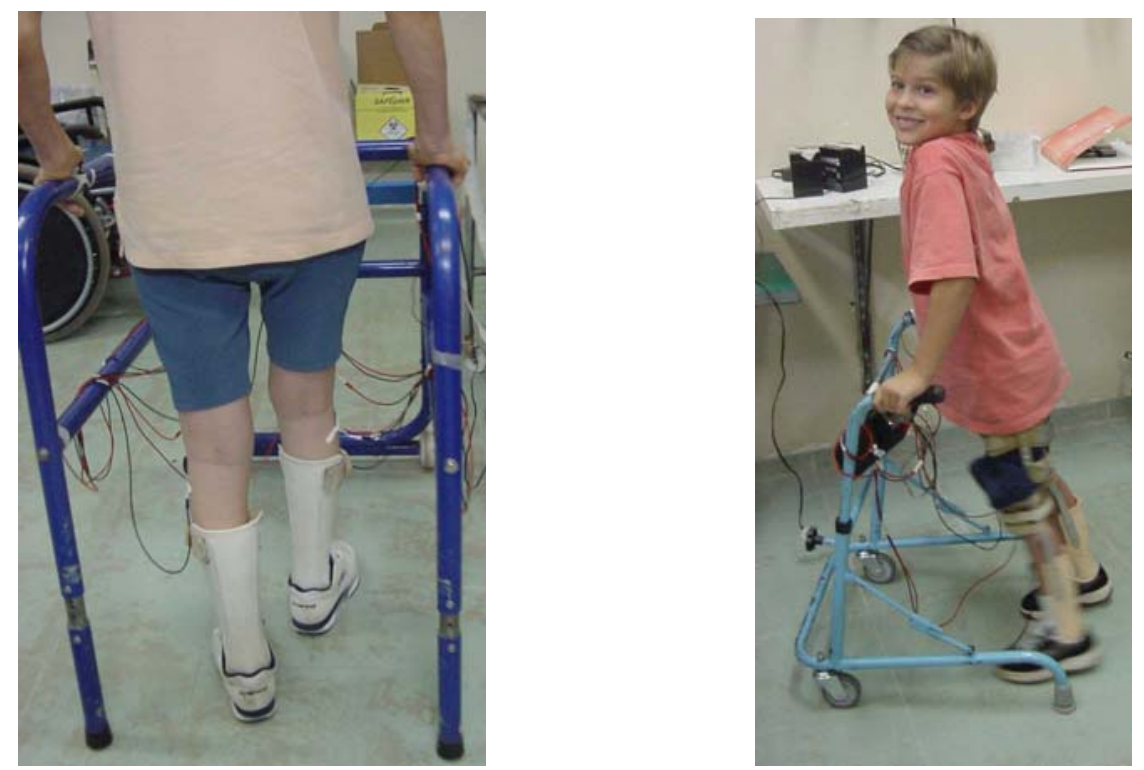

FIGURA 8 - Paciente com lesão medular cervical incompleta realizando a marcha assistida por EENM (a) e utilizando o sistema híbrido para marcha (b).

Portanto, os Sitemas Híbridos são utilizados tanto nos membros inferiores para auxiliar na marcha (CLIQUET Jr., BAXENDALE \& ANDREWS, 1989), quanto nos membros superiores para facilitação da execução de atividades funcionais (NATHAN, 1989). 


\section{CAPÍtulo 3}

\subsection{ESTIMULAÇÃO ELÉTRICA NEURO-MUSCULAR}

A Estimulação Elétrica tem uma longa história envolvendo a terapia de diversas patologias, podendo ser aplicada para o tratamento de distúrbio do sistema nervoso autônomo e dos músculos lisos, como os órgãos digestivo ou urogenital (HANDA, 1997).

Quanto à disfunção sexual, urinária e intestinal, a Estimulação Elétrica apresenta-se como uma das técnicas promissoras para melhorar a qualidade de vida dos usuários (BURNS, 2001), (GRILL et al., 2001), (HEIDUSCHKA \& THANOS, 1998). Esta mesma técnica, também é utilizada para redução da dor crônica (HEIDUSCHKA \& THANOS, 1998) e prevenção das úlceras de pressão (KERN,1997).

Vários estudos foram realizados em animais e humanos lesados medulares, visando a contribuição mecânica para gerar pressão positiva nos músculos respiratórios e a restauração da tosse, através de Estimulação Elétrica (DiMARCO et al., 1999), (GRILL et al., 2001), (HEIDUSCHKA \& THANOS, 1998).

Outras aplicações são os implantes bioeletrônicos, como o marcapasso cardíaco, a estimulação elétrica para prevenção da angina e da apnéia durante o sono (GRILL et al., 2001), bem como as neuropróteses implantáveis auditivas e visuais (HEIDUSCHKA \& THANOS, 1998). 
Entretanto, prioriza-se a restauração e/ou recuperação da função sensóriomotora em indivíduos portadores de lesão medular, traumatismo crânio-encefálico, acidente vascular cerebral, paralisia cerebral e esclerose múltipla (DAVIS, 2002).

Os sistemas de Estimulação Elétrica Neuro-Muscular podem ser realizados através de eletrodos de superfície, percutâneos e implantáveis. Os eletrodos de superfície comparados aos eletrodos implantáveis apresentam algumas vantagens, tais como: facilidade na colocação e na alteração de posição, atingem grandes áreas musculares e não são invasivos. Com relação às desvantagens, apresentam menor especificidade, os músculos profundos não são estimulados, além da possibilidade da estimulação dos receptores da dor (VOSSIUS, 1986).

O uso diário desta técnica em pacientes é restrito por vários motivos, dentre eles: métodos de controle robustos, rápida instalação da fadiga muscular (THOMAS, 1997); (THOMAS et al., 1997) e sérias infecções decorrentes de dispositivos implantáveis e percutâneos (BHADRA, KILGORE e PECKHAM, 2001). Porém, sua aplicabilidade vem se desenvolvendo há mais de quatro décadas, devido aos estudos fisiológicos, neurofisiológicos e biomecânicos, consolidação das técnicas da interface homem-máquina e o aperfeiçoamento de estimuladores percutâneos e implantáveis (controle, arquitetura, miniaturização e encapsulamento), além dos avanços das técnicas cirúrgicas (DAVIS, 2002); (MAYR et al., 2001); (SALMONS et al., 2001); (TROYK \& DONALDSON, 2001).

Na literatura, as pesquisas referentes a reabilitação de membros superiores através de Estimulação Elétrica Neuro-Muscular apresentam-se restritas, quando comparadas aos membros inferiores. Isto ocorre devido a complexidade dos membros superiores, que possuem mais de 50 músculos concentrados numa pequena área (DANGELO \& FATTINI, 1984), além de sistemas de alavancas complexos e músculos que apresentam mais de uma função (CHADWICK \& NICOL, 2000). Estes fatores podem dificultar a colocação dos eletrodos e influenciar a contração e força muscular.

No deslocamento de um segmento ou de todo o membro superior é necessária a excitação de vários músculos de forma coordenada, graduada e distribuída para que o movimento seja adequado em sua força, orientação, amplitude e velocidade 
(BRANDÃO, 1994). O movimento do membro superior pode ser tri-dimensional, além de possuir mais de 40 graus de liberdade, sendo que a mão com os dedos possui aproximadamente 30 graus de liberdade (VOSSIUS, 1986). Desta forma, as seqüências de movimento por meio de estimulação artificial tornam-se complexas.

Ainda, teoricamente, o número de soluções para realização de uma tarefa motora envolvendo o membro superior é infinita, devido a ampla variedade de movimentos articulares, bem como a variedade de padrão de ativação muscular e a produção de movimento ordenado espaço-temporalmente em um padrão adequado, que constituem "o problema da redundância dos graus de liberdade”, formulado por Bernstein (COSTA \& VIEIRA, 2000); (ETTEMA; STYLES \& KIPPERS, 1998).

Entretanto, recentemente, as neuropróteses para membros superiores apresentam avanços, devido a sua aplicação funcional, uso diário e efeitos terapêuticos.

\subsection{NEUROPRÓTESES PARA MEMBROS SUPERIORES}

A Estimulação Elétrica dos membros superiores vêm suprir as necessidades básicas do tetraplégico, possibilitando sua maior independência, melhora de sua auto-estima e qualidade de vida, promovendo sua reinserção social e favorecendo as atividades cotidianas, como beber, comer, cuidados pessoais e de higiene, transferências, escrever, digitar, entre outros.

Desde a década de 60 até os dias atuais, os sistemas de Estimulação vêm apresentando evoluções.

Long \& Masciarelli em 1963, motivados pelos resultados obtidos por Liberson na restauração do movimento do pé em gota de hemiplégicos durante a marcha assistida por Estimulação Elétrica Neuro-Muscular, realizaram a restauração dos movimentos da mão. Foram utilizados eletrodos de superfície para estimular os extensores dos dedos e a preensão foi obtida através de uma mola na órtese externa que posicionava o polegar e os dedos, gerando movimentos simples de pegar e soltar objetos.

Posteriormente, Nathan (1989) utilizou órtese de suspensão (Balanced Forearm Orthosis) e splint para gerar posicionamento do membro superior no espaço 
e estimulador multicanal microcontrolado para restaurar as atividades funcionais de comer, beber, escrever e desenhar, implementando o sistema com a ativação por voz da seqüência de movimentos.

Recentemente, foi desenvolvida uma luva instrumentalizada com sensores de força (FSR), para controle da preensão durante a estimulação elétrica, concomitante a estimulação eletrotáctil, possibilitando o feedback sensorial da força exercida durante a preensão (CLIQUET, Jr, \& CASTRO, 2000 a); (CLIQUET, Jr, \& CASTRO, 2000 b).

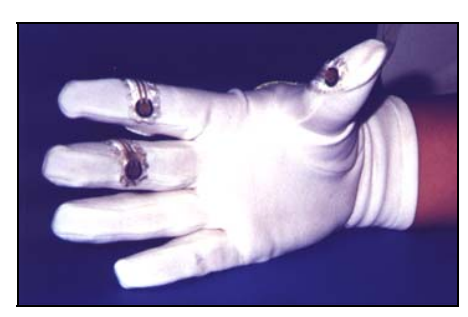

FIGURA 9 - Luva instrumentalizada.

Entre outras formas de controle, pode-se citar o sinal obtido pela eletromiografia (MICERA et al., 1999) e pelo eletroencefalograma (PFURTSCHELLER et al., 2000) para ativar os músculos paralisados.

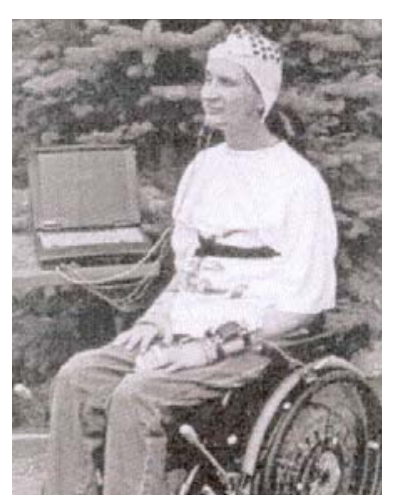

FIGURA 10 - Sistema de controle por sinal de eletroencefalograma.

As neuropróteses para preensão mais conhecidas são: Belgrade Grasping System (BGS), ETHZ-ParaCare e Compex Motion desenvolvidas pela equipe de Popovic; e as comercializadas Bionic Glove, Handmaster e Freehand. Além da Freehand, outro sistema implantável é a NEC-FES Mate. 
A Bionic Glove é uma neuroprótese para preensão, projetada para potencializar a preensão em tenodese, em pacientes que possuem controle ativo da flexão e extensão do punho. Este sistema possui 3 eletrodos de superfície autoadesivos (2 ativos e 1 inativo) colocados sob a luva de neoprene. $\mathrm{O}$ estimulador encontra-se sobre esta luva, na região do antebraço, além de um transdutor posicionado próximo ao punho, para detectar a sua flexão e extensão. Quando o paciente flete o punho voluntariamente, os extensores dos dedos são estimulados gerando a abertura da mão e quando estende o punho, os flexores dos dedos são estimulados obtendo o fechamento da mão. Foi constatado que durante 6 meses de utilização deste sistema houve melhora nas AVDs, na força de preensão de objetos grandes e em alguns pacientes não houve mais a necessidade do uso da neuroprótese, devido aos efeitos terapêuticos. Embora apresente algumas vantagens funcionais, ainda existem alguns problemas, como a localização do estimulador no antebraço, que fica exposto a freqüentes impactos, pois os pacientes geralmente utilizam o antebraço para realizar de maneira compensatória algumas atividades, por exemplo abrir/fechar a porta. Ainda, o transdutor deve ser recolocado com freqüência devido a sua localização e a conexão do estimulador com os eletrodos pode ser rompida, com os movimentos dos braços (POPOVIC, D.B. et al.,1999); (POPOVIC, M.R. et al., 2001 a); (POPOVIC, M.R. et al., 2001 b); (POPOVIC, M.R.; POPOVIC, D.B. \& KELLER, 2002); (PROCHAZKA et al., 1997).

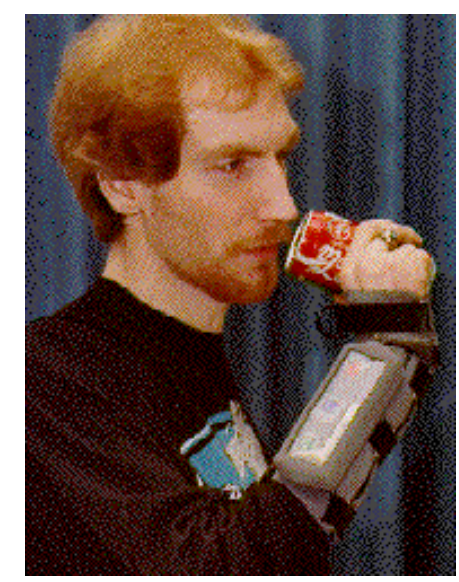

FIGURA 11 - Bionic Glove. 
A Handmaster é uma neuroprótese para preensão com três pares de eletrodos de superfície, utilizados para gerar a abertura da mão e as preensões lateral e palmar. Originalmente, este sistema foi idealizado como um instrumento de exercício e reabilitação, mas também é utilizado como um sistema protético permanente. O controle do acionamento da abertura e fechamento da mão é realizado por botão. O paciente pode regular o modo de flexão do polegar, através do potenciômetro de deslizamento linear. $\mathrm{O}$ ajuste da força de preensão para o tamanho e forma do objeto, pode ser controlado por dois botões adicionais. Uma das vantagens é que pode ser facilmente colocada e retirada. Uma das desvantagens é não permitir ao usuário liberdade para colocação dos eletrodos. Ainda, a órtese é muito curta não possibilitando a estimulação dos flexores dos dedos, na posição proximal do antebraço, local que gera o movimento mais adequado. Outra limitação deste sistema é ser uma órtese rígida que restringe a amplitude de movimento do punho e não permite realização da supinação completa (ALLON et al., 1998); (LJZERMAN et al., 1996); (POPOVIC, M.R. et al., 2001 a); (POPOVIC, M.R. et al., 2001 b); (POPOVIC, M.R.; POPOVIC, D.B. \& KELLER, 2002).
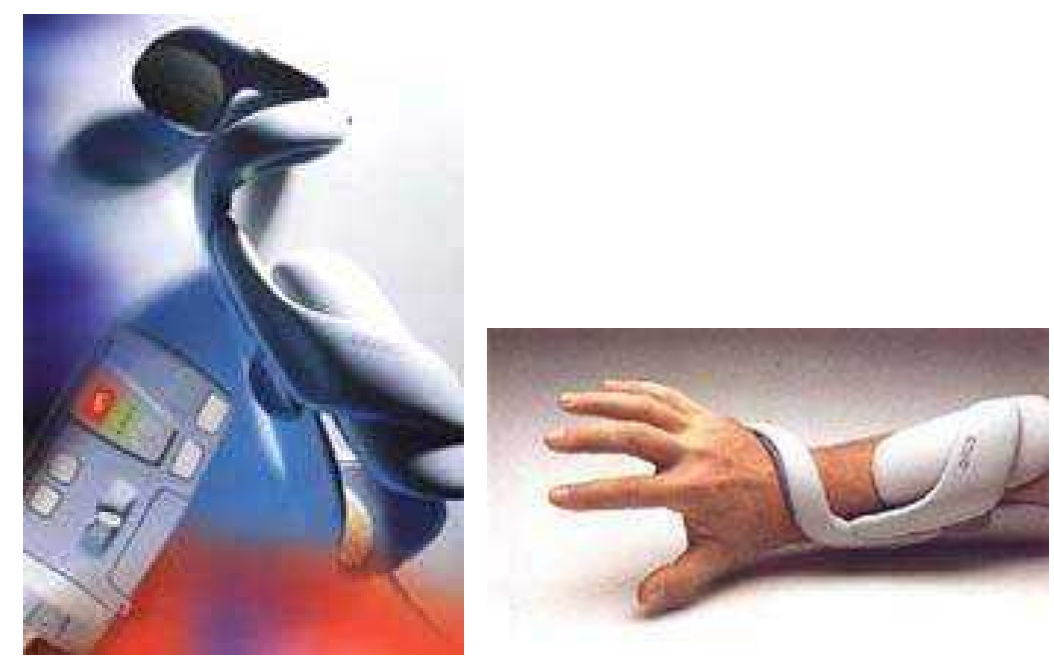

FIGURA 12 - Handmaster.

Popovic e sua equipe apresentaram novos sistemas para membros superiores (BGS, ETHZ-ParaCare, Compex Motion), que estão em fase de evolução. 
O Belgrade Grasping Systems (BGS) é uma neuroprótese para preensão, que também permite a função de alcance. O BGS tem 4 canais de estimulação, dos quais 3 são utilizados para gerar a função de preensão e o quarto canal, para estimulação do tríceps braquial, permitindo o alcance dos objetos pela extensão do cotovelo. A preensão é controlada por um botão, que aciona a abertura/fechamento da mão. A função de alcance é obtida pela mensuração da velocidade do ombro, além do goniômetro e geração de movimento sinérgico do cotovelo. A desvantagem deste sistema, é o maior tempo para a colocação dos eletrodos, comparado a Handmaster e não possui autorização para ser comercializado (POPOVIC, M.R. et al., 2001 a); (POPOVIC, M.R. et al., 2001 b); (POPOVIC, M.R.; POPOVIC, D.B. \& KELLER, 2002). Atualmente, o BGS já está sendo implementado, com o controle para os movimentos 3-D de ombro e cotovelo, visando a execução de maior número de atividades cotidianas, realizando estudos preliminares em indivíduo saudável (POPOVIC, M.B. \& POPOVIC, D.B., 2001); (POPOVIC, M.B.; POPOVIC, D.B. \& TOMOVIC, 2002).

O ETHZ-ParaCare foi projetado para melhorar as funções de preensão e marcha de portadores de lesão neurológica. Este sistema é programável, possui 4 canais de estimulação para gerar as preensões palmar e lateral, além de permitir a interface com sensores. O sistema pode ser controlado utilizando as seguintes estratégias: potenciômetro linear de deslizamento, sinal mioelétrico ou botão. Uma desvantagem deste sistema é que requer entre sete a dez minutos para ser colocado/retirado (KELLER et al., 1998); (POPOVIC, M.R. et al., 2001 a); (POPOVIC, M.R. et al., 2001 b); (POPOVIC, M.R.; POPOVIC, D.B. \& KELLER, 2002).

O Compex Motion é a nova geração do ETHZ-ParaCare, que pode ser programado para gerar seqüências de preensão ou marcha, além do tratamento da subluxação do ombro e fortalecimento muscular. O controle pode ser realizado por sensores. As seqüências de estimulação e as estratégias de controle são programadas e armazenadas em cartões com chip de memória que podem ser trocados. Testes clínicos ainda serão realizados (KELLER et al, 2002). 

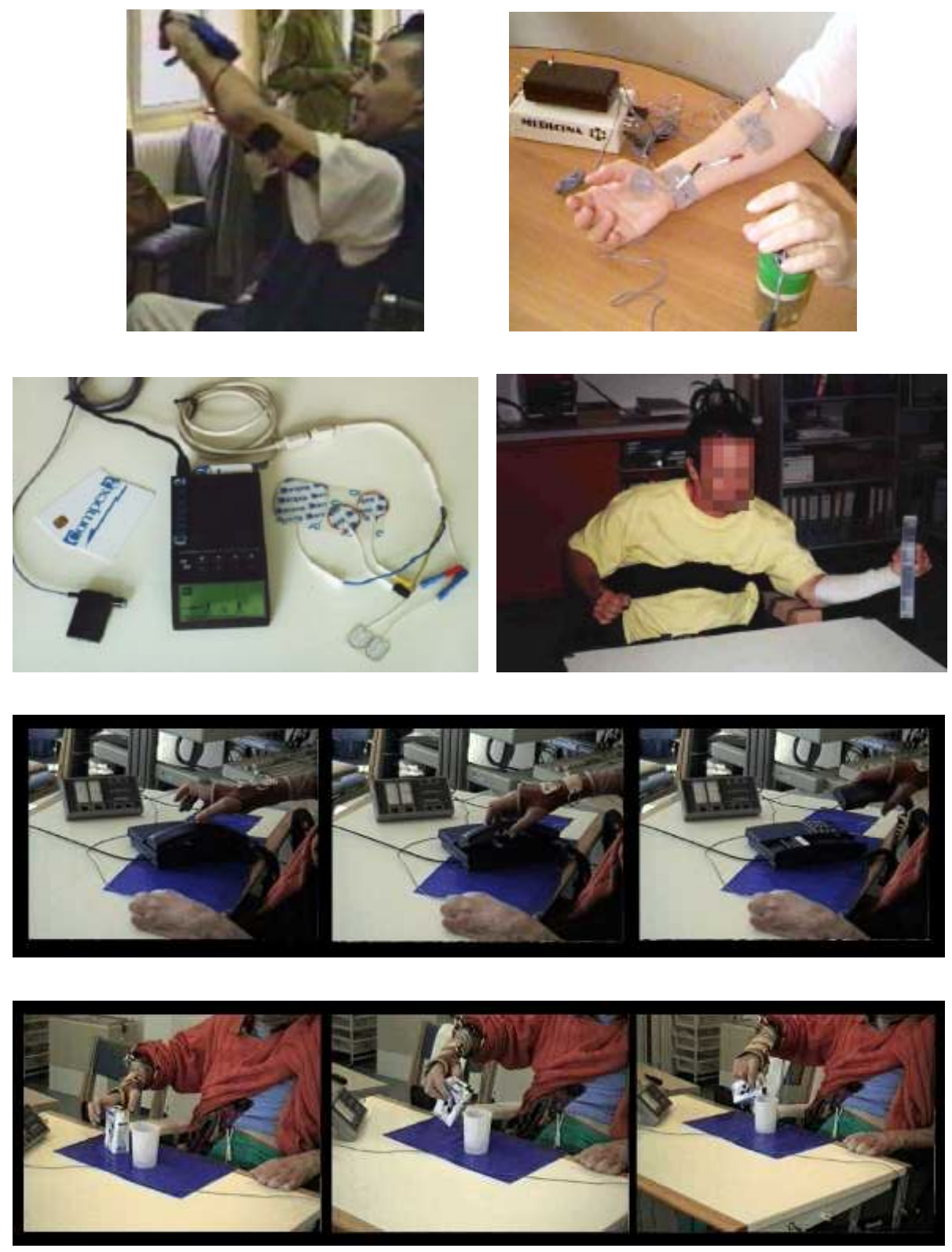

FIGURA 13 - Neuropróteses propostas pela equipe de Popovic.

O Freehand System possui oito eletrodos epimisiais implantáveis e um estimulador, também implantável. Este sistema gera as preensões lateral e palmar, através de comandos obtidos do sensor de posição, colocado no ombro contra- lateral do sujeito, que monitora dois eixos de movimento do ombro (protração/retração e elevação/depressão). Os movimentos de protração/retração do ombro são utilizados como um sinal proporcional para abertura e fechamento da mão. Os movimentos de elevação/depressão do ombro geram comandos lógicos, que visam estabelecer um 
nível zero para o comando de protração/retração, fixando os níveis de estimulação, até o próximo comando lógico ser emitido. Uma chave adicional também permite ao usuário escolher o tipo de preensão. O sensor de posição e o controlador não são implantáveis. Uma das principais vantagens deste sistema é o tempo reduzido para colocá-lo e retirá-lo, comparado aos sistemas de estimulação de superfície, por outro lado, só pode ser implantado em torno de 18-24 meses após a lesão, o que limita os efeitos terapêuticos na fase inicial pós-lesão. Ainda, os pacientes são submetidos com freqüência a uma cirurgia adicional, necessária para recolocar os componentes falhos ou corrigir a localização dos eletrodos. O Freehand System vem sendo implementado para permitir o movimento de alcance através da extensão do cotovelo, além de apresentar a versão percutânea (BHADRA, KILGORE \& PECKHAM, 2001); (HAUSMAN \& MASTERS, 2002); (HOBBY; TAYLOR \& ESNOUF, 2001); (POPOVIC, M.R. et al., 2001 a); (POPOVIC, M.R. et al., 2001 b); (POPOVIC, M.R.; POPOVIC, D.B. \& KELLER, 2002).
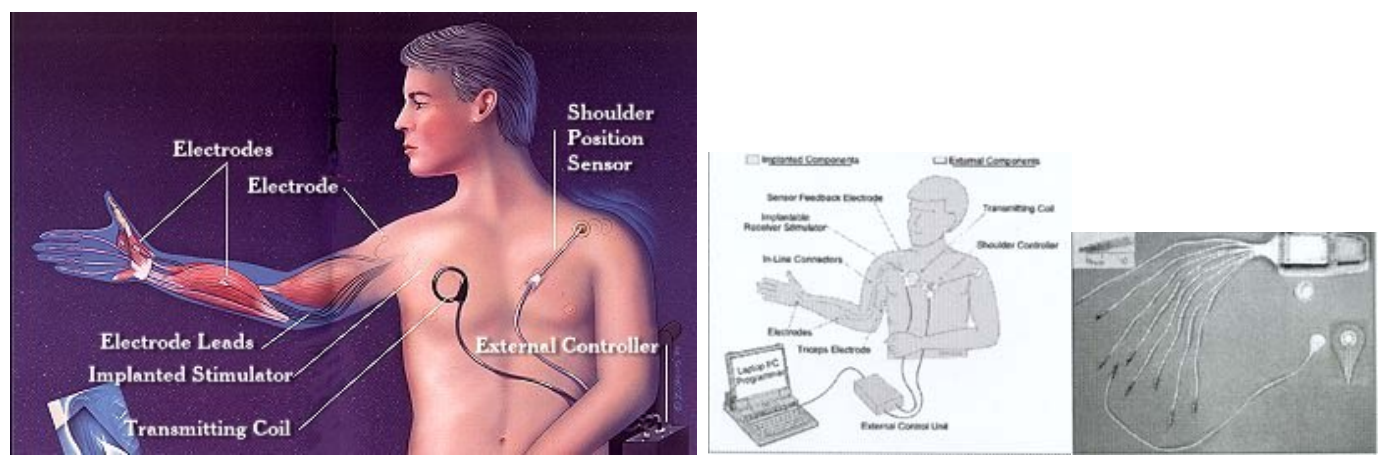

FIGURA 14 - Freehand System ${ }^{\mathrm{TM}}$.

A neuroprótese NEC-FES Mate foi desenvolvida pela equipe de Handa, este sistema implantável possui 16 canais de estimulação, que são acionados por botão ou sensor de pressão pneumático, já o percutâneo possui 30 canais (HANDA, 1997).

Atualmente, a atenção dos grupos de pesquisa está voltada para a implementação do sistema com movimentos de alcance e manipulação do objeto.

Para o controle efetivo das neuropróteses de membros superiores, foram realizados vários estudos, como utilização de acelerômetro para ativar a extensão artificial do cotovelo (CRAGO et al., 1998); desenvolvimento de um modelo 
dinâmico para simular os movimentos do cotovelo, antebraço e punho (LEMAY \& CRAGO, 1996); realização de avaliações biomecânicas como da prono-supinação do antebraço (LEMAY, CRAGO \& KEITH, 1996), dos movimentos de ombro durante a execução de AVDs (GRONLEY, 2000) e para detecção da fadiga muscular durante as contrações isométricas máxima dos movimentos de flexão/extensão do cotovelo com preensão (ODA \& KIDA, 2001), além do modelamento músculo-esquelético do cotovelo e ombro para restaurar o movimento funcional de tetraplégicos com EENM (KIRSCH et al., 2001).

\subsection{EFEITOS TERAPÊUTICOS DA ESTIMULAÇÃO ELÉTRICA} NEURO-MUSCULAR

A Estimulação Elétrica Neuro-Muscular, além de propiciar a restauração do movimento, quando aplicada durante um longo período em portadores de lesão medular, pode aumentar a força e o volume do músculo, bem como reduzir a espasticidade e rigidez (HANDA, 1997).

Quanto à plasticidade muscular, foi constatado aumento no diâmetro das fibras musculares (KERN, 1997), aumento na proporção de fibras tipo I e da atividade enzimática oxidativa (BIJAK et al., 1999); (HARTKOPP et al., 1999).

Os estudos referentes ao efeito da Estimulação sobre o aumento ou redução da espasticidade são divergentes, devido à ausência de uniformidade dos procedimentos e métodos de avaliação adotados. Porém, a redução da espasticidade tem sido observada durante a Estimulação Elétrica (MELA, VELTINK \& HUIJING, 2001). Foi constatado que a baixa intensidade de estimulação (20 Hz), em 10 minutos de realização dos movimentos de flexão e extensão do cotovelo, reduziu o pico do momento articular e a amplitude do sinal mioelétrico do tríceps, evidenciando redução da espasticidade severa (DALY et al., 1996).

Outros efeitos benéficos são a melhora da circulação sangüínea, da microcirculação e das trocas transcapilares (DALY et al., 1996). O aumento da perfusão de sangue no tecido muscular e na pele é importante para a prevenção das úlceras de decúbito (KERN,1997). 
As mudanças cardiovasculares abruptas observadas durante a postura sentada, ereta e durante o exercício com os membros superiores, podem ser minimizadas com o uso da Estimulação Elétrica nos membros inferiores, devido a ativação da bomba músculo-esquelética (ELOKDA, NIELSEN \& SHIELDS, 2000); (HOPMAN et al., 1998). Esta técnica também promove o aumento da capacidade cardiovascular e respiratória (BARSTOW et al., 1996); (HOPMAN et al., 1998).

Ainda, a perda ou redução da independência na realização de atividades de vida diária (AVDs) e o estado sedentário, fazem com que a fadiga muscular se instale rapidamente durante as atividades de propulsão da cadeira de rodas, transferências, vestir-se, comer, realização da higiene pessoal, caminhar, entre outros (DALLMEIJER et al., 1999). Entretanto, a Estimulação Elétrica em portadores de lesão medular pode aumentar a resistência à fadiga (PEIXOTO \& CLIQUET JR.,1996), melhorando o desempenho na execução das atividades de vida diária, realizadas com mais autonomia.

Outro aspecto benéfico é a socialização e aumento da auto-estima (MUCCIO, ANDREWS \& MARSOLAIS, 1989).

O treinamento da marcha através de Estimulação Elétrica Neuro-Muscular em indivíduos lesados medulares possibilita a prevenção/redução/reversão da osteoporose, por permitir a sustentação do peso corpóreo e atividade muscular, gerando aumento do estímulo mecânico para o remodelamento e crescimento ósseo, devido ao efeito piezoelétrico (CARVALHO, CARVALHO \& CLIQUET JR.., 2001). A postura bípede e o treinamento da marcha favorecem ainda o alívio da pressão na região glútea (MUCCIO, ANDREWS \& MARSOLAIS, 1989), o trânsito intestinal, prevenção de infecção no trato urinário e contraturas articulares (THOUMIE et al., 1995).

\subsubsection{PLASTICIDADE NEURAL}

A Estimulação Elétrica causa recuperação da função medular, inicialmente observada em experimentos de plasticidade do sistema locomotor em animais (WHELAN, 1996) e posteriormente durante a reabilitação da marcha de portadores 
de lesão medular, constatando que a repetição dos movimentos torna-os espontâneos (FOUAD et al., 2000); (WICKELGREN, 1998).

Experimentos evidenciam a ativação do Gerador de Padrão Central (CPG), através de "inputs" aferentes durante o período de treinamento da marcha. Nessa perspectiva, é importante ressaltar a atuação do reflexo de Hoffmann (H-reflexo) evocado dos extensores do tornozelo, bem como, dos Órgãos Tendinosos de Golgi, que possuem função antigravitacional, representando o mecanismo de recepção de carga, responsável pelo controle do centro de massa do corpo durante a postura e o andar. Assim, o CPG interage com os Órgãos Tendinosos de Golgi dos músculos extensores dos membros inferiores, favorecendo o Padrão Rítmico Locomotor (BARBEAU et al., 1999); (DIETZ, 1996); (DIETZ, GOLLHOFER \& TRIPPEL, 1992); (KOJIMA, NAKAZAWA \& YANO, 1999).

Com estes estímulos há uma reorganização dos reflexos e o aumento da excitabilidade de motoneurônios (BARBEAU et al., 1999).

Portanto, estudos neurofisiológicos sugerem que a reabilitação da marcha assistida por Estimulação Elétrica Neuromuscular induz alterações nos circuitos interneurais na medula espinhal, que facilitam e melhoram as habilidades funcionais dos portadores de lesão medular, com retorno da sensibilidade, do movimento e da marcha não-assistida, como no caso de alguns pacientes que fazem/fizeram parte do Programa de Estimulação Elétrica Neuromuscular, na FCM/UNICAMP e USP/São Carlos (CLIQUET, 1994); (PAOLILLO, PAOLILLO \& CLIQUET, 2002).

Atualmente, a plasticidade neural também é investigada através do reflexo de interconexão entre os membros superiores e inferiores, a maioria destes estudos são realizados em pacientes lesados medulares cervicais.

O reflexo intermembros é evocado a partir da estimulação de nervos periféricos mistos dos membros inferiores que podem evocar respostas motoras nos músculos distais dos membros superiores, constatados através de eletromiografia (CALANCIE, 1991); (CALANCIE; LUTTON \& BROTON, 1996).

A Estimulação Elétrica é freqüentemente utilizada para evocar estes reflexos, mas Calancie; Lutton e Broton (1996), também realizaram estimulação sensorial e térmica. O local estimulado com maior freqüência é o nervo tibial. 
Calancie (1991), constatou que a magnitude da resposta evocada independe da magnitude do estímulo, seja sublimiar para evocar o H-reflexo ou supralimiar, por exemplo dois pulsos em $500 \mathrm{~Hz}$.

A atividade mioelétrica nos membros superiores e os resultados do Potencial Evocado indicam que estes reflexos são conseqüência de novas conexões sinápticas entre as fibras aferentes da extremidade inferior e os motoneurônios- $\alpha$ que inervam os músculos distais dos membros superiores. Portanto, ocorre uma reorganização medular caudal ao nível de lesão, com desenvolvimento de novas conexões sinápticas, sugerindo uma possível regeneração medular (CALANCIE; LUTTON \& BROTON, 1996); (CALANCIE, MOLANO \& BROTON, 2002).

O reflexo intermembros também foi evocado através da Estimulação Elétrica do membro superior, gerando sinal mioelétrico no quadríceps e nos adutores da coxa em pacientes com disfunção na medula espinhal, por exemplo poliomielite, sugerindo que há denervação parcial ou reinervação dos neurônios motores inferiores (ERTEKIN et al., 2002).

As respostas evocadas pelo reflexo intermembros podem ser ipslateral, contralateral ou ambos em cada paciente com disfunção medular. Nos sujeitos saudáveis a resposta é ausente, pois não há necessidade de utilização destas vias, já em animais quadrúpedes estes circuitos neurais são mais atuantes (CALANCIE, MOLANO \& BROTON, 2002); (ERTEKIN et al., 2002).

Outra técnica eletrofiosiológica utilizada para evidenciar novas conexões sinápicas ou a regeneração medular é a quantificação da atividade córtico-cerebral.

As avaliações realizadas em sujeitos com paraplegia completa, através de Magneto Encefalografia, constataram ativação cortical durante a Estimulação Elétrica abaixo do nível de lesão (IOANNIDES et al., 2002).

A ativação artificial do membro superior de tetraplégicos gera input central, que pode ser combinado com movimento voluntário, conduzindo à reorganização do córtex somato-sensorial. Portanto, a plasticidade cortical ocorre, devido a integração sensório-motora promovida pela Estimulação Elétrica Neuro-Muscular, que aumenta o ganho de função através da repetibilidade do movimento, possibilitando o 
reaprendizado sensório-motor (BURRIDGE \& LADOUCEUR, 2002); (POPOVIC, D.B.; POPOVIC, M.B. \& SINKJAER, 2002).

Em experimentos, constatou-se que os efeitos terapêuticos decorrentes da realização de atividades de vida diária através de Estimulação Elétrica dos membros superiores com manipulação de objetos, aumentaram o número de movimentos repetidos que apresentaram sucesso, além da redução do tempo para a realização do movimento, com conseqüente ganho de função (POPOVIC, D.B.; POPOVIC, M.B. \& SINKJAER, 2002); (POPOVIC, M.B.; POPOVIC, D.B. \& TOMOVIC, 2002); (POPOVIC et al., 2002). Ainda, a realização de tarefas motoras complexas, como as seqüências de movimentos rápidos, pode ser melhorada em sua velocidade e precisão através de várias sessões diárias de prática (ROSSINI \& PAURI, 2000).

Portanto, a Estimulação Elétrica Neuro-Muscular é importante para possibilitar alterações no córtex cerebral, não permitindo que as áreas cooperativas substituam progressivamente uma área de disfunção, pois após a lesão medular, ocorrem mudanças adaptativas. Assim, as alterações nos focos de ativação durante as tarefas motoras foram obtidas pelo registro da expansão espacial da representação cortical da musculatura proximal para o nível de lesão, quando associadas com tarefas motoras simples. Foi constatado - através de ressonância magnética funcional em tetraplégicos - que durante a execução de movimentos da língua e do membro superior, a representação cortical da língua migrou sobre a da mão, como a que ocorre em indivíduos amputados (MIKULIS et al., 2002). Este fenômeno, também ocorre após a privação sensorial (ROSSINI \& PAURI, 2000).

O controle sensório-motor na realização de atividades com os membros superiores é complexo, ainda mais em indivíduos tetraplégicos, sendo um desafio, no qual a biomecânica traz contribuições para o melhor entendimento destes movimentos e inclusive para o aprimoramento da interface homem-máquina. 


\section{CAPÍtUlO 4}

\subsection{ASPECTOS BIOMECÂNICOS APLICADOS À REABILITAÇÃO DE MEMBROS SUPERIORES}

A Biomecânica como Ciência Interdisciplinar abrange a descrição, análise e interpretação dos movimentos dos segmentos do corpo humano, através da aplicação de conceitos da física, química, matemática, anatomia, fisiologia, entre outros (AMADIO \& BAUMANN, 2000). Sua contribuição ocorre em várias áreas, como nos Esportes, Ergonomia, Engenharia de Reabilitação, Ortopedia e Traumatologia.

Na Ortopedia, possibilitou o aumento do entendimento das funções dos ossos, músculos, ligamentos e tendões; permitiu uma melhor compreensão dos efeitos da tensão mecânica sobre as propriedades físicas dos óssos, possibilitando novas técnicas cirúrgicas e tratamentos para deformidades ósseas, consolidação de fraturas, osteoporose por desuso e atrofia muscular. Outros avanços tecnológicos na prática ortopédica são as avaliações biomecânicas nas disfunções de ombro e joelho, bem como, o desenvolvimento de instrumentação médica para uso clínico (CLIQUET Jr. et al., 2002).

Na Engenharia de Reabilitação, possibilitou o desenvolvimento de próteses, órteses, neuropróteses e novos equipamentos para a reabilitação de membros superiores e inferiores, bem como o desenvolvimento de instrumentação eletrônica em dispositivos de auxílio para avaliações clínicas em portadores de lesão neurológica (CLIQUET Jr., 2002); (CLIQUET Jr. et al, 2001); (CLIQUET Jr. \& CASTRO, 2000a); (SEPÚLVEDA \& CLIQUET Jr., 1998). 
Os fundamentos da Biomecânica são apresentados por diversos autores entre eles, Allard, Stokes e Blanchi (1995), Amadio (1996); Amadio \& Barbanti (2000); Latash (1993) e; Winter (1990).

A descrição do movimento é realizada por quatro métodos de mensuração: antropometria, dinamometria, cinemetria e eletromiografia.

Esses procedimentos são essenciais para a avaliação do processo de reabilitação dos membros superiores, como os seguintes exemplos:

A antropometria define as propriedades mecânicas da massa do corpo humano, que são fundamentais para o estudo cinético e cinemático do movimento, como a massa, o momento de inércia e a posição do centro de gravidade de cada segmento envolvido no movimento. Os cálculos são realizados através de modelos físico-geométricos, entre outros tipos de procedimentos, que representam o corpo humano; como referido em estudos de membros superiores por Van der Helme e Veeger (1996).

A força muscular e as cargas mecânicas no membro superior, em especial o ombro, são essenciais para a eficiência durante a propulsão em cadeira de rodas. Van der Helme e Veeger (1996) utilizaram o modelo da dinâmica inversa do mecanismo do ombro, através de equações de regressão derivadas de dados obtidos em cadáveres e determinaram a atuação dos músculos e a carga mecânica sobre as estruturas morfológicas durante a análise do movimento do membro superior em ergômetro de cadeira de rodas.

A dinamometria analisa a distribuição da força de interação entre o corpo e o meio externo. A força externa é uma variável cinética que pode ser medida através de transdutores de força. Os dados obtidos quando sincronizados com a cinemetria, possibilitam a formulação mais precisa das equações que descrevem o movimento. De acordo com vários estudos (CASTRO \& CLIQUET Jr, 1997); (CHADWICK \& NICOL, 2000); (INMAN \& HAUGLAND, 2001), a avaliação quantitativa da força 
de preensão durante as atividades funcionais pode ser realizada por objetos/dispositivos instrumentalizados.

Ainda, Inman e Haugland (2001), desenvolveram e avaliaram um objeto instrumentalizado (garfo) durante a atividade de comer, utilizando a preensão lateral, visando fornecer dados da força de preensão para controle das neuropróteses, com feedback sensorial em um sistema de malha fechada.

A cinemetria consiste na aquisição de imagens para descrição cinemática (deslocamentos, velocidades e acelerações lineares e angulares) de determinados pontos anatômicos (extremidade do segmento, centro de rotação da articulação e centro de gravidade do segmento) durante o movimento. A aplicação dos princípios da mecânica para a descrição da trajetória de uma partícula requer um sistema de referência que para figura humana é dado pela convenção:

$$
\begin{array}{ll}
\text { eixo vertical - eixo Y } & \text { ângulos positivos - sentido anti-horário } \\
\text { direção ântero-posterior - eixo X } & \text { referência plano XY - eixo X } \\
\text { direção látero-medial - eixo Z } & \text { referência plano YZ - eixo Y }
\end{array}
$$

A partir da escolha do sistema de referência (absoluto: externo ao corpo ou relativo: fixo no segmento do corpo), as trajetórias dos centros de massa são observadas, registrando-se as posições $(\mathrm{x}, \mathrm{y}, \mathrm{z})$ ao longo da trajetória. Considerando a variação do tempo, obtêm-se a velocidade linear $\left(\mathrm{v}_{\mathrm{x}}, \mathrm{v}_{\mathrm{y}}, \mathrm{v}_{\mathrm{z}}\right)$, aceleração linear $\left(\mathrm{a}_{\mathrm{x}}, \mathrm{a}_{\mathrm{y}}\right.$, $\mathrm{a}_{\mathrm{z}}$ ), velocidade angular $\left(\omega_{\mathrm{xy}}, \omega_{\mathrm{yz}}\right)$ e aceleração angular $\left(\alpha_{\mathrm{xy}}, \alpha_{\mathrm{yz}}\right)$. Portanto, a velocidade é considerada como a derivada do deslocamento em relação ao tempo (ou taxa de variação da posição em relação ao tempo), enquanto a aceleração é considerada como a derivada da velocidade em relação ao tempo (ou taxa de variação da velocidade com o tempo).

A aplicação da cinemetria para avaliação do membro superior é exdmplificada por Feng e Mak (1997).

A análise tridimensional do movimento do cotovelo foi realizada em sujeitos com e sem espasticidade. Os dados obtidos indicaram que houve a elevação do ombro durante o movimento, com desvio do punho no plano medial, devido aos 
espasmos involuntários, resultando em movimento compensatório, com pouca coordenaação e baixa velocidade, além da dificuldade de extensão do cotovelo, devido a espasticidade que envolve os músculos flexores dos membros superiores de portadores de lesões neurológicas (FENG \& MAK, 1997).

A Eletromiografia (EMG) é o registro da atividade elétrica de um músculo em contração, e propicia a correlação entre atividade muscular e controle neurológico. A Eletroneuromiografia (realização de Potencial Evocado e EMG) é muito utilizada durante a reabilitação de portadores de lesão medular através de Estimulação Elétrica Neuro-Muscular para determinar a integridade do sistema nervoso central e do sistema neuromuscular (CALANCIE, 2002).

As variáveis que não são mensuráveis diretamente, como as forças internas e os momentos que atuam nas articulações, são obtidas através de cálculos matemáticos a partir da combinação dos dados coletados.

A interpretação dos dados fornece parâmetros para diagnóstico, prognóstico e intervenções terapêuticas em diversas patologias, auxiliando na elaboração de protocolos de tratamento mais direcionados ao quadro clínico de cada paciente, além de avaliar a instrumentação biomédica desenvolvida para a reabilitação de portadores de deficiência física.

Portanto, atualmente, a Biomecânica é caracterizada por novos procedimentos para análise do movimento humano e pelo desenvolvimento de técnicas de medição, armazenamento e processamento de dados, contribuindo para os avanços tecnológicos nos procedimentos clínicos. 


\section{Capítulo 5}

\subsection{MATERIAIS E MÉTODOS}

\subsection{RECURSOS HUMANOS}

Esta pesquisa foi aprovada pelo Comitê de Ética Local da Universidade Estadual de Campinas (UNICAMP).

Os critérios de exclusão para o estudo foram: presença de doenças metabólicas, cardiopatias, processos inflamatórios, calcificação e osteoporose intensa nos portadores de tetraplegia, que foram selecionados a partir dos prontuários médicos do Hospital das Clínicas / UNICAMP.

A seleção ocorreu de acordo com os seguintes critérios:

- Pacientes com lesão do neurônio motor superior entre os níveis C4 e C7;

- Pacientes com o tempo de lesão acima de 1 ano;

- $\quad$ Sexo masculino e feminino;

- $\quad$ Idade entre 25 e 45 anos;

- Pacientes que estão ingressando/ingressaram no programa de Estimulação Elétrica Neuro-Muscular.

Os indivíduos portadores de tetraplegia selecionados foram devidamente informados sobre o projeto de pesquisa e posteriormente assinaram o Termo de 
Consentimento Pós-Informação ou realizaram impressão digital, diante de uma testemunha, que também assinou o documento (ANEXO A).

Inicialmente, faziam parte desta pesquisa doze sujeitos, nove portadores de tetraplegia do sexo masculino e três do sexo feminino. Por motivos pessoais, como contenção de gastos com viagem, necessidade de realização de cirurgia e problemas de ordem familiar, as três voluntárias do sexo feminino e um voluntário do sexo masculino desistiram da participação neste projeto.

O estudo foi realizado, então, com oito indivíduos portadores de tetraplegia (Tabela 2) e um indivíduo saudável, voluntário padrão, do sexo masculino, com 26 anos de idade.

TABELA 2 - Perfil dos pacientes tetraplégicos participantes da pesquisa.

\begin{tabular}{cccccc}
\hline Pacientes & $\begin{array}{c}\text { Idade } \\
\text { (anos) }\end{array}$ & $\begin{array}{c}\text { Nível } \\
\text { de } \\
\text { Lesão }\end{array}$ & Causa da Lesão & $\begin{array}{c}\text { Tempo } \\
\text { de Lesão } \\
\text { (anos) }\end{array}$ & $\begin{array}{c}\text { Data de } \\
\text { Iní́cio da } \\
\text { EENM }\end{array}$ \\
\hline 1 & 35 & C7 & ferimento por arma de fogo & 8 & Jun/2002 \\
2 & 31 & C6-C7 & acidente automobilístico & 12 & Mar/1999 \\
3 & 36 & C6 & acidente automobilístico & 2 & Set/2002 \\
4 & 41 & C5-C6 & acidente automobilístico & 21 & Mar/2002 \\
5 & 26 & C5 & mergulho & 2 & Fev/2001 \\
6 & 37 & C5 & atropelamento & 7 & Fev/2003 \\
7 & 28 & C4-C5 & mergulho & 14 & Mar/1999 \\
8 & 25 & C4 & mergulho & 6 & Mar/1998 \\
\hline
\end{tabular}

\subsection{METODOLOGIA}

A presente pesquisa foi realizada no Laboratório de Biomecânica e Reabilitação do Aparelho Locomotor (Departamento de Ortopedia e Traumatologia / 
Hospital das Clínicas da UNICAMP) e no LABCIBER - Laboratório de Biocibernética e Engenharia de Reabilitação (Departamento de Engenharia Elétrica / EESC, USP).

O sistema de reabilitação de tetraplégicos através de Estimulação Elétrica Neuro-Muscular é realizado de acordo com o seguinte procedimento:

Esta técnica consiste na colocação de eletrodos auto-adesivos na superfície da pele, sobre o ponto motor dos músculos e/ou diretamente nos nervos periféricos, de acordo com os movimentos desejados.

A rotina de tratamento destes indivíduos é caracterizada por uma sessão semanal, com duração aproximada de 60 minutos. As sessões são realizadas, com os indivíduos sentados na própria cadeira de rodas, ocorrendo a ativação dos músculos responsáveis pelos movimentos de flexão-extensão de punhos e dedos, além da estimulação dos músculos intrínsecos da mão, através de Estimulador Multicanal, durante 20 minutos. Posteriormente, os tetraplégicos realizam estimulação de membros inferiores, com duração de 20 minutos de ativação do músculo quadríceps, gerando extensão de joelho, seguidos por 15 minutos de estimulação do nervo fibular, evocando por reflexo a dorsiflexão do pé, para condicionar a musculatura, favorecer o retorno venoso e potencializar a plasticidade neural.

\subsection{1 ÓRTESES INSTRUMENTALIZADAS PARA MEMBROS} SUPERIORES

Foi realizado o Eletrodiagnóstico de estímulo nos pacientes tetraplégicos para investigar as condições de excitabilidade neuromuscular, isto é, a presença ou ausência de contração muscular através de EENM que permite os movimentos de ombro, cotovelo, punho e mão. Desta forma verificou-se a necessidade da utilização do dispositivo mecânico para gerar a extensão do cotovelo e estabilização do punho. Posteriormente, foram realizadas as medidas antropométricas do membro superior dominante (direito) dos pacientes e a escolha dos materiais, atuadores, acionadores e design das órteses, (i) estática para punho e (ii) dinâmica para cotovelo. 


\subsubsection{AVALIAÇÕES BIOMECÂNICAS}

O estudo piloto foi realizado com o Sistema Qualisys (APÊNDICE A) e com o eletrogoniômetro.

Optou-se pelo eletrogoniômetro, pois mostrou ser um método mais adequado para avaliação da medida angular durante a flexão e extensão do cotovelo com e sem EENM, por ser uma avaliação monoarticular, monoaxial e realizada no plano sagital, além de apresentar sistema de referência relativo e permitir a análise dinâmica do movimento.

Para a realização do procedimento experimental os pacientes foram posicionados próximos a uma mesa, na postura sentada, com o antebraço na posição neutra e com o ombro flexionado a $90^{\circ}$.

O membro superior dominante (direito) dos pacientes e do indivíduo saudável foi avaliado durante a execução de dez tentativas dos movimentos de flexão e extensão do cotovelo no plano sagital nos seguintes protocolos:

1) Sem preensão e com movimento voluntário;

2) Sem preensão e com EENM;

3) Com preensão palmar de objeto cilíndrico (copo) e movimento voluntário sem carga;

4) Com preensão palmar de objeto cilíndrico (copo) e movimento voluntário com carga de $5 \mathrm{~N}$;

5) Com preensão palmar de objeto cilíndrico (copo) e movimento voluntário com carga de $10 \mathrm{~N}$;

6) Com preensão palmar de objeto cilíndrico (copo), com EENM, sem carga;

7) Com preensão palmar de objeto cilíndrico (copo), com EENM e carga de $5 \mathrm{~N}$;

8) Com preensão palmar de objeto cilíndrico (copo), com EENM e carga de $10 \mathrm{~N}$. 
O indivíduo saudável realizou os mesmos protocolos sem a utilização da EENM.

Para não caracterizar um teste de fadiga, as avaliações sem preensão foram realizadas no mesmo dia, com intervalo mínimo de 30 minutos entre os protocolos com movimento voluntário e com Estimulação. Em dias diferentes, as avaliações com $0 \mathrm{~N}, 5 \mathrm{~N}$ e $10 \mathrm{~N}$ de carga foram realizadas em um intervalo mínimo de 30 minutos cada.
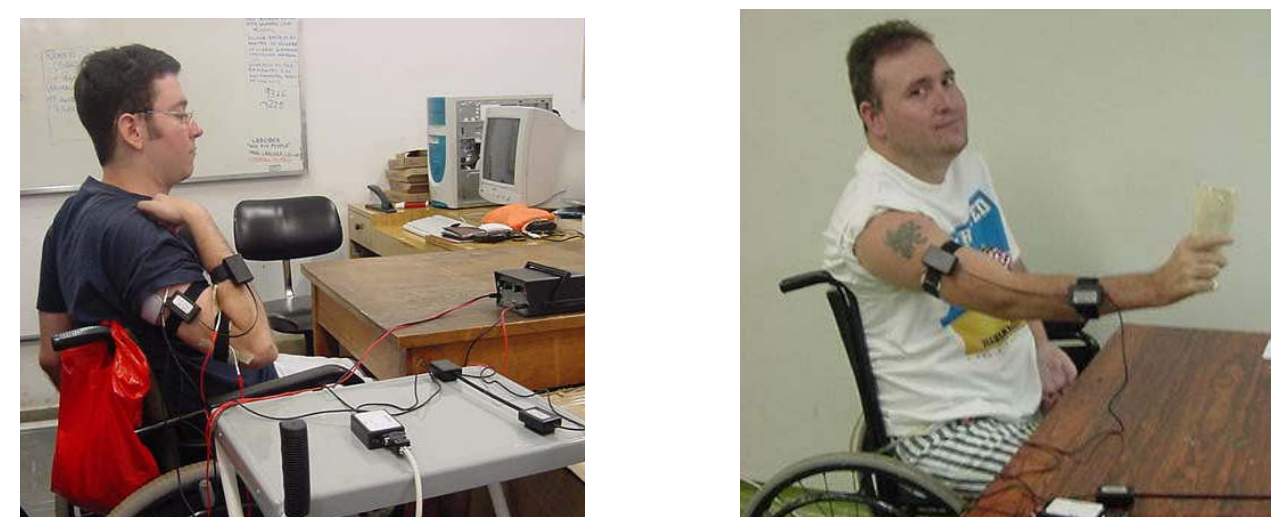

FIGURA 15 - Procedimento experimental sem preensão (a) e com preensão (b).

A preensão utilizada foi a palmar, quando necessário, utilizou-se adaptação para preensão do objeto, fixando-o com tira de Velcro. Durante a EENM, a força de preensão foi determinada pelo ajuste da amplitude do sinal através dos potenciômetros.

Os músculos estimulados foram: Bíceps Braquial, Tríceps Braquial, Flexor Superficial dos Dedos e Oponente do Polegar. No paciente 7, o tríceps não foi estimulado, por possuir denervação.

A carga máxima de $10 \mathrm{~N}$ foi determinada, pois os objetos utilizados no cotidiano, como copo, talheres, escova de dente, telefone, caneta, entre outros, não excedem o peso de $10 \mathrm{~N}$. Entretanto, as medidas angulares não foram mensuradas durante a simulação de atividades funcionais, mas durante o movimento completo da articulação do cotovelo, por permitir a obtenção dos valores de pico máximo e 
mínimo dos ângulos articulares durante a flexão e a extensão que os pacientes tetraplégicos conseguem realizar, possibilitando a amplitude de movimento para o alcance do objeto e sua condução tanto para a boca, quanto para a orelha, cabelos, como atender um telefone, comer, beber, pentear-se, por exemplo.

O estimulador utilizado foi desenvolvido pelo Prof. Dr. Alberto Cliquet Jr. (Departamento de Ortopedia e Traumatologia - FCM/UNICAMP e Departamento de Engenharia Elétrica - USP/ São Carlos) e possui os seguintes parâmetros: tipo de onda monofásica bipolar, ciclo de trabalho de 33\%, freqüência de $25 \mathrm{~Hz}$, duração de pulso de $300 \mu$ s e amplitude de 0 a $150 \mathrm{~V}$.

A avaliação da medida angular do cotovelo foi realizada por Eletrogoniômetro com Fibra Óptica, Shape Sensor ${ }^{\mathrm{TM}}$ - S700 Joint Angle, de acordo com o seguinte procedimento:

O ângulo é determinado a partir da monitoração do tempo, no qual o feixe de luz - enviado pelo sensor - se desloca pela fibra óptica até sua extremidade e retorna ao local de origem. De acordo com o ângulo formado, ocorre um tempo de atraso do sinal. A cada segundo registra-se 120 posições - $120 \mathrm{~Hz}$, sendo então, o valor máximo para registro 240. Os valores obtidos em Tensão ou Voltagem são enviados para o microcomputador e a aquisição de dados é obtida utilizando-se o software WinDaq Lite.

A fibra óptica contém um marco central que é colocado na articulação estudada (epicôndilo lateral do cotovelo) e fixada ao indivíduo com velcro.

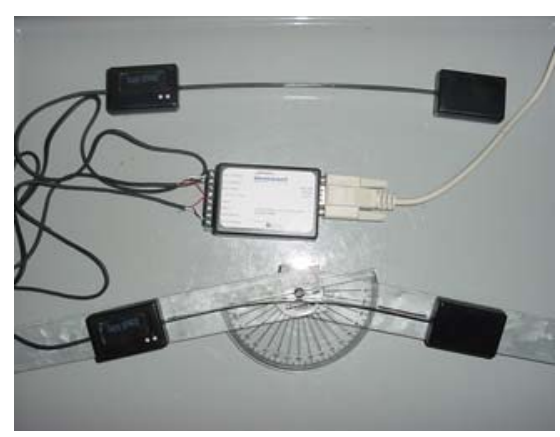

FIGURA 16 - Calibração do sensor. 
Para análise da medida angular, a transformação de Volts em graus, deve ser realizada através da calibração do sensor, ou seja, o sensor deve ser colocado em posição retilínea $\left(0^{\circ}\right)$, posteriormente altera-se o ângulo e verifica-se a Voltagem de Saída (FIGURA 16). O cálculo dos parâmetros para conversão foi realizado pela equação da melhor curva dos pontos do ângulo medido utilizando-se o Mat Lab:

$$
\theta=-5,09137+(91,82212 \times U)
$$

O movimento de extensão completa do cotovelo foi definido como sendo $0^{\circ}$.

\subsubsection{AVALIAÇÕES QUALITATIVAS}

Para determinar se houve ganho neurológico e aumento do nível de independência funcional em um período de 6 meses de reabilitação com Estimulação Elétrica foram realizados o Protocolo ASIA (escala de deficiência da American Spinal Injury Association) e o Protocolo FIM (Functional Independence Measure), no período pré e pós-tratamento.

O Protocolo ASIA (ANEXO B) consiste na realização do exame neurológico sensorial e motor, bilateramente, através dos dermátomos e miótomos. Foram examinados dois aspectos da sensibilidade, a dolorosa (com utilização de agulha) e toque leve (com algodão). Os músculos-chave examinados foram classificados de acordo com a contração obtida, variando da paralisia total até o movimento ativo contra grande resistência (escala de 0-5). O tipo de lesão, completa (A) ou incompleta (B, C, D), foi determinado através do exame de toque na região perianal.

O Protocolo FIM (ANEXO B) avalia o grau de independência funcional, na execução das AVDs, descrevendo o impacto da lesão medular sobre o indivíduo, além de monitorar a evolução do tratamento. 


\subsection{ANÁLISE DOS DADOS}

A análise dos ângulos articulares foi realizada pela inspeção visual da variação angular, amplitude, duração e forma de onda.

O nível de lesão neurológica e o índice motor, sensorial e de independência funcional foram analisados comparando-se os resultados do período pré e póstratamento com EENM.

Os dados coletados foram descritos e analisados em estudos de caso, devido à variabilidade intersujeitos. 


\section{CAPÍtulo 6}

\subsection{RESULTADOS E DISCUSSÃO}

\section{1 ÓRTESES INSTRUMENTALIZADAS PARA MEMBROS SUPERIORES}

Os resultados do Eletrodiagnóstico de estímulo mostraram que dois pacientes não apresentam contração muscular adequada através de EENM, ou seja, o paciente 7 possui tríceps denervado e o paciente 8 possui os músculos extensores de punho parcialmente denervados, necessitando do uso de órteses mecânicas, juntamente com a EENM (Sistema Híbrido). Os demais pacientes possuem resposta adequada à EENM, sendo indicado o uso de neuropróteses. O primeiro protótipo das órteses instrumentalizadas é mostrado a seguir.

As órteses foram projetadas, digitalizadas e finalmente conformadas no formato desejado, de acordo com os moldes dos membros superiores dos pacientes. O material escolhido foi o termoplástico, que garante melhor moldagem e adaptabilidade às necessidades de cada paciente, além de oferecer a resistência mecânica desejada.

A órtese estática de punho foi projetada para possibilitar o posicionamento funcional da articulação do punho ( $30^{\circ}$ de extensão), estabilidade articular, com menor área possível que envolva o antebraço e a mão, para que não restrinja o ato de pegar/soltar objetos com EENM e para manter a integridade da pele (FIGURA 17-a, 
17-b). Este dispositivo está sendo desenvolvido para que, no futuro, seja implementado com eletrodos acoplados à própria órtese e sistema de Estimulação por telemetria.
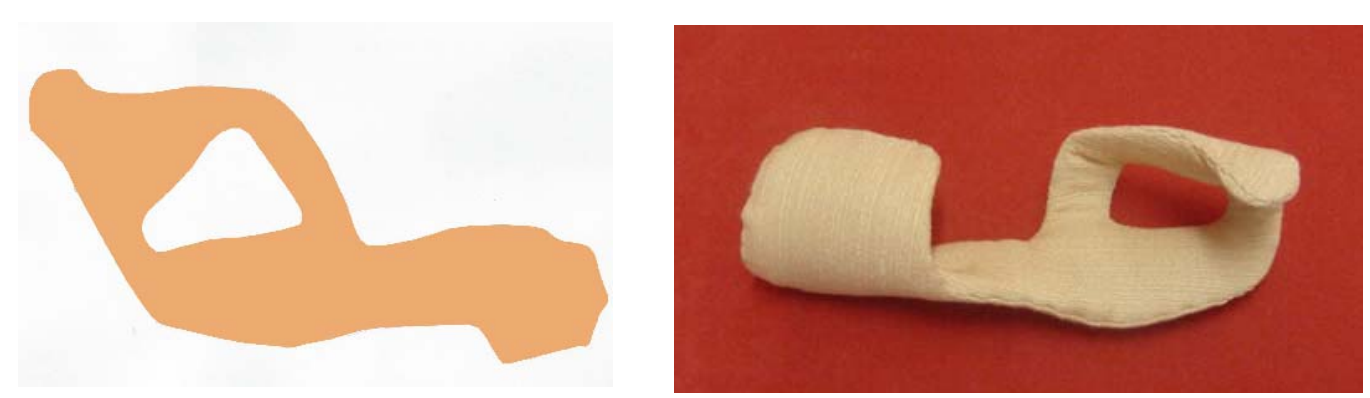

FIGURA 17 - Planificação (a) e primeiro protótipo da órtese de punho (b).

O mecanismo dinâmico da órtese para cotovelo engloba um sistema mecatrônico com engrenamento coroa-pinhão, servomotor e acionamento por movimentos remanescentes do paciente para gerar o movimento relativo de rotação entre braço e antebraço. Os dispositivos podem ser descritos pelo diagrama de blocos na Figura 18.

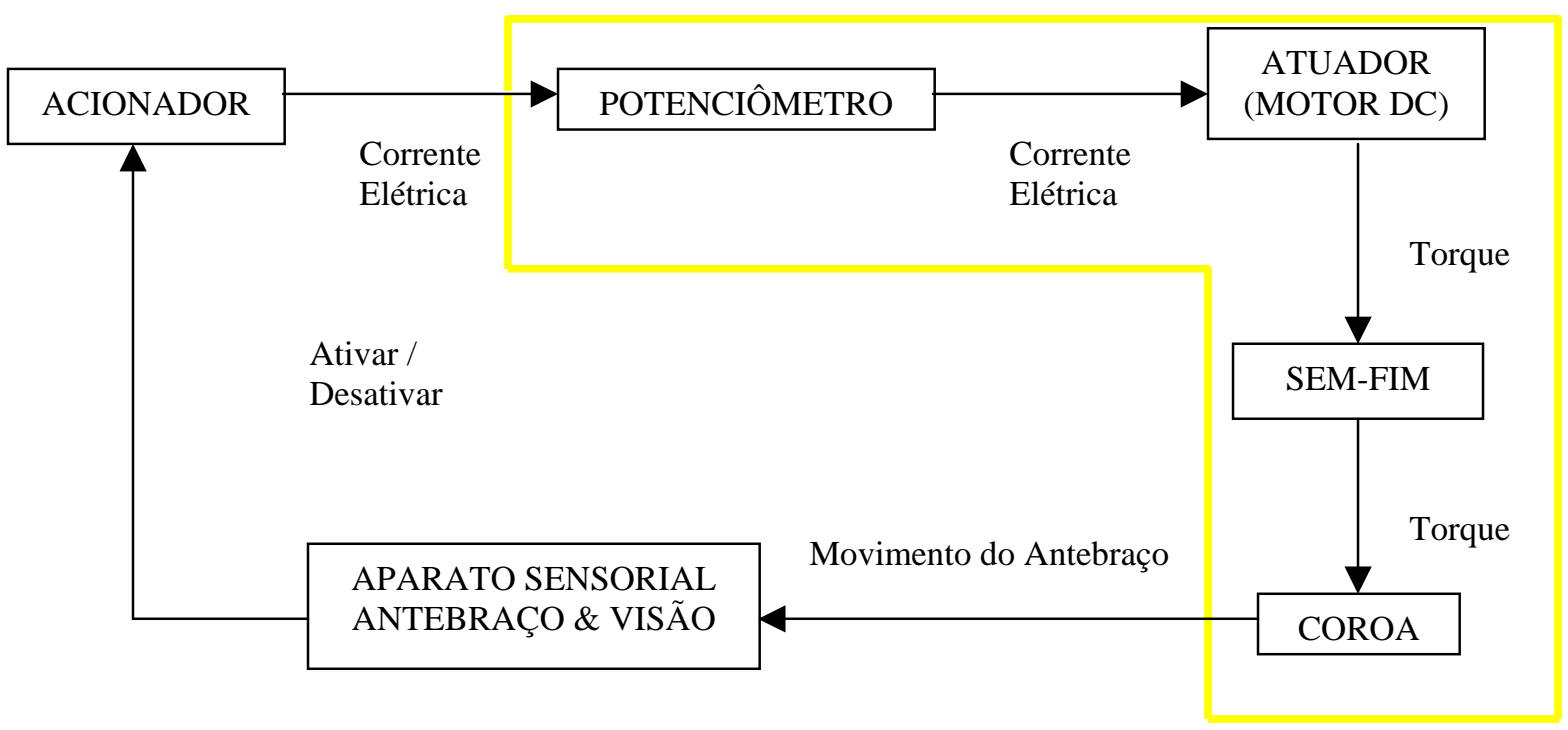

FIGURA 18 - Diagrama de blocos da órtese robótica de cotovelo. 
A órtese robótica (FIGURA 19-a, 19-b) se necessária poderá ser acoplada à órtese estática para possibilitar o movimento de alcance e preensão.
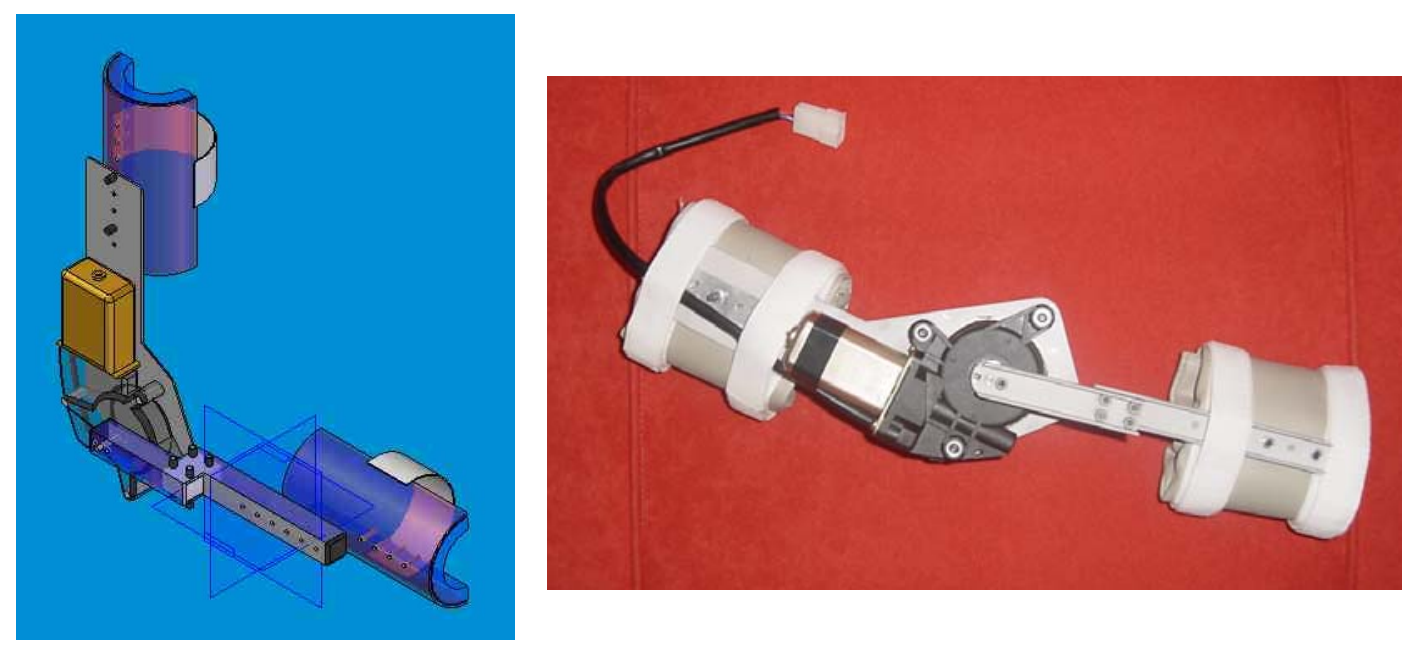

FIGURA 19 - Projeto virtual (a) e primeiro protótipo da órtese robótica para cotovelo (b).

\section{2 AVALIAÇÕES QUANTITATIVAS E QUALITATIVAS}

Os resultados abaixo mostram inicialmente a descrição cinemática do movimento de flexão e extensão do cotovelo de oito pacientes tetraplégicos, bem como, a descrição qualitativa neurológica e do índice funcional por meio de estudos de caso. Posteriormente, ocorre a descrição do padrão cinemático do movimento de flexão e extensão do cotovelo do sujeito saudável.

\subsubsection{ESTUDOS DE CASO}

\section{ESTUDO DE CASO 1}

Durante o movimento voluntário de flexão/extensão do cotovelo sem preensão, o paciente 1 apresentou forma de onda em pico e variação da amplitude de onda. O mesmo movimento realizado com EENM apresentou predomínio da forma de onda retangular, menor medida angular durante a flexão comparada ao 
movimento voluntário, ainda, o tempo da atividade realizada foi maior durante a EENM. Atingiu a extensão completa duas vezes tanto durante o movimento voluntário, como com o uso da EENM.

Para o movimento voluntário realizado com preensão de objeto e aplicação de carga externa, observou-se a redução da amplitude de onda de acordo com a magnitude das cargas aplicadas e com aumento do tempo de execução da atividade. No mesmo movimento com EENM, a forma de onda predominante foi em rampa; houve aumento da medida angular na extensão, com aumento no tempo de execução da atividade e não apresentou variação de acordo com a carga aplicada.

Em relação aos Protocolos ASIA e FIM, o Paciente 1 apresentou aumento da força nos músculos flexores do cotovelo, com alteração na classificação de 4 para 5 do lado direito e de 3 para 4 do esquerdo; o flexor profundo do terceiro dedo evoluiu de 3 para 4 do lado direito e de 0 para 1 do esquerdo. Nas áreas correspondentes ao dermátomo C8 (mão), a sensibilidade apresentou alteração na classificação do lado direito de 0 para 2 e do esquerdo de 0 para 1, em T1 (antebraços) e L1-S3 (membros inferiores) de 0 para 1 ; houve aumento no índice motor $(\Delta=7)$, sensorial com agulha ( $\Delta=6)$ e toque leve $(\Delta=17)$, além do aumento da independência funcional $(\Delta=15)$.

Os resultados com valores brutos das medidas angulares do paciente 1 são mostrados na Figura 20. Os valores de pico mínimo e máximo na Tabela 3. O Índice Sensorial, Motor e de Independência Funcional na Tabela 6. Além do nível neurológico no período pré e pós-tratamento na Tabela 7.

\section{ESTUDO DE CASO 2}

Durante o movimento voluntário de flexão/extensão do cotovelo sem preensão, o paciente 2 apresentou variação na medida angular durante a extensão, entretanto, o mesmo não ocorreu durante a flexão. As formas de onda predominantes foram: retangular para a flexão e em pico para a extensão. O tempo de execução da atividade foi maior com o uso da EENM comparado ao movimento voluntário. Durante a EENM, a medida angular foi maior para flexão e menor para extensão, 
com predominância da forma de onda retangular para extensão e de rampa para flexão.

Durante o movimento voluntário com preensão de objeto e aplicação de carga externa, observou-se a forma de onda em pico. Houve aumento da medida angular para flexão, de acordo com a magnitude da carga aplicada, além do aumento no tempo de execução da atividade. Com EENM, houve aumento da medida angular para a flexão e redução para a extensão, de acordo com a magnitude da carga aplicada; com predomínio da forma de onda em rampa. Com o uso da EENM atingiu $0^{\circ}$ mais vezes comparado ao movimento voluntário.

Em relação aos Protocolos ASIA e FIM, o paciente 2 obteve ganho de força nos extensores do punho, com conseqüente alteração na classificação de 4 para 5. A sensibilidade alterou-se de 1 para 2 nas áreas correspondentes aos dermátomos T1T4 (antebraços/região torácica); houve um discreto aumento no índice motor $(\Delta=1)$, sensorial com agulha $(\Delta=3)$ e toque leve $(\Delta=4)$, além do aumento da independência funcional $(\Delta=9)$.

Os resultados com valores brutos das medidas angulares do paciente 2 são mostrados na Figura 21. Os valores de pico mínimo e máximo na Tabela 3. O Índice Sensorial, Motor e de Independência Funcional na Tabela 6. Além do nível neurológico no período pré e pós-tratamento na Tabela 7.

\section{ESTUDO DE CASO 3}

Durante o movimento voluntário de flexão/extensão do cotovelo sem preensão, o paciente 3 apresentou predomínio da forma de onda em pico, com aumento da medida angular para a flexão, que atingiu $170^{\circ}$ e não apresentou variação significativa na extensão, sem atingir $0^{\circ}$. Com EENM, houve redução na medida angular tanto para a flexão, quanto para a extensão, que atingiu $0^{\circ}$ na maioria das tentativas; o tempo de execução da atividade foi maior comparado ao movimento voluntário. 
Com preensão de objeto e aplicação de carga externa, observou-se variação da amplitude de onda de acordo com a magnitude da carga, entretanto, o tempo de execução das atividades foi maior com o uso da EENM. Ainda, durante o movimento com EENM não houve alteração da amplitude de onda com a aplicação das diferentes cargas e a forma de onda predominante foi a retangular.

Em relação aos Protocolos ASIA e FIM, o paciente 3 apresentou aumento da força nos flexores do cotovelo do lado esquerdo, com alteração da classificação de 4 para 5. Os extensores do punho obtiveram aumento de força com classificação de 4 para 5 em ambos os lados. O adutor do quinto dedo dos lados direito e esquerdo alteraram a classificação de 0 para 1 . A sensibilidade evoluiu na área correspondente ao dermátomo T3 (região torácica) do lado direito de 0 para 1 e do esquerdo de 0 para 2; houve um discreto aumento no índice motor $(\Delta=5)$, sensorial com agulha ( $\Delta$ = 3) e toque leve $(\Delta=3)$, além do aumento da independência funcional $(\Delta=8)$.

Os resultados com valores brutos das medidas angulares do paciente 3 são mostrados na Figura 22. Os valores de pico mínimo e máximo na Tabela 3. O Índice Sensorial, Motor e de Independência Funcional na Tabela 6. Além do nível neurológico no período pré e pós-tratamento na Tabela 7.

\section{ESTUDO DE CASO 4}

Durante o movimento voluntário de flexão/extensão do cotovelo sem preensão, o paciente 4 apresentou predomínio da forma de onda em pico nas quatro primeiras tentativas e em rampa nas posteriores. Com EENM, houve maior tempo de execução da atividade e menor medida angular para a flexão comparada ao movimento voluntário. Ainda, houve pouca variação angular para extensão e a forma de onda predominante foi a retangular.

Durante os movimentos com preensão e aplicação de carga externa, houve aumento da medida angular para flexão de acordo com a magnitude da carga aplicada, tanto para o movimento voluntário quanto para com EENM, entretanto durante o movimento com EENM houve maior tempo de execução da atividade e as 
medidas angulares para flexão foram menores comparadas ao movimento voluntário. Ainda, a extensão apresentou maior variação da medida angular durante o movimento voluntário comparado ao movimento com EENM.

Em relação aos Protocolos ASIA e FIM, o paciente 4 apresentou aumento da força nos extensores do punho com classificação de 4 para 5 do lado esquerdo, igualmente aos flexores do cotovelo direito/esquerdo e extensores do punho do lado direito. Os extensores do cotovelo alteraram a classificação de 3 para 4 do lado direito e de 1 para 3 do esquerdo. O flexor profundo do terceiro dedo evoluiu de 0 para 1 em ambos os lados. A sensibilidade aumentou nas áreas correspondentes aos dermátomos T1-T9 (antebraço/tórax/abdômen), com alteração da classificação de 0 para 1; Houve aumento no índice motor $(\Delta=6)$, sensorial com agulha $(\Delta=19) \mathrm{e}$ toque leve $(\Delta=8)$, além do aumento da independência funcional $(\Delta=7)$.

Os resultados com valores brutos das medidas angulares do paciente 4 são mostrados na Figura 23. Os valores de pico mínimo e máximo na Tabela 3. O Índice Sensorial, Motor e de Independência Funcional na Tabela 6. Além do nível neurológico no período pré e pós-tratamento na Tabela 7.

\section{ESTUDO DE CASO 5}

Durante o movimento voluntário de flexão/extensão do cotovelo sem preensão, o paciente 5 apresentou forma de onda em pico. Não observou-se variação angular para extensão e com relação a flexão houve variação da medida angular tanto durante o movimento voluntário quanto com o uso da EENM. Entretanto, durante o movimento com EENM houve predominância da forma de onda retangular, além da menor medida angular para flexão e maior tempo de execução da atividade comparados ao movimento voluntário.

Para os movimentos realizados com preensão e aplicação de cargas, observou-se predomínio da forma de onda em pico para o movimento voluntário e da forma de onda retangular para EENM. Durante o movimento voluntário houve aumento da amplitude de onda de acordo com a magnitude das cargas aplicadas. Durante a EENM houve redução da amplitude de onda de acordo com a magnitude 
das cargas aplicadas. Entretanto as medidas angulares para flexão foram maiores com o uso da EENM comparado ao movimento voluntário. A medida angular para extensão foi menor com a aplicação de cargas, enquanto com EENM, houve o aumento da medida angular com a aplicação de cargas, em especial com 10N. O tempo de execução da atividade foi maior durante a EENM em todos os protocolos comparado ao movimento voluntário.

Em relação aos Protocolos ASIA e FIM, o paciente 5 apresentou aumento da força dos flexores do cotovelo com classificação de 4 para 5 e dos extensores do punho de 3 para 4. A sensibilidade alterou-se na área dos dermátomos correspondentes a C5 (braço) do lado direito de 1 para 2, em C6 (antebraço/mão) de 1 para 2, em C8 (mão) de 0 para 2, em T2 (região axilar/tórax) de 1 para 2 e em T5 (tórax) de 0 para 1 ; Houve um discreto aumento no índice motor $(\Delta=5)$, sensorial com agulha $(\Delta=2)$ e toque leve $(\Delta=5)$, além do aumento da independência funcional $(\Delta=8)$.

Os resultados com valores brutos das medidas angulares do paciente 5 são mostrados na Figura 24. Os valores de pico mínimo e máximo na Tabela 4. O Índice Sensorial, Motor e de Independência Funcional na Tabela 6. Além do nível neurológico no período pré e pós-tratamento na Tabela 7.

\section{ESTUDO DE CASO 6}

Durante o movimento voluntário de flexão/extensão do cotovelo sem preensão, o paciente 6 apresentou forma de onda em pico, com repetibilidade da medida angular para a flexão e extensão. Com o uso da EENM durante a flexão a medida angular foi maior, apresentou variabilidade e a forma de onda predominante foi em rampa, para extensão houve repetibilidade, atingindo $0^{\circ}$ na maioria das tentativas e a forma de onda predominante foi a retangular.

Durante o movimento realizado com preensão e aplicação de cargas, houve o aumento da amplitude de onda de acordo com a magnitude da carga aplicada, entretanto houve maior variação e menor tempo de execução da atividade durante o 
movimento voluntário comparado ao uso da EENM. As formas de onda predominantes foram em pico para o movimento voluntário e retangular com EENM.

Em relação aos Protocolos ASIA e FIM, o Paciente 6 não apresentou aumento da força muscular nos membros superiores, porém, manteve as classificações obtidas. A sensibilidade alterou-se de 1 para 2 do lado direito nas áreas correspondentes aos dermátomos T11-S3 (região inferior do abdômen, membros inferiores, região glútea) e do lado esquerdo nas áreas de L2, L3, L5, S2 e S3 (coxa, joelho, pé, região poplítea e região glútea); Houve aumento no índice motor $(\Delta=4)$, sensorial com agulha $(\Delta=8)$ e toque leve $(\Delta=16)$, além do aumento da independência funcional $(\Delta=4)$.

Os resultados com valores brutos das medidas angulares do paciente 6 são mostrados na Figura 25. Os valores de pico mínimo e máximo na Tabela 4. O Índice Sensorial, Motor e de Independência Funcional na Tabela 6. Além do nível neurológico no período pré e pós-tratamento na Tabela 7.

\section{ESTUDO DE CASO 7}

O paciente 7 possui tríceps denervado, realiza o movimento de extensão do cotovelo à favor da gravidade e não apresenta resposta à EENM. Durante o movimento voluntário de flexão e extensão do cotovelo sem preensão, apresentou forma de onda em pico e variação da medida angular, com diminuição da amplitude de onda. Com o uso da EENM, houve aumento na amplitude de onda e da medida angular para a flexão, além da repetibilidade para flexão e maior tempo de duração na execução da atividade, entretanto houve variação da medida angular para extensão.

Com a preensão de objeto e aplicação de carga externa, houve predominância da forma de onda em pico e redução da amplitude de onda, com aumento da medida angular para flexão e extensão de acordo com a magnitude da carga aplicada. Com o uso da EENM a forma de onda predominante foi em rampa, durante a flexão houve maior medida angular de acordo com a magnitude da carga aplicada. Ainda, houve maior repetibilidade, menor medida angular tanto para flexão quanto para extensão, 
além do aumento do tempo de execução da atividade comparados ao movimento voluntário.

Em relação aos Protocolos ASIA e FIM, o Paciente 7 apresentou alteração na classificação dos flexores do cotovelo do lado esquerdo de 0 para 1 e dos extensores do punho de ambos os lados de 0 para 1 . A sensibilidade alterou-se de 1 para 2 até os dermátomos correspondentes a C4 (ombro) e C5 (braço); Houve um discreto aumento no índice motor ( $\Delta=2)$, sensorial com agulha $(\Delta=1)$, além do aumento da independência funcional $(\Delta=2)$. O paciente não apresentou aumento no índice sensorial com toque leve $(\Delta=0)$.

Os resultados com valores brutos das medidas angulares do paciente 7 são mostrados na Figura 26. Os valores de pico mínimo e máximo na Tabela 4. O Índice Sensorial, Motor e de Independência Funcional na Tabela 6. Além do nível neurológico no período pré e pós-tratamento na Tabela 7.

\section{ESTUDO DE CASO 8}

Durante o movimento voluntário e com EENM, o paciente 8 apresentou predomínio da forma de onda retangular e repetibilidade. Entretanto, durante a EENM a medida angular foi menor para flexão e houve maior tempo de execução da atividade comparados ao movimento voluntário.

Com preensão de objeto e aplicação de carga externa, a forma de onda predominante durante o movimento voluntário foi em pico, com redução da medida angular tanto para a flexão quanto para extensão de acordo com a magnitude da carga aplicada. Com o uso da EENM, houve aumento da medida angular para flexão especialmente com carga de $10 \mathrm{~N}$ e houve a redução da medida angular para o movimento de extensão com as cargas de $5 \mathrm{~N}$ e $10 \mathrm{~N}$. Ainda, durante a EENM a forma de onda predominante foi em rampa e houve o aumento no tempo de execução da atividade.

Em relação aos Protocolos ASIA e FIM, o paciente 8 apresentou aumento da força no flexor do cotovelo do lado esquerdo com alteração na classificação de 4 
para 5, para os flexores profundos do terceiro dedo de 0 para 1. A sensibilidade aumentou na área correspondente ao dermátomo C6 (tórax) e S2 (fossa poplítea), com alteração na classificação de 1 para 2 e de 0 para 1 respectivamente. Houve um discreto aumento no índice motor $(\Delta=3)$ e sensorial com agulha $(\Delta=1)$. O paciente não apresentou aumento no índice sensorial com toque leve $(\Delta=0)$ e de independência funcional $(\Delta=0)$.

Os resultados com valores brutos das medidas angulares do paciente 8 são mostrados na Figura 27. Os valores de pico mínimo e máximo na Tabela 4. O Índice Sensorial, Motor e de Independência Funcional na Tabela 6. Além do nível neurológico no período pré e pós-tratamento na Tabela 7.

\section{O SUJEITO SAUDÁVEL}

Durante o movimento voluntário de flexão/extensão do cotovelo sem preensão, o sujeito saudável apresentou repetibilidade dos ciclos nas dez tentativas, atingiu em todas a extensão completa e a forma de onda observada foi em pico. Durante o movimento voluntário de flexão e extensão do cotovelo com preensão e aplicação de carga externa, observou-se a forma de onda em pico e pequena variação na amplitude de onda durante a execução das dez tentativas e nas diferentes cargas. Ainda, durante a extensão não foi atingido $0^{\circ}$ em nenhuma tentativa. Entretanto, durante os movimentos com preensão e aplicação de cargas as medidas angulares para flexão foram maiores e o tempo de execução da atividade foi menor comparado ao movimento sem preensão.

Os resultados com valores brutos das medidas angulares do sujeito saudável são mostrados na Figura 28. Os valores de pico mínimo e máximo na Tabela 5. 


\subsubsection{RESULTADOS COM OS VALORES BRUTOS DOS PACIENTES} TETRAPLÉGICOS E DO SUJEITO SAUDÁVEL

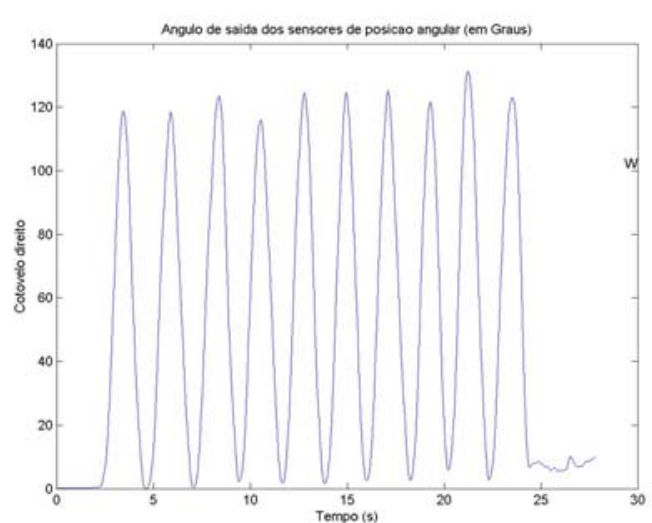

(a)

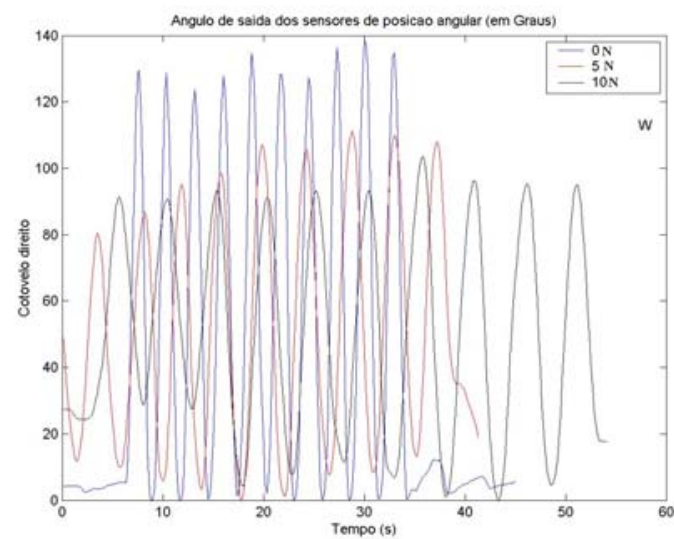

(c)

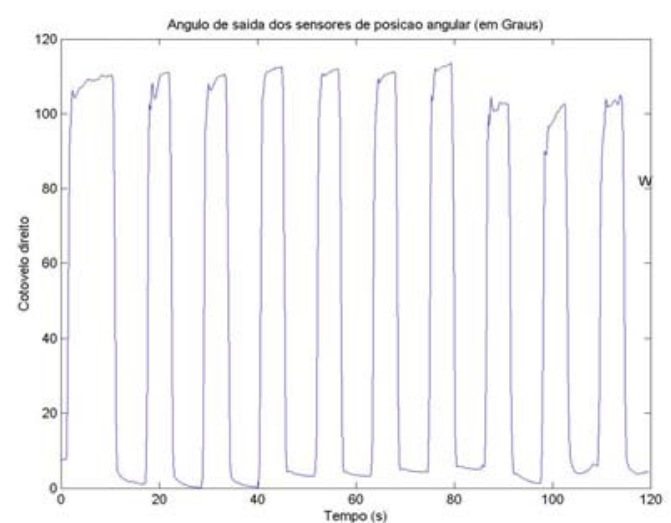

(b)

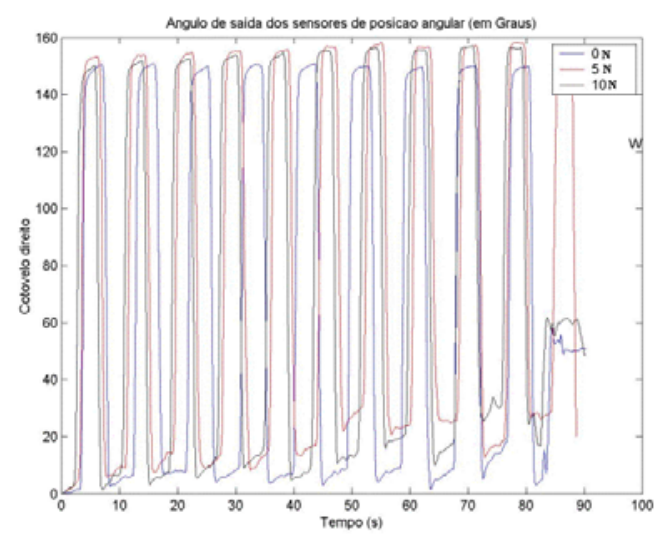

(d)

FIGURA 20 - Medida Angular vs. Tempo durante o movimento de flexão e extensão do cotovelo do paciente 1: sem preensão e sem EENM (a); sem preensão e com EENM (b); com preensão e adição de cargas sem EENM (c); com preensão e adição de cargas com EENM. 


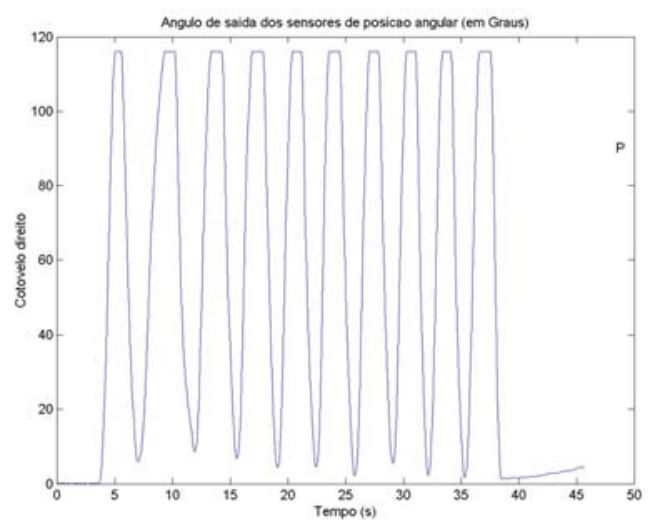

(a)

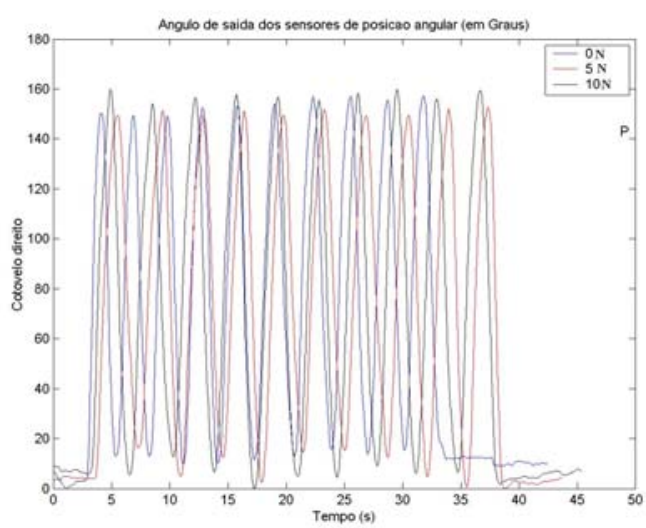

(b)

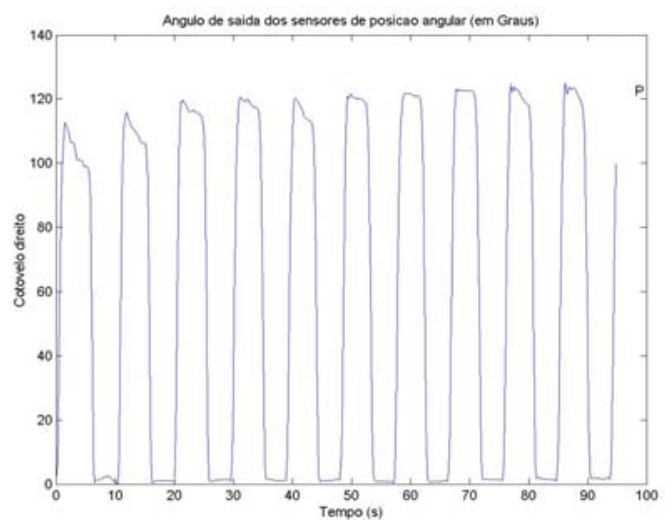

(b)

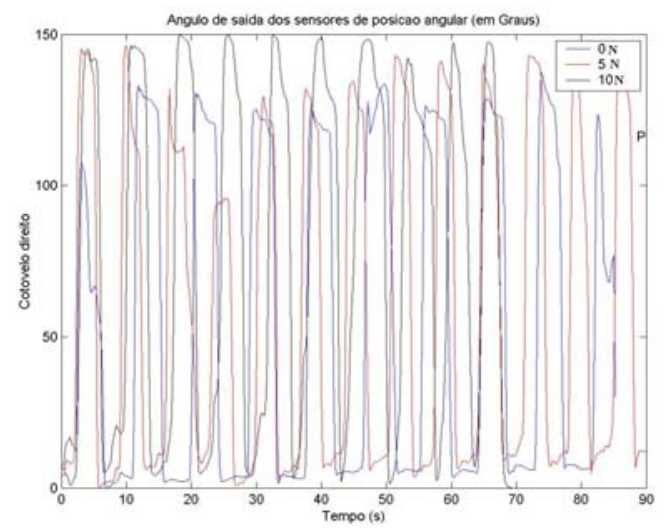

(d)

FIGURA 21 - Medida Angular vs. Tempo durante o movimento de flexão e extensão do cotovelo do paciente 2: sem preensão e sem EENM (a); sem preensão e com EENM (b); com preensão e aplicação de cargas sem EENM (c); com preensão e aplicação de cargas com EENM. 


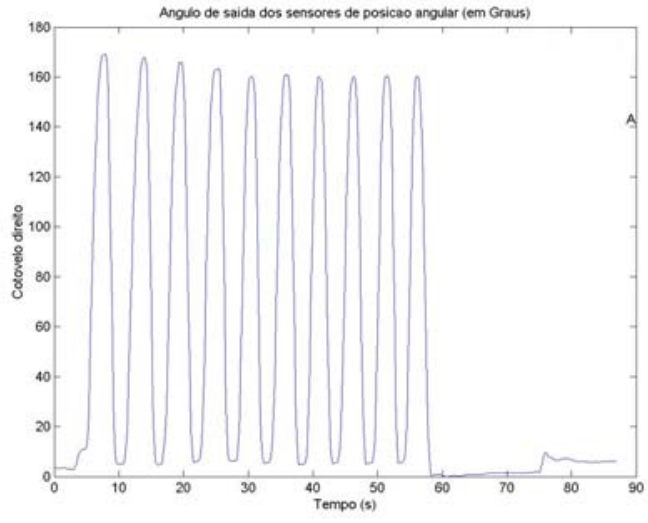

(a)

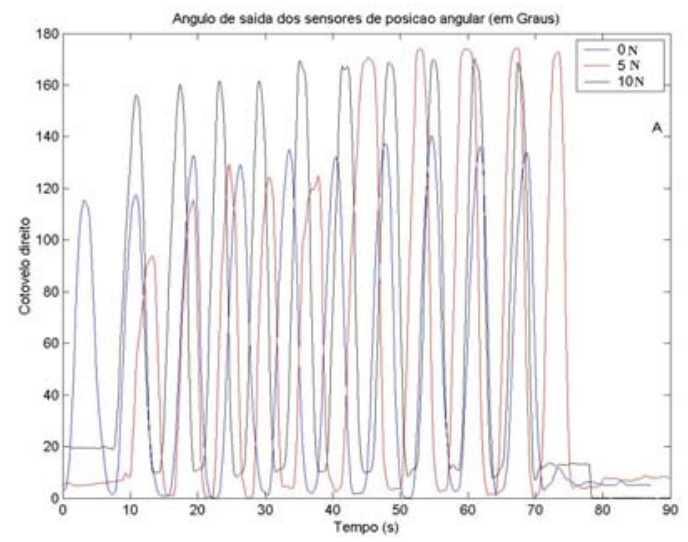

(b)

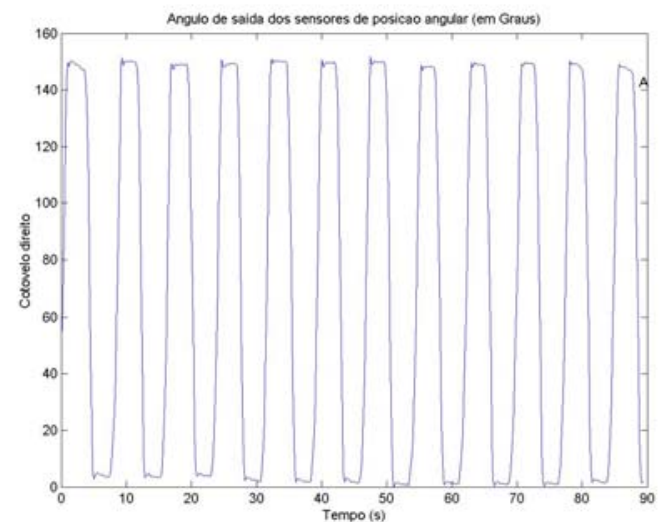

(b)

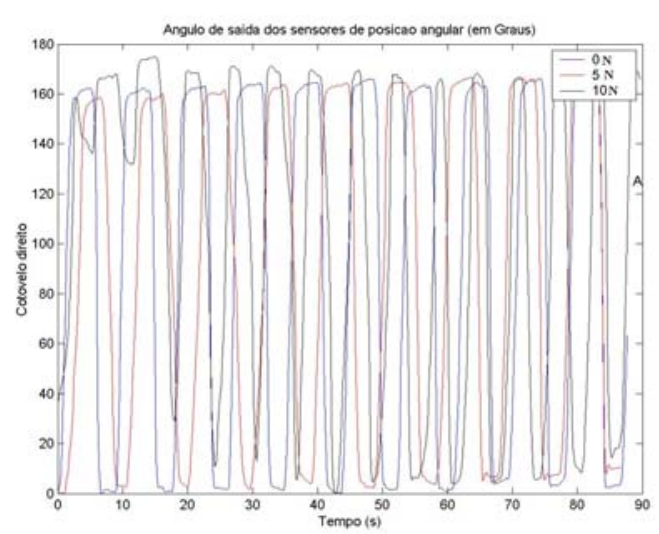

(d)

FIGURA 22 - Medida Angular vs. Tempo durante o movimento de flexão e extensão do cotovelo do paciente 3: sem preensão e sem EENM (a); sem preensão e com EENM (b); com preensão e aplicação de cargas sem EENM (c); com preensão e adição de cargas com EENM. 


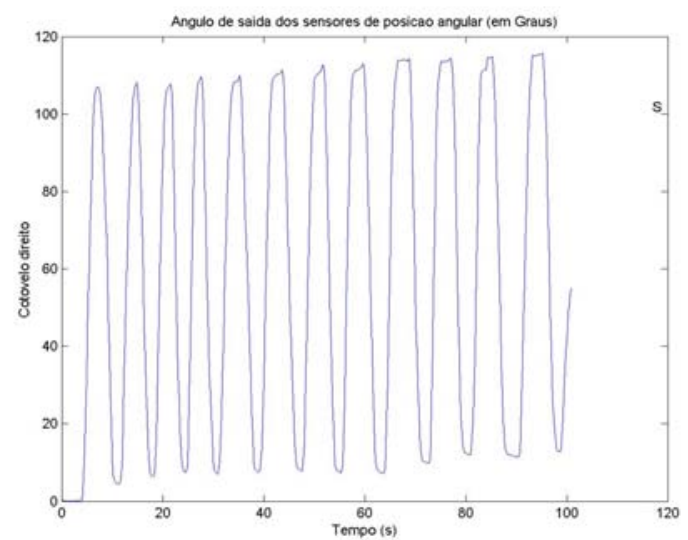

(a)

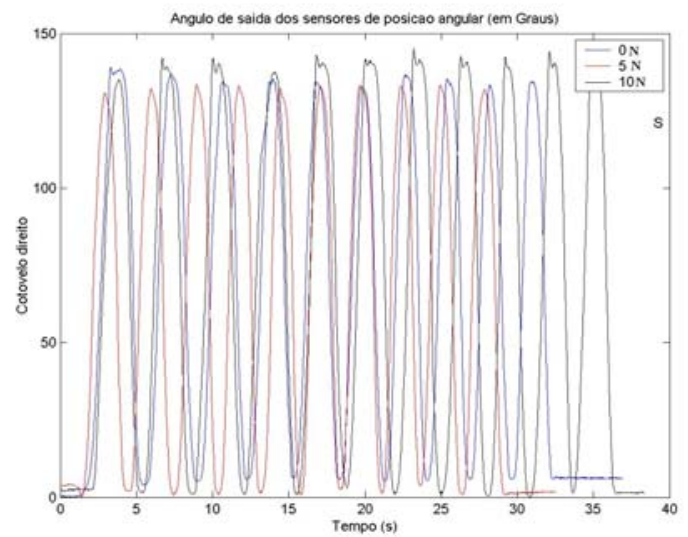

(c)

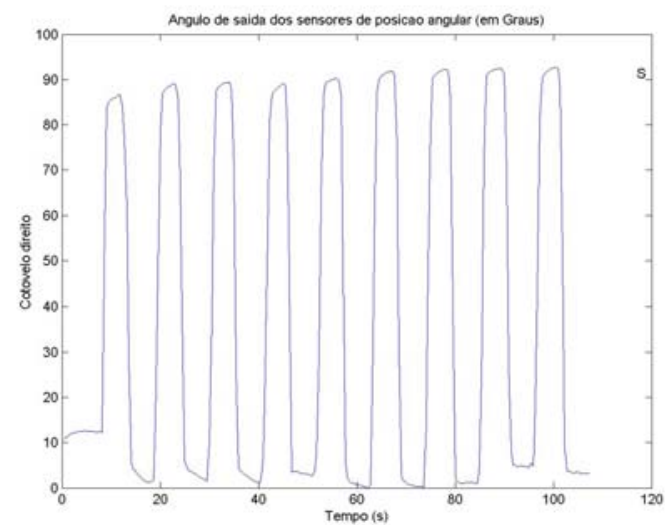

(b)

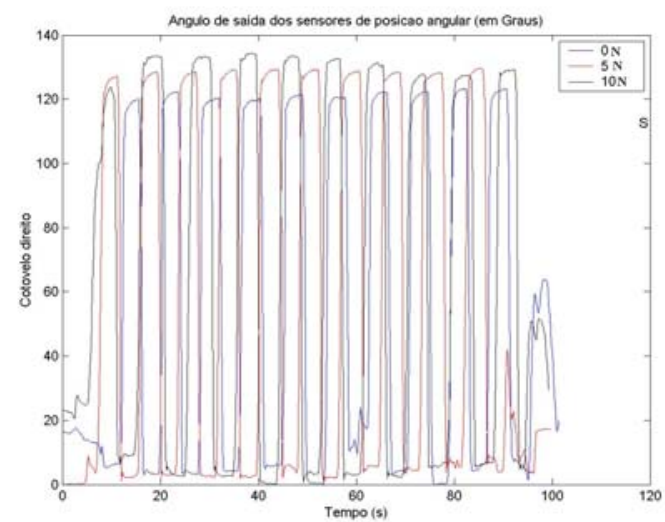

(d)

FIGURA 23 - Medida Angular vs. Tempo durante o movimento de flexão e extensão do cotovelo do paciente 4: sem preensão e sem EENM (a); sem preensão e com EENM (b); com preensão e adição de cargas sem EENM (c); com preensão e adição de cargas com EENM. 


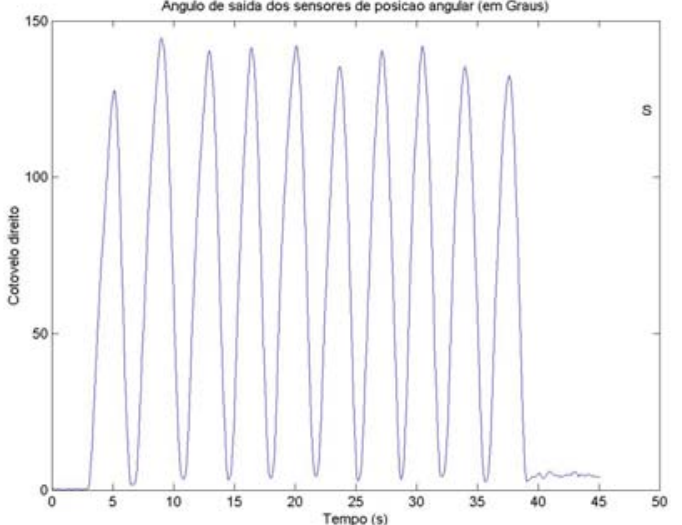

(a)

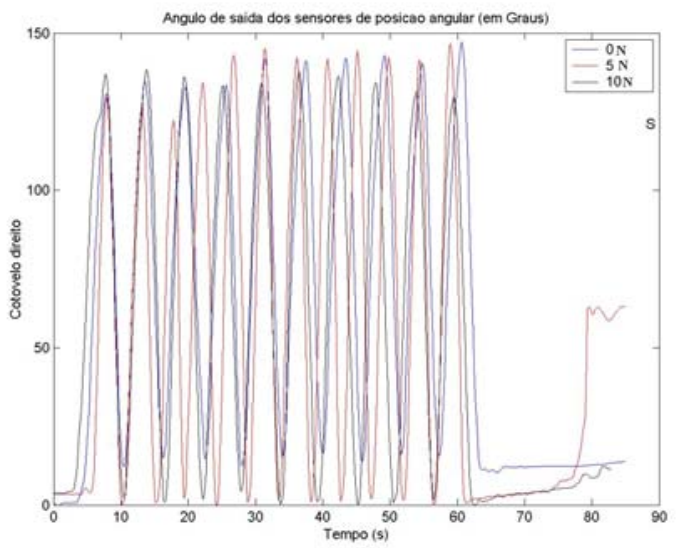

(d)

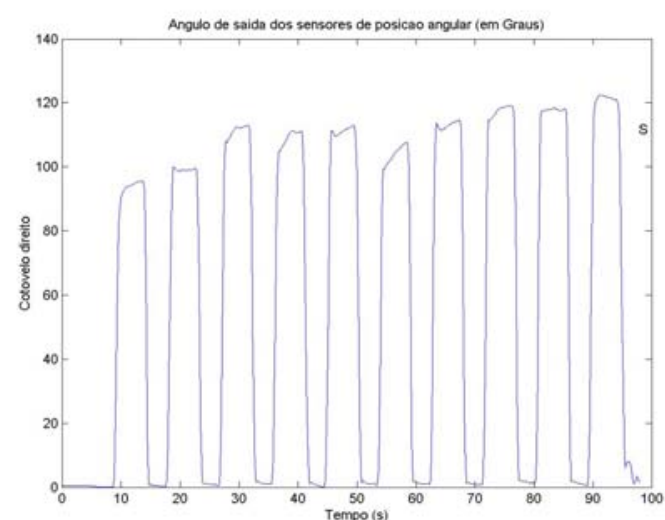

(b)

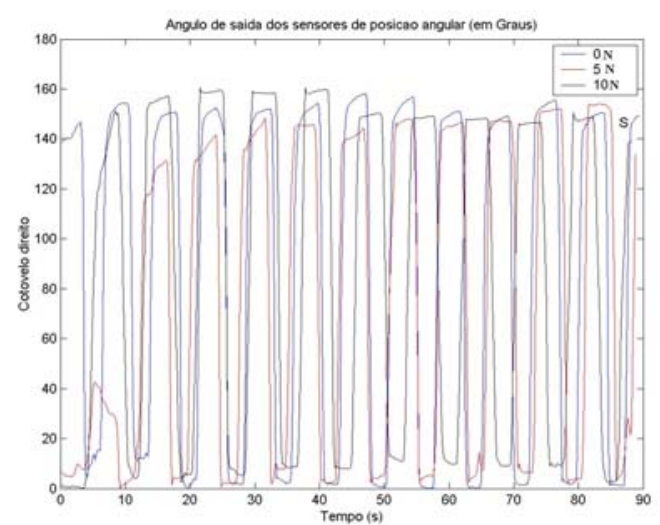

(d)

FIGURA 24 - Medida Angular vs. Tempo durante o movimento de flexão e extensão do cotovelo do paciente 5: sem preensão e sem EENM (a); sem preensão e com EENM (b); com preensão e adição de cargas sem EENM (c); com preensão e adição de cargas com EENM. 


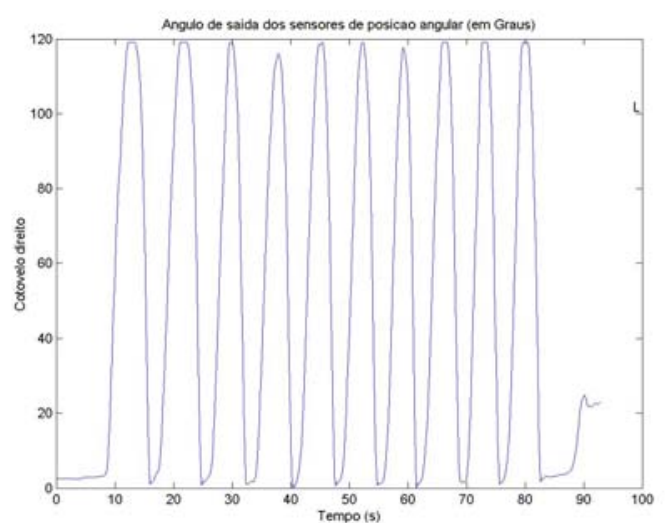

(a)

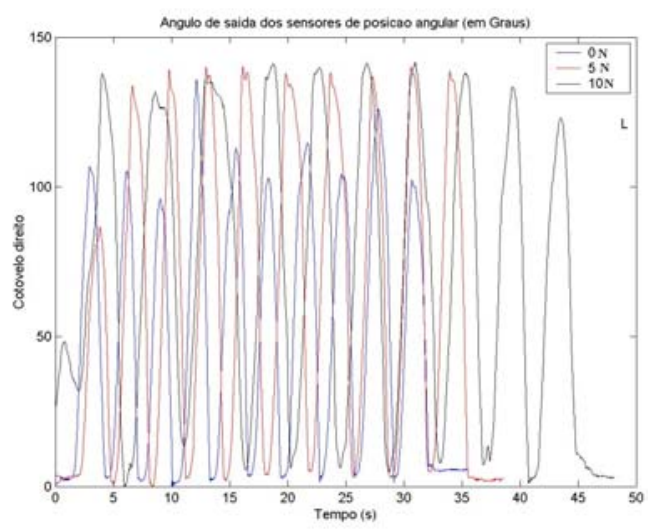

(c)

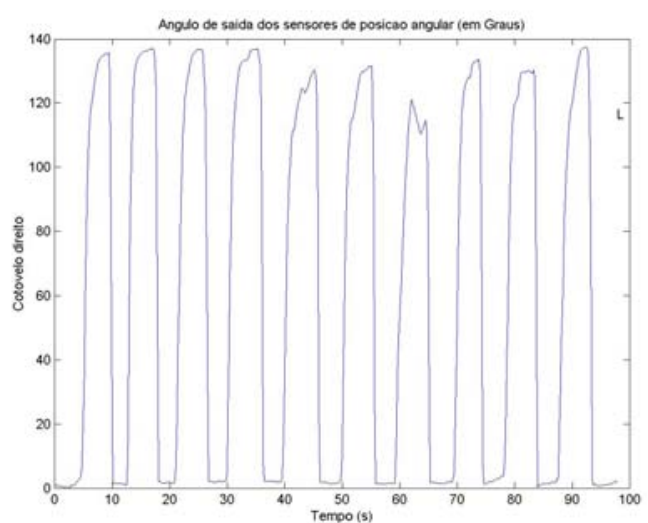

(b)

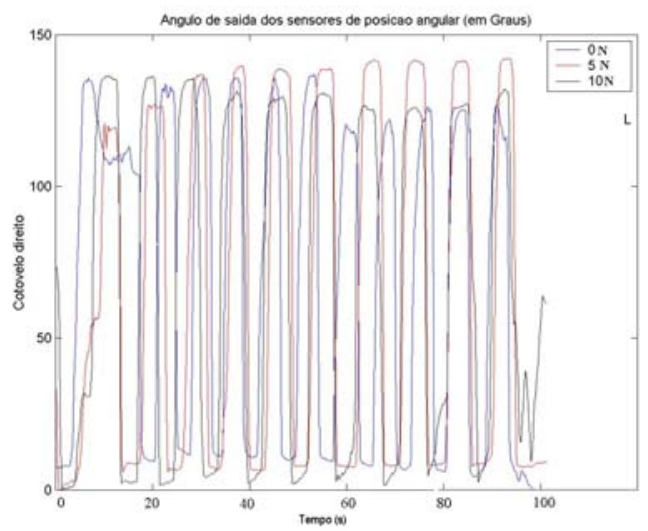

(d)

FIGURA 25 - Medida Angular vs. Tempo durante o movimento de flexão e extensão do cotovelo do paciente 6: sem preensão e sem EENM (a); sem preensão e com EENM (b); com preensão e adição de cargas sem EENM (c); com preensão e adição de cargas com EENM. 


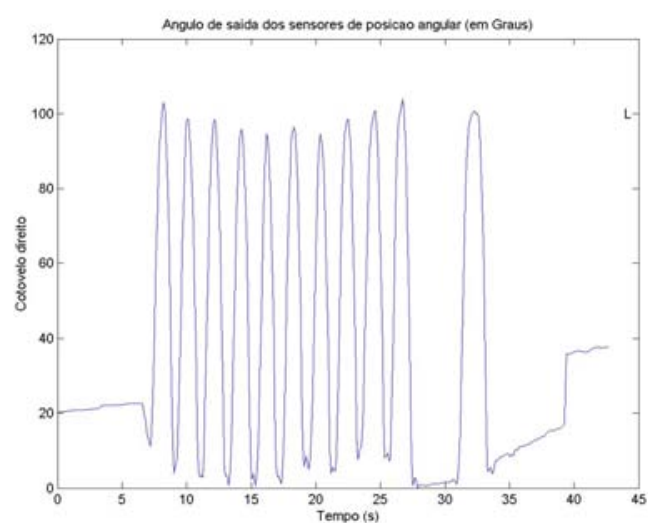

(a)

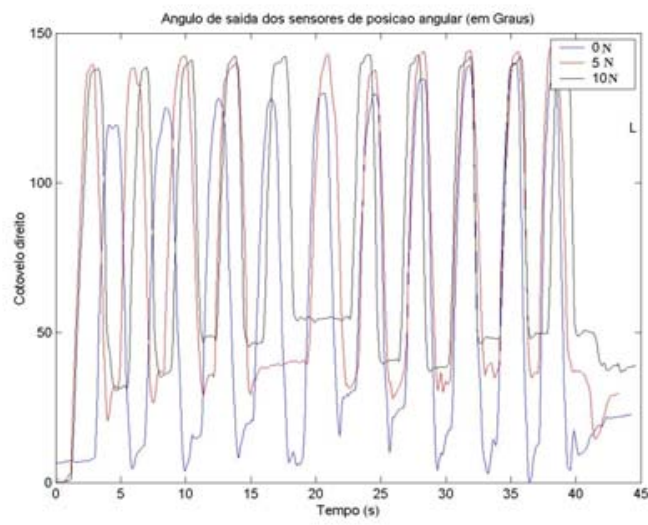

(c)

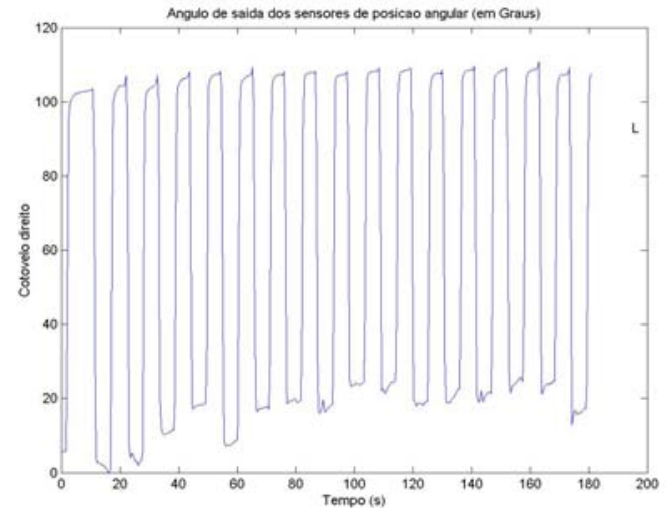

(b)

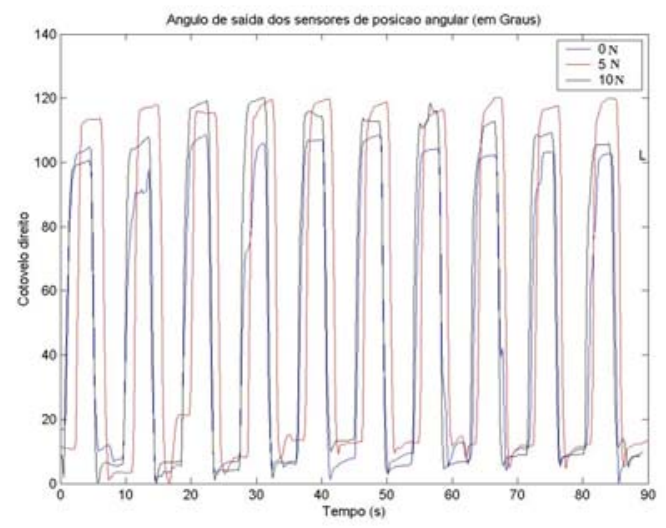

(d)

FIGURA 26 - Medida Angular vs. Tempo durante o movimento de flexão e extensão do cotovelo do paciente 7: sem preensão e sem EENM (a); sem preensão e com EENM (b); com preensão e adição de cargas sem EENM (c); com preensão e adição de cargas com EENM. 


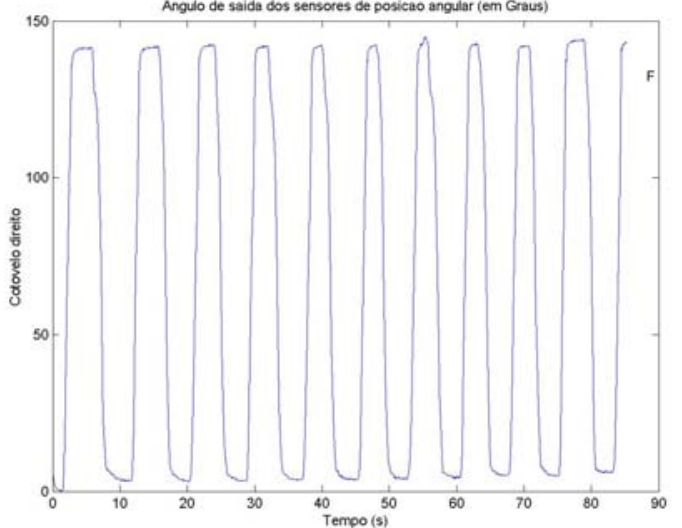

(a)

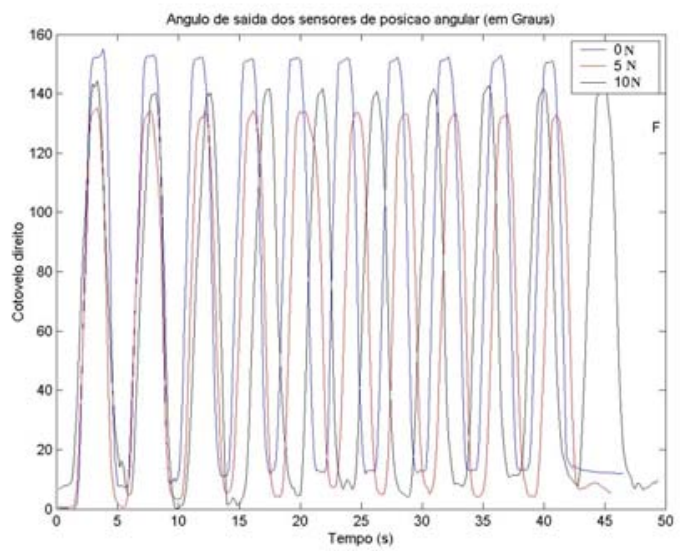

(c)

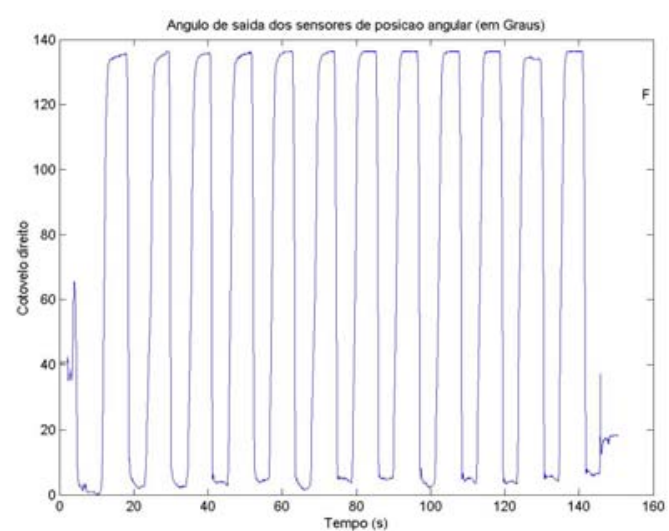

(b)

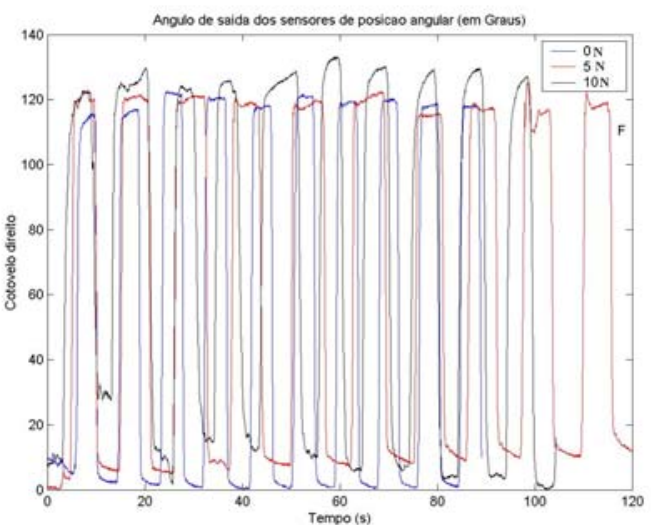

(d)

FIGURA 27 - Medida Angular vs. Tempo durante o movimento de flexão e extensão do cotovelo do paciente 8: sem preensão e sem EENM (a); sem preensão e com EENM (b); com preensão e adição de cargas sem EENM (c); com preensão e adição de cargas com EENM. 


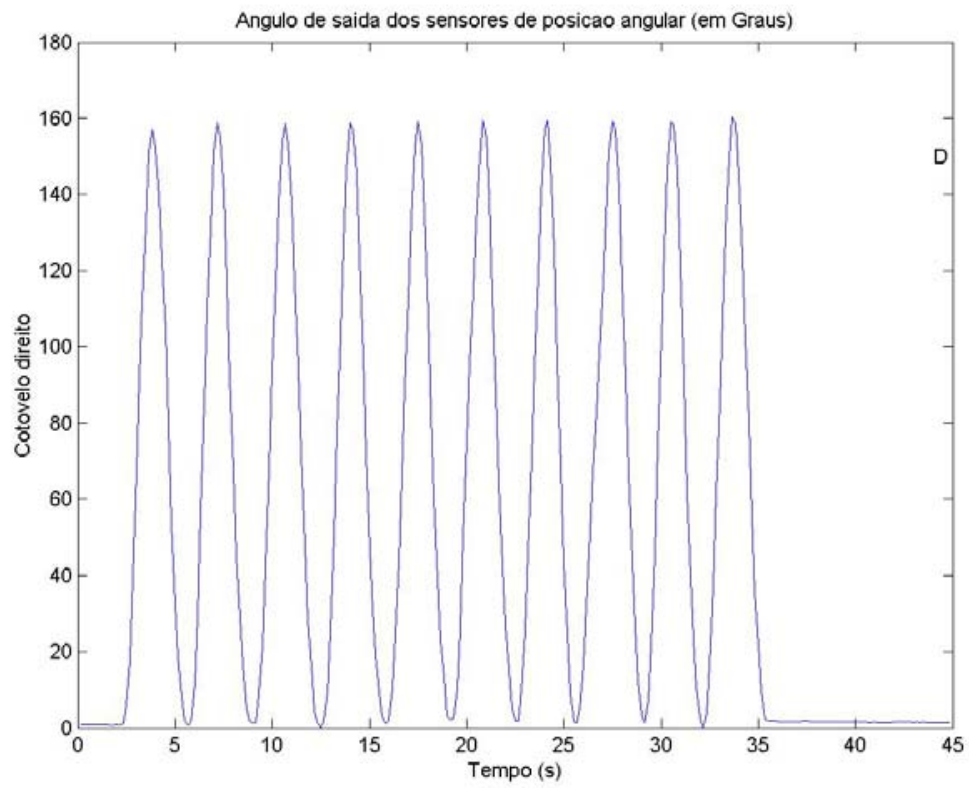

(a)

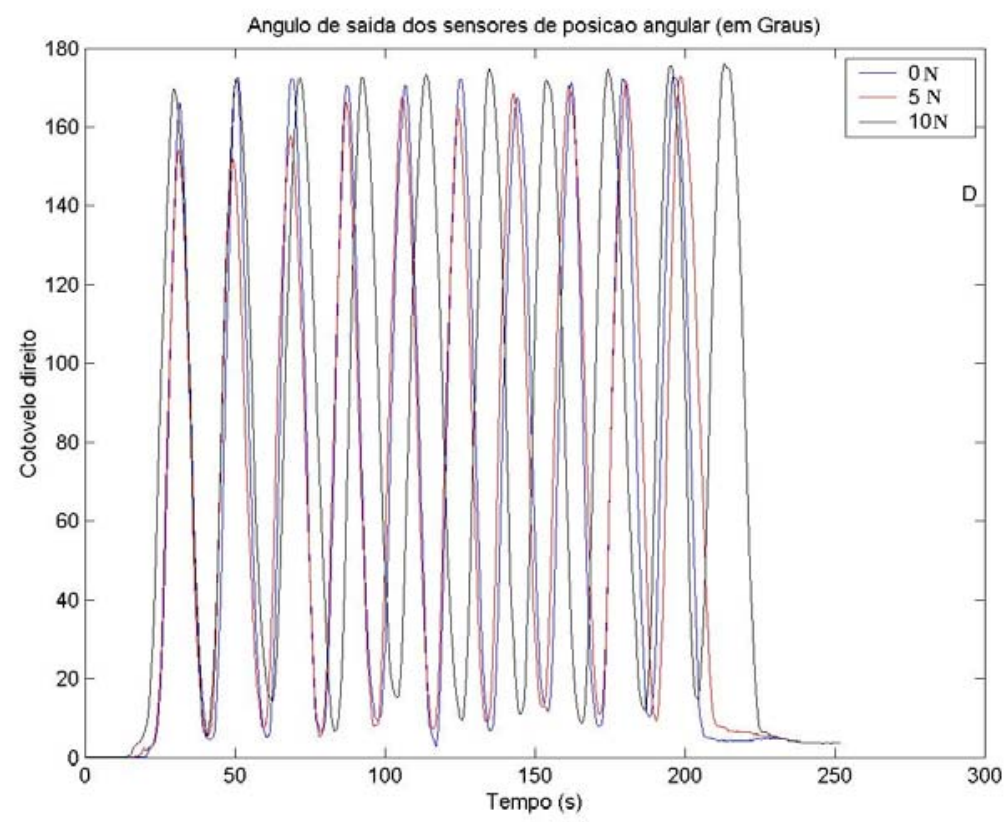

(b)

FIGURA 28 - Medida Angular vs. Tempo durante o movimento de flexão e extensão do cotovelo do sujeito saudável: sem preensão e sem EENM (a); com preensão e adição de cargas sem EENM (b). 
TABELA 3 - Medidas angulares da flexão e extensão do cotovelo dos pacientes 1, 2, 3 e 4.

\begin{tabular}{|c|c|c|c|c|c|}
\hline \multirow{2}{*}{ Pacientes } & \multirow{2}{*}{\multicolumn{2}{|c|}{ Protocolos }} & \multicolumn{2}{|c|}{ Medida Angular (graus) } & \multirow{2}{*}{$\begin{array}{c}\text { Tempo } \\
\text { (segundos) }\end{array}$} \\
\hline & & & Flexão & Extensão & \\
\hline \multirow{8}{*}{1} & \multirow{2}{*}{ Sem Preensão } & Sem EENM & $117^{\circ}$ a $130^{\circ}$ & $0^{\circ}$ a $6^{\circ}$ & 25 \\
\hline & & Com EENM & $104^{\circ}$ a $112^{\circ}$ & $0^{\circ}$ a $6^{\circ}$ & 120 \\
\hline & \multirow{3}{*}{$\begin{array}{l}\text { Com Preensão e } \\
\text { Sem EENM }\end{array}$} & $0 \mathrm{~N}$ & $120^{\circ}$ a $140^{\circ}$ & $0^{\circ}$ a $10^{\circ}$ & 30 \\
\hline & & $5 \mathrm{~N}$ & $80^{\circ}$ a $115^{\circ}$ & $0^{\circ}$ a $15^{\circ}$ & 40 \\
\hline & & $10 \mathrm{~N}$ & $90^{\circ}$ a $100^{\circ}$ & $0^{\circ}$ a $30^{\circ}$ & 55 \\
\hline & \multirow{3}{*}{$\begin{array}{l}\text { Com Preensão e } \\
\text { Com EENM }\end{array}$} & ON & $145^{\circ}$ a $160^{\circ}$ & $0^{\circ}$ a $5^{\circ}$ & 85 \\
\hline & & $5 \mathrm{~N}$ & $150^{\circ}$ a $160^{\circ}$ & $0^{\circ}$ a $20^{\circ}$ & 85 \\
\hline & & $10 \mathrm{~N}$ & $145^{\circ}$ a $150^{\circ}$ & $0^{\circ}$ a $25^{\circ}$ & 85 \\
\hline \multirow{8}{*}{2} & \multirow{2}{*}{ Sem Preensão } & Sem EENM & $116^{\circ}$ & $1^{\circ}$ a $9^{\circ}$ & 37 \\
\hline & & Com EENM & $116^{\circ}$ a $122^{\circ}$ & $0^{\circ}$ a $1^{\circ}$ & 90 \\
\hline & \multirow{3}{*}{$\begin{array}{l}\text { Com Preensão e } \\
\text { Sem EENM }\end{array}$} & 0N & $150^{\circ}$ a $158^{\circ}$ & $10^{\circ}$ a $17^{\circ}$ & 33 \\
\hline & & $5 \mathrm{~N}$ & $150^{\circ}$ a $152^{\circ}$ & $0^{\circ}$ a $17^{\circ}$ & 38 \\
\hline & & $10 \mathrm{~N}$ & $155^{\circ}$ a $160^{\circ}$ & $0^{\circ}$ a $12^{\circ}$ & 39 \\
\hline & \multirow{3}{*}{$\begin{array}{c}\text { Com Preensão e } \\
\text { Com EENM }\end{array}$} & ON & $107^{\circ}$ a $138^{\circ}$ & $0^{\circ}$ a $8^{\circ}$ & 85 \\
\hline & & $5 \mathrm{~N}$ & $95^{\circ}$ a $148^{\circ}$ & $0^{\circ}$ a $9^{\circ}$ & 70 \\
\hline & & $10 N$ & $140^{\circ}$ a $150^{\circ}$ & $0^{\circ}$ a $7^{\circ}$ & 69 \\
\hline \multirow{8}{*}{3} & \multirow{2}{*}{ Sem Preensão } & Sem EENM & $160^{\circ}$ a $170^{\circ}$ & $4^{\circ}$ a $6^{\circ}$ & 58 \\
\hline & & Com EENM & $145^{\circ}$ a $149^{\circ}$ & $0^{\circ}$ a $3^{\circ}$ & 75 \\
\hline & \multirow{3}{*}{$\begin{array}{l}\text { Com Preensão e } \\
\text { Sem EENM }\end{array}$} & $0 \mathrm{~N}$ & $118^{\circ}$ a $138^{\circ}$ & $0^{\circ}$ a $2^{\circ}$ & 72 \\
\hline & & $5 \mathrm{~N}$ & $95^{\circ}$ a $173^{\circ}$ & $0^{\circ}$ a $3^{\circ}$ & 75 \\
\hline & & $10 N$ & $155^{\circ}$ a $170^{\circ}$ & $5^{\circ}$ a $9^{\circ}$ & 70 \\
\hline & \multirow{3}{*}{$\begin{array}{l}\text { Com Preensão e } \\
\text { Com EENM }\end{array}$} & $0 \mathrm{~N}$ & $159^{\circ}$ a $165^{\circ}$ & $1^{\circ}$ a $5^{\circ}$ & 85 \\
\hline & & $5 \mathrm{~N}$ & $159^{\circ}$ a $165^{\circ}$ & $1^{\circ}$ a $5^{\circ}$ & 85 \\
\hline & & $10 \mathrm{~N}$ & $165^{\circ}$ a $170^{\circ}$ & $0^{\circ}$ a $12^{\circ}$ & 85 \\
\hline \multirow{8}{*}{4} & \multirow{2}{*}{ Sem Preensão } & Sem EENM & $110^{\circ}$ a $115^{\circ}$ & $3^{\circ}$ a $9^{\circ}$ & 80 \\
\hline & & Com EENM & $87^{\circ}$ a $92^{\circ}$ & $0^{\circ}$ a $5^{\circ}$ & 103 \\
\hline & \multirow{3}{*}{$\begin{array}{l}\text { Com Preensão e } \\
\text { Sem EENM }\end{array}$} & 0N & $134^{\circ}$ a $139^{\circ}$ & $3^{\circ}$ a $6^{\circ}$ & 33 \\
\hline & & $5 \mathrm{~N}$ & $132^{\circ}$ a $134^{\circ}$ & $1^{\circ}$ a $3^{\circ}$ & 28 \\
\hline & & $10 N$ & $139^{\circ}$ a $146^{\circ}$ & $0^{\circ}$ a $3^{\circ}$ & 34 \\
\hline & \multirow{3}{*}{$\begin{array}{l}\text { Com Preensão e } \\
\text { Com EENM }\end{array}$} & $0 \mathrm{~N}$ & $120^{\circ}$ a $122^{\circ}$ & $0^{\circ}$ a $9^{\circ}$ & 95 \\
\hline & & $5 \mathrm{~N}$ & $126^{\circ}$ a $128^{\circ}$ & $2^{\circ}$ a $5^{\circ}$ & 90 \\
\hline & & $10 \mathrm{~N}$ & $123^{\circ}$ a $134^{\circ}$ & $0^{\circ}$ a $6^{\circ}$ & 95 \\
\hline
\end{tabular}


TABELA 4 - Medidas angulares da flexão e extensão do cotovelo dos pacientes 5, 6, 7 e 8.

\begin{tabular}{cccccc}
\hline \multirow{2}{*}{ Pacientes } & \multicolumn{2}{c}{ Protocolos } & \multicolumn{2}{c}{ Medida Angular (graus) } & Tempo \\
\cline { 3 - 5 } (segundos)
\end{tabular}


TABELA 5 - Medidas angulares da flexão e extensão voluntária do cotovelo do sujeito saudável.

\begin{tabular}{|c|c|c|c|c|}
\hline \multirow{2}{*}{\multicolumn{2}{|c|}{ Protocolos }} & \multicolumn{2}{|c|}{ Medida Angular (graus) } & \multirow{2}{*}{$\begin{array}{c}\text { Tempo } \\
\text { (segundos) }\end{array}$} \\
\hline & & Flexão & Extensão & \\
\hline \multicolumn{2}{|c|}{ Sem Preensão e sem EENM } & $159^{\circ}$ a $160^{\circ}$ & $0^{\circ}$ a $2^{\circ}$ & 35 \\
\hline $\begin{array}{l}\text { Com Preensão e } \\
\text { Sem EENM }\end{array}$ & $\begin{array}{c}0 \mathrm{~N} \\
5 \mathrm{~N} \\
10 \mathrm{~N}\end{array}$ & $\begin{array}{l}166^{\circ} \text { a } 172^{\circ} \\
152^{\circ} \text { a } 171^{\circ} \\
174^{\circ} \text { a } 179^{\circ}\end{array}$ & $\begin{array}{l}3^{\circ} \text { a } 11^{\circ} \\
5^{\circ} \text { a } 12^{\circ} \\
5^{\circ} \text { a } 15^{\circ}\end{array}$ & $\begin{array}{l}23 \\
25 \\
22\end{array}$ \\
\hline
\end{tabular}


TABELA 6 - Protocolo ASIA e FIM (índice motor, sensorial e de independência funcional).

\begin{tabular}{|c|c|c|c|c|c|}
\hline \multirow[b]{2}{*}{ Pacientes } & \multirow[b]{2}{*}{ Avaliações } & \multicolumn{3}{|c|}{ ASIA } & \multirow[b]{2}{*}{ FIM } \\
\hline & & $\begin{array}{l}\text { Índice } \\
\text { Motor }\end{array}$ & $\begin{array}{l}\text { Índice } \\
\text { Agulha }\end{array}$ & $\begin{array}{c}\text { nsorial } \\
\text { Toque } \\
\text { Leve }\end{array}$ & \\
\hline \multirow[t]{2}{*}{1} & pré & 21 & 39 & 39 & 56 \\
\hline & pós & 28 & 45 & 56 & 71 \\
\hline \multirow[t]{2}{*}{2} & pré & 30 & 38 & 45 & 79 \\
\hline & pós & 31 & 41 & 49 & 88 \\
\hline \multirow[t]{2}{*}{3} & pré & 27 & 34 & 46 & 61 \\
\hline & pós & 32 & 37 & 46 & 69 \\
\hline \multirow[t]{2}{*}{4} & pré & 25 & 30 & 60 & 64 \\
\hline & pós & 31 & 49 & 68 & 71 \\
\hline \multirow[t]{2}{*}{5} & pré & 23 & 25 & 30 & 66 \\
\hline & pós & 28 & 27 & 35 & 74 \\
\hline \multirow[t]{2}{*}{6} & pré & 32 & 62 & 90 & 92 \\
\hline & pós & 36 & 70 & 106 & 96 \\
\hline \multirow[t]{2}{*}{7} & pré & 5 & 18 & 25 & 53 \\
\hline & pós & 7 & 19 & 25 & 55 \\
\hline \multirow[t]{2}{*}{8} & pré & 17 & 77 & 80 & 77 \\
\hline & pós & 20 & 78 & 80 & 77 \\
\hline
\end{tabular}

Índice Motor Máximo: 100; Índice Sensorial Máximo: 112; Índice Máximo de Independência Funcional: 126. 
TABELA 7 - Protocolo ASIA (nível neurológico).

\begin{tabular}{|c|c|c|c|c|c|c|}
\hline \multirow[b]{2}{*}{ Pacientes } & \multirow[b]{2}{*}{ Avaliações } & \multicolumn{5}{|c|}{ ASIA: nível neurológico } \\
\hline & & $\begin{array}{l}\text { Motor } \\
\text { Direito }\end{array}$ & $\begin{array}{c}\text { Motor } \\
\text { Esquerdo }\end{array}$ & $\begin{array}{c}\text { Sensorial } \\
\text { Direito }\end{array}$ & $\begin{array}{l}\text { Sensorial } \\
\text { Esquerdo }\end{array}$ & Classificação \\
\hline \multirow[t]{2}{*}{1} & pré & C7 & C4 & $\mathrm{C} 7$ & $\mathrm{C} 4$ & A \\
\hline & pós & C8 & C5 & C7 & C6 & A \\
\hline \multirow[t]{2}{*}{2} & pré & C7 & $\mathrm{C} 7$ & T3 & C7 & B \\
\hline & pós & C7 & C7 & $\mathrm{T} 4$ & C7 & $\mathrm{B}$ \\
\hline \multirow[t]{2}{*}{3} & pré & C7 & $\mathrm{C} 7$ & C7 & C7 & A \\
\hline & pós & $\mathrm{C} 7$ & $\mathrm{C} 7$ & C7 & $\mathrm{C} 7$ & A \\
\hline \multirow[t]{2}{*}{4} & pré & C6 & $\mathrm{C} 5$ & C6 & C5 & $\mathrm{B}$ \\
\hline & pós & C6 & C6 & C7 & C6 & B \\
\hline \multirow[t]{2}{*}{5} & pré & C7 & $\mathrm{C} 7$ & C4 & C5 & A \\
\hline & pós & C7 & $\mathrm{C} 7$ & C6 & C5 & A \\
\hline \multirow[t]{2}{*}{6} & pré & C7 & C7 & $\mathrm{T} 10$ & T10 & B \\
\hline & pós & C7 & C7 & S3 & L1 & B \\
\hline \multirow[t]{2}{*}{7} & pré & C5 & C4 & C4 & C4 & A \\
\hline & pós & C5 & C4 & C4 & C4 & A \\
\hline \multirow[t]{2}{*}{8} & pré & C5 & C4 & C6 & C6 & B \\
\hline & pós & C5 & C5 & C6 & C7 & $\mathrm{B}$ \\
\hline
\end{tabular}




\subsection{DISCUSSÃO}

Quanto ao desenvolvimento do primeiro protótipo das órteses, a equipe multidiciplinar de Cliquet Jr. constatou que a órtese dinâmica para cotovelo mostrou eficácia em relação às necessidades de torque (4 N.m) e velocidade (4 rpm), bem como às funções de sustentação e movimentação, porém a massa (750 g) ainda é um pouco elevada, o que dificulta a utilização pelo paciente que possui alterações no sistema ósteo-músculo-tendíneo. A órtese estática possibilitou a estabilização do punho e a alocação dos eletrodos superficiais para a realização das preensões com EENM, entretanto, a área deverá ser aumentada para melhor alojar os eletrodos (de LIMA et al., 2004).

Então, como qualquer dispositivo de auxílio, simplicidade e cosmética ditam de maneira imediata e em longo prazo a aceitação das órteses pelo paciente, e de modo geral ainda precisam ser aprimoradas. Ainda, o movimento do membro superior pode ser tridimensional, além de possuir mais de 40 graus de liberdade, sendo que a mão com os dedos possui aproximadamente 30 graus de liberdade, o que torna complexo o desenvolvimento de um sistema homem-máquina (WIERZBICKA \& WIERGNER, 1996); (BENJUYA \& KENNEY, 1990).

Além da restauração do movimento, outro aspecto relevante é que as órteses dinâmicas com dispositivo mecatrônico podem ser utilizadas como tratamento, denominado terapia assistida por robô. Os indivíduos portadores de lesão neurológica podem interagir com o robô passiva ou ativamente. O membro superior é fixado ao braço robótico e a terapia consiste em movimentos rotacionais e de flexão/extensão das articulações do ombro e cotovelo. O movimento é inicialmente passivo e conforme o paciente ganha função motora, o robô requer iniciação voluntária da atividade. O braço robótico pode aplicar precisos graus de força, velocidade, duração e repetição do movimento com padrão esteriotipado. Ainda, pode possibilitar grande reprodutibilidade nas sessões, além de terapia intensiva para reabilitação sensóriomotora (AISEN et al., 1997); (VOLPE et al., 2000). 
Desta forma, a tecnologia assistida torna-se um desafio para Engenharia de Reabilitação e o segundo protótipo já está sendo elaborado visando adequação da área para a órtese de punho e da massa para a órtese robótica de cotovelo, que possuirá acionamento por voz e controle por malha fechada com sensor angular, para gerar o movimento relativo de rotação entre braço e antebraço. Então, as medidas angulares obtidas nesta pesquisa serão utilizadas no controle de malha fechada.

Os dados sobre forma, amplitude e variação dos ângulos articulares, bem como, a duração do ciclo de movimento indica que:

O tempo do ciclo do movimento de flexão/extensão durante a EENM foi realizado em um período maior, comparado ao movimento sem EENM. Assim, a maior duração do movimento ativado artificialmente caracteriza a forma de onda retangular, diferente da forma de onda em pico observada durante o movimento voluntário tanto para os pacientes quanto para o sujeito saudável.

A variabilidade observada nos resultados durante o movimento voluntário dos pacientes 1, 2, 5 e 7 sugere declínio de força muscular, espasticidade e incoordenação de ativação muscular, fatores que podem diminuir a funcionalidade e a amplitude do movimento em pacientes com lesão neurológica (JU et al., 2002). Ainda, a rigidez muscular e articular, contraturas, deformidades, encurtamento do sistema músculo-tendíneo e denervação parcial ou total também reduzem a contração e força muscular que influenciam no desempenho do movimento executado (FREEHAFER, 1998); (STEIN, PECKHAM \& POPOVIC, 1992); (WIERZBICKA \& WIEGNER, 1996).

Em relação ao movimento de extensão do cotovelo dos pacientes, com e sem EENM, não houve diferença significativa, pois todos os pacientes conseguiram realizar a extensão voluntária com movimentos compensatórios e com utilização da força da gravidade.

Entretanto, o uso da EENM é importante devido a eliminação do torque gravitacional, maior recrutamento de unidades motoras remanescentes, aumento da 
força muscular, além da sua influência no aumento do tempo de manutenção do movimento, bem como sua repetibilidade para a execução das Atividades de Vida Diária (AVDs), favorecendo o alcance e o deslocamento do membro superior no espaço (MAKSIMOVIC \& POPOVIC, 1999).

Em relação aos movimentos compensatórios, não houve relevância nesta pesquisa, uma vez que o teste não foi realizado com restrição dos movimentos de tronco e ombro, para assemelhar-se o máximo possível ao cotidiano. Ainda, o paciente com lesão medular cervical possui comprometimento do controle de tronco (GRONLEY et al., 2000) e os movimentos compensatórios, em especial do ombro, são estratégias para tornar possível a realização de uma tarefa com o cotovelo em diferentes planos de movimento (POPOVIC; POPOVIC \& TOMOVIC, 2002).

Durante a EENM, os pacientes 1, 3, 4, 5 e 8 apresentaram menores medidas angulares para flexão comparada ao movimento voluntário, enquanto os pacientes 2 , 6 e 7 apresentaram valores superiores.

Então, as menores medidas angulares obtidas durante o movimento de flexão com estimulação podem estar relacionadas ao aumento do volume muscular - por exemplo, do bíceps - em pacientes que apresentam maior percentual de massa muscular, menor comprometimento neuromuscular, com maior recrutamento de unidades motoras remanescentes, inclusive as que não podem ser controladas voluntariamente (THOMAS et al., 1997).

As diferenças nas amplitudes articulares podem ser devidas à relação do ângulo com o comprimento muscular, torque, momento e força. Fatores que influenciam na capacidade de excursão do movimento do cotovelo (BUCHANAN, 1995); (LEMAY \& CRAGO, 1996); (MURRAY, BUCHANAN \& DELP, 2000); (MURRAY, DELP \& BUCHANAN, 1995) por causa das diferenças nas propriedades visco-elásticas do sistema músculo-esquelético, arquitetura muscular, braço de força e no padrão de ativação muscular (ETTEMA, STYLES \& KIPPERS, 1998); (UCHIYAMA, BESSHO \& AKAZAWA, 1998). 
Durante o movimento voluntário com preensão e adição de cargas, os pacientes 1, 3, 6, 7 e 8 apresentaram variabilidade, ou seja, alteração na amplitude de onda com conseqüente alteração na cinemática do movimento de acordo com a magnitude das cargas aplicadas. Ainda, para os pacientes 1, 6 e 7 houve diminuição no tempo de execução da atividade com a utilização das diferentes cargas. Entretanto, os pacientes 2, 4 e 5 não apresentaram diferenças significativas na cinemática do movimento.

Durante a EENM com preensão e adição de cargas, os pacientes 1, 3, 4, 5 e 7 apresentaram aumento da amplitude de onda, menor variabilidade e aumento no tempo da execução da atividade comparado ao movimento voluntário. Entretanto, os pacientes 2, 6 e 8 apresentaram pequena alteração na cinemática do movimento mesmo com o uso da EENM. Ainda, na maioria destes pacientes foi observada a predominância da forma de onda em rampa.

Estas diferenças na cinemática do movimento com a adição de cargas externas observadas durante o movimento voluntário e com EENM, sugerem:

1) Insegurança em relação à preensão;

2) Perturbação no controle motor;

3) Fraqueza e incoordenação muscular;

4) Que o torque externo resistido por aplicação de carga e o torque assistido por EENM aumentaram o desempenho motor e;

5) Ação sinergista;

A variabilidade e conseqüente alteração na cinemática do movimento podem estar relacionas com a insegurança em relação a preensão; com o controle sensóriomotor ineficiente, que torna-se inadequado para correções de alterações decorrentes de perturbações; com a fraqueza e incoordenação muscular; além da deficiência de condução neural. 
Possivelmente a ausência de sensibilidade na região distal do membro superior influenciou na cinemática do movimento conduzindo o paciente à insegurança com relação a eficiência da preensão do objeto, pois o déficit sensorial pode influenciar na falência de condução neural durante as atividades (THOMAS et al., 1997). Então, sugere-se a utilização do Estimulador Eletrotátil desenvolvido pela equipe de Cliquet Jr., que permite a restauração proprioceptiva acima do nível de lesão através do aumento ou diminuição da pressão realizada em forma de figuras elípticas sobre a pele, de acordo com a intensidade da força de preensão exercida em torno do objeto, o que proporciona segurança em relação a preensão e maior funcionalidade do membro superior para a realização de atividades (CLIQUET \& CASTRO, 2000).

Para que o movimento seja funcional é necessário que haja equilíbrio de força entre os grupos musculares agonistas e antagonistas, coordenação e ações sinergistas, que estão relacionados ao controle motor.

Costa e Vieira (2000) descrevem os conceitos de sinergia, controle e coordenação motora de acordo com a perspectiva de Bernstein.

"Sinergia é definida (...) como ligações entre estruturas neuro-músculoesqueléticas anatomica e funcionalmente independentes que atuam de forma cooperativa como uma unidade. Estas ligações sinérgicas são estratégias que simplificam um controle, por reduzir o número de parâmetros a serem controlados, levando à redução dos graus de liberdade do sistema (...) A superação dos graus de liberdade redundantes na produção de um movimento, é definido como coordenação (...) que resulta no aumento da organização e, portanto, no controle do movimento. Assim, a conseqüência final do processo de coordenação de movimentos é a transformação do sistema motor em uma unidade controlável e, conseqüentemente, no aumento do controle na interação entre o organismo e o ambiente. Esta definição distingue coordenação e controle. Controle passa a ser a parametrização do sistema motor, ou seja, o processo de atribuição de valores à unidade que está sendo coordenada” (COSTA \& VIEIRA, 2000, p. 58-59). 
A coordenação e controle motor podem ser influenciados, por exemplo, pela aplicação de cargas e mudanças nos ritmos de movimentos que induzem à perturbação (LATASH, ARUIN \& ZATSIORSKY, 1999); (STERNAD, DEAN \& SCHAAL, 2000).

As respostas pré-programadas, ou seja, reações ao estímulo externo (perturbações mecânicas), possuem latência mais longa comparada as latências típicas de reflexo e mais curtas em relação ao tempo de reação voluntária. Estas respostas podem ser moduladas primeiro por instrução, que produzem rápidas ações corretivas (grosseiras) para conter os efeitos mecânicos da perturbação original. Ainda, o input sensorial é importante por possibilitar informações sobre a perturbação, assim os sinais para as reações pré-programadas podem ser gerados por receptores periféricos que conduzem as informações dos receptores visuais, auditivos e vestibulares, bem como, de mudanças de cargas, posição e pressão (LATASH, 1998).

Uma das hipóteses de controle motor, assume que as funções são geradas pelo cérebro e baseadas no requerimento da atividade. Outra, assume que a função de controle está relacionada aos mecanismos segmentais da medula e é executada sem qualquer modificação adicional, como o reflexo de estiramento (LATASH, 1993).

Ainda, Latash, Aruin \& Zatsiorski (1999) utilizaram a variabilidade natural do movimento, como origem da perturbação, necessária para reconstruir as trajetórias do ponto de equilíbrio (hipótese de controle motor que assume que o Sistema Nervoso Central manipula o estado de equilíbrio efetor + carga) para sugerir a definição de uma sinergia simples durante a flexão e extensão do cotovelo de sujeitos saudáveis em diferentes ritmos, com movimentos rápidos e lentos no plano sagital. Os dados cinemáticos e de EMG indicaram a ação de mecanismos complexos, no qual o cérebro pode usar funções diferentes, como a função em rampa, processada posteriormente ao feedback dos sinais proprioceptivos refletido no movimento atual, que indica interação entre o sinal proprioceptivo e central, conduzindo para a definição de uma sinergia simples. 
Em relação ao modelo de coordenação de Sternad, Dean e Schaal (2000), durante movimentos rítmicos e discretos de flexão e extensão do cotovelo de sujeitos saudáveis no plano horizontal, os movimentos discretos foram perturbados pelas oscilações rítmicas e vice e versa. Com base nestes resultados os autores sugeriram a coexistência de padrões geradores (dois geradores de padrão rítmico) que se inibem mutuamente, alternando sua atividade, sendo importante para a cooperação de dois músculos antagonistas ou sinergistas.

Ainda, os pacientes tetraplégicos podem apresentar reflexos intermembros e portanto, estudos devem ser elaborados para maior compreensão sobre os circuitos espinhais, uma vez que estes reflexos não foram observados em sujeitos saudáveis (CLIQUET, 2003).

Outros fatores relacionados à alteração da cinemática do movimento de flexão e extensão do cotovelo nos pacientes são a fraqueza muscular e falência da condução motora central.

Thomas, C.K. et al. (1997) realizaram estimulação cortical magnética, bem como EENM e contração voluntária máxima durante a flexão e extensão do cotovelo de tetraplégicos. Os resultados do EMG e do potencial evocado revelaram que a paralisia parcial e a atrofia muscular severa podem ser conseqüência do desuso ou degeneração, devido a perda de motoneurônios. Durante a contração voluntária máxima foi constatada fraqueza muscular severa e redução da força voluntária máxima do tríceps; durante a estimulação cortical, não houve limiar de excitação nos motoneurônios dos músculos relaxados, o que indicou falência na condução motora central para as áreas de fraqueza muscular. Entretanto, a força máxima evocada por EENM não indicou limitações na condução nervosa periférica, e portanto, os autores sugeriram que a limitação na condução possui origem central.

Então, a contração máxima evocada por EENM favorece a funcionalidade durante a flexão e extensão do cotovelo dos tetraplégicos. 
Yanagy et. al (2003), constataram que em 12 semanas de EENM do tríceps concomitante ao movimento voluntário resistido, durante a flexão e extensão do cotovelo, houve aumento de força e do volume muscular do tríceps.

Ainda, na atual pesquisa, alguns pacientes apresentaram diminuição da amplitude de onda, com aumento da medida angular para a extensão, provavelmente devido à ação do bíceps que desacelerou o movimento, na tentativa de conter o conjunto antebraço-mão para não atingir a extensão completa do cotovelo a favor da gravidade. Este fato foi mais pronunciado durante os movimentos realizados pelo paciente 7, que possui tríceps denervado.

Então, quando não é possível realizar a EENM de determinado músculo, como no caso do paciente 7 , ou não se obteve a resposta adequada, como no caso do paciente 8, indica-se a utilização do Sistema Híbrido. Estas restrições fisiológicas ao uso da EENM são devido a denervação do músculo esquelético (NATHAN, 1989) que apresenta uma diminuição no potencial de liberação do neurotransmissor entre o nervo motor e a fibra muscular, comprometendo a resposta desejada, já que esta técnica estimula o nervo motor para produzir as contrações musculares, tal efeito não será satisfatório devido à falta do neurotransmissor (BHADRA, KILGORE e PECHAM, 2001). Assim, para estes casos são utilizadas as órteses, dinâmica para cotovelo e estática para punho, na tentativa de superar estas limitações para a obtenção de movimentos funcionais de alcance e preensão.

Com a utilização das cargas de $5 \mathrm{~N}$ e $10 \mathrm{~N}$, a repetibilidade e/ou as maiores medidas angulares para flexão e as menores medidas angulares para extensão comparado à condição livre de carga, indicaram que o torque externo resistido por aplicação de carga e/ou o torque assistido por EENM aumentaram o desempenho motor.

Então, a magnitude do torque externo pode modificar o padrão de ativação neuromuscular. Assim, se o torque externo for maior do que o necessário para produzir a velocidade desejada, a musculatura flexora é ativada para desacelerar o 
movimento de extensão, por outro lado, a musculatura extensora é usada para aceleração, consistindo em ações sinergistas. Assim, o torque externo compensa a redução da força muscular, favorecendo a coordenação intermuscular, pela coativação dos músculos agonistas e antagonistas, conduzindo à estabilidade articular e suavidade do movimento (Ju et al., 2002).

Ainda, a EENM, bem como a utilização de cargas, podem conduzir à perturbações durante a atividade proposta. Alguns pacientes apresentaram forma de onda em rampa durante a avaliação dinâmica do movimento de flexão e extensão do cotovelo, que possivelmente resultou da interferência voluntária na tentativa de tornar os movimentos artificiais mais suaves, bem como, indicou provável ação sinergista.

Assim, torna-se necessária maior investigação da ação sinergista durante os movimentos do cotovelo, através de EMG e acelerômetro, por exemplo, inclusive durante a realização de AVDs. Pois, os músculos sinergistas do movimento de alcance variam de acordo com o número de tarefas, localização, distância, forma e peso do objeto. Então, são necessários métodos de controle em tempo real, para os ajustes dos parâmetros de Estimulação, para gerarem, por exemplo, a velocidade angular desejada e sincronia temporal (POPOVIC, M.B.; POPOVIC, D.B. \& TOMOVIC, R., 2002); (POPOVIC, D.B.; POPOVIC, M.B. \& SINKJAER, T., 2002).

Para o sujeito saudável, a pequena magnitude das cargas parece não ter afetado de maneira significativa o padrão cinemático do movimento de flexão e extensão do cotovelo. Enquanto a maioria dos pacientes, apesar de ter conseguido realizar o movimento de flexão e extensão voluntária do cotovelo, apresentou alteração no padrão cinemático do movimento. O que pode influenciar a funcionalidade do movimento do membro superior no cotidiano, durante a preensão de objetos de diferentes massas, devido provavelmente à resistência oferecida pela gravidade durante a flexão, presença de incoordenação e desequilíbrio muscular (tríceps com força diminuída). Estes fatores que limitam o deslocamento do membro superior no espaço podem ser superados com o uso da EENM para restauração e 
reabilitação inclusive com a utilização de cargas e realização de atividades funcionais durante as sessões terapêuticas, além de favorecer o reaprendizado sensório-motor.

Segundo Popovic, D.B., Popovic, M.B. e Sinkjaer, T. (2002), os efeitos terapêuticos da estimulação estão associados ao input central que combinado ao comando voluntário, promovem a integração do sistema sensório-motor, que é responsável pelo aumento da funcionalidade, além de contribuir para a organização cortical do movimento.

As pesquisas realizadas com os membros superiores de indivíduos tetraplégicos que avaliam a capacidade funcional após a lesão medular são restritas e não são classificadas de acordo com o nível de lesão, pois um mesmo nível de lesão resulta em habilidades motoras diferentes. Assim, a avaliação funcional é o principal diagnóstico.

O sujeito saudável e a maioria dos pacientes apresentaram durante o movimento voluntário de flexão e extensão do cotovelo sem preensão, forma de onda em pico. Com o uso da EENM, todos os pacientes apresentaram predomínio da forma de onda retangular.

Quando o movimento voluntário foi realizado com preensão e aplicação de cargas externas, o sujeito saudável e todos os pacientes apresentaram forma de onda em pico. Com o uso da EENM, a maioria dos pacientes apresentou predomínio da forma de onda em rampa.

Durante o movimento voluntário de flexão e extensão do cotovelo sem preensão, a maioria dos pacientes apresentou valores inferiores para flexão e superiores para extensão, comparados ao sujeito saudável. Com o uso da EENM, os pacientes apresentaram valores inferiores para a flexão e para a extensão os valores foram semelhantes.

Durante o movimento voluntário de flexão e extensão do cotovelo com preensão de objeto e adição de carga externa, o sujeito saudável apresentou valores superiores comparado a maioria dos pacientes. Com o uso da EENM e aplicação de cargas, os valores obtidos pelos pacientes foram semelhantes aos do sujeito saudável. 
O tempo de execução das atividades aumentou com o uso da EENM em todos os protocolos. Durante o movimento voluntário, de acordo com a magnitude das cargas aplicadas, houve aumento no tempo de duração da atividade, diferente do que ocorreu com o sujeito saudável, que com a utilização da maior carga, realizou a atividade em menor tempo.

Maksimovic, R. e Popovic, M. (1999), realizaram a classificação do movimento do membro superior de tetraplégicos de acordo com os dados obtidos pelos sujeitos saudáveis, por meio de Redes Neurais Artificiais (RNA). Constataram que a amplitude do movimento de flexão e extensão voluntária do cotovelo de tetraplégicos no plano horizontal, com eletrogoniômetro, mostrou valores de amplitude angular quase constante. A forma e amplitude dos ângulos articulares durante estes movimentos executados por tetraplégicos foram similares aos indivíduos saudáveis e portanto considerados satisfatórios. Resultados semelhantes foram obtidos durante o movimento de rotação interna/externa do antebraço e de flexão/extensão do ombro, no plano frontal. Entretanto, a duração dos movimentos foi maior para os pacientes. Constatou-se então, que a RNA avaliou objetivamente e classificou o movimento funcional de alcance dos tetraplégicos com referência aos valores de indivíduos saudáveis a partir de uma escala. Em relação aos níveis de lesão, houve ampla variação no padrão de movimentos do membro superior entre os pacientes, de acordo com o esperado pelos autores (MAKSIMOVIC \& POPOVIC, 1999).

Então, cada paciente apresenta um quadro clínico e habilidades específicas, que não permitem a compartimentalização das suas características de acordo com o nível de lesão.

Embora as respostas tenham sido individualizadas, a maioria dos pacientes apresentou ganho neurológico, com conseqüente diminuição do nível de lesão, bem como, aumento no índice de independência funcional, de acordo com os dados obtidos pelos protocolos ASIA e FIM, que mostraram aumento de força muscular e sensibilidade principalmente nos membros superiores, com conseqüente aumento da autonomia, em um período de 6 meses de tratamento com EENM. 
Não foi constatada a piora do quadro clínico, uma vez que estes pacientes podem apresentar atrofia do sistema musculo-esquelético, redução da capacidade cardio-vascular e respiratória, alterações metabólicas, hormonais e neuromusculares (EDGERTON et al., 2000), que juntamente com o estado sedentário podem ter como conseqüência a rápida instalação da fadiga, que reduz a independência nas atividades cotidianas e a qualidade de vida (DALLMEIJER et al., 1999).

A recuperação sensório-motora constatada foi maior nos membros superiores comparado aos membros inferiores na maioria dos pacientes. Portanto, a importância da EENM nos membros inferiores também consiste em benefícios hemodinâmicos devido a ativação da bomba muscular esquelética que favorece o retorno venoso e melhora a eficiência cardíaca de acordo com a Lei de Frank Starling (HOPMAN et al., 1998), bem como, no aumento da força, massa e volume muscular (KERN, 1997), além de potencializar a plasticidade neural (CALANCIE, LUTTON \& BROTON, 1996); (CALANCIE, MOLANO \& BROTON, 2002); (CLIQUET, 2003).

A reaprendizagem sensório-motora é obtida pela repetibilidade de movimentos dos membros superiores, ativados artificialmente, que geram input central e podem ser combinados com movimentos voluntários, conduzindo à reorganização cortical e aumento do ganho de função (POPOVIC, D.B.; POPOVIC, M.B. \& SINKJAER, 2002); (POPOVIC, M.B.; POPOVIC, D.B. \& TOMOVIC, 2002); (POPOVIC, M.B. et al., 2002).

Assim, o retorno da sensibilidade, do movimento voluntário e da marcha nãoassistida em alguns pacientes paraplégicos e tetraplégicos que fazem/fizeram parte do Programa de EENM é explicado por recentes estudos neurofisiológicos realizados com potencial evocado e eletromiografia, baseados em movimentos sincrônicos e repetitivos que induzem a alterações nos circuitos interneurais da medula espinhal, por inputs aferentes (estímulo elétrico), possibilitando a reorganização dos reflexos, aumento da excitabilidade dos motoneurônios e a recuperação da função medular. (CLIQUET Jr., 2002); (CLIQUET Jr., 2003).

Ainda, foi constatada em alguns pacientes tetraplégicos que fazem parte do Programa de EENM, a presença de reflexos intermembros, sugerindo possível recuperação medular (APÊNDICE C). 
A presença do reflexo intermembros pode ser decorrente de dois fatores:

1) os circuitos interneurais que são pré-existentes e inativos sob condições comuns (sinapses latentes) podem tornar-se funcionais após a lesão neural, ou

2) presença de novas conexões sinápticas entre as fibras aferentes da extremidade inferior e os motoneurônios- $\alpha$ que inervam os músculos distais dos membros superiores.

Entretanto, os dados obtidos na literatura fundamentam a segunda hipótese, ou seja, ocorre uma reorganização medular caudal ao nível da lesão, com desenvolvimento de novas conexões sinápticas, sugerindo uma possível recuperação da medula (CALANCIE; LUTTON \& BROTON, 1996); (CALANCIE, MOLANO \& BROTON, 2002). Sugere-se, então, que os resultados obtidos da atividade mioelétrica dos membros superiores dos tetraplégicos - reflexo intermembros indicam reorganização dos reflexos, aumento da excitabilidade neural e possível recuperação medular.

Portanto, a EENM promove o aumento da sensibilidade e da força muscular, além da possível recuperação medular, fatores estes, centrais e periféricos que podem favorecer o controle e a coordenação motora, que conduzem à funcionalidade dos membros superiores, com conseqüente aumento da independência nas AVDs e melhora da qualidade de vida. Então, indica-se o uso de Neuropróteses para o membro superior de tetraplégicos e quando a resposta ao estímulo elétrico for insuficiente, utiliza-se o Sistema Híbrido, com as órteses robótica e estática. Ainda, devem ser consideradas para a elaboração do controle do sistema homem-máquina a ação sinergista, a interferência do paciente na execução do movimento com EENM, a restauração da propriocepção artificial e os sistemas de controle em tempo real, além da cosmética e portabilidade do sistema. 


\section{CONSIDERAÇõES FINAIS}

Os sistemas de estimulação privilegiam os movimentos de mão, pois dependendo do nível de lesão medular, os tetraplégicos preservam os movimentos de ombro e cotovelo. Entretanto, o estágio de funcionalidade dos membros superiores de indivíduos tetraplégicos depende do nível em que ocorreu a lesão.

A literatura apresenta seqüelas típicas nos membros superiores de tetraplégicos, ou seja, os que sofreram lesão medular ao nível C4 geralmente apresentam controle escapular, mas não de todo braço. Uma lesão em C5 pode resultar em limitação do controle do ombro e flexão do cotovelo, embora estejam ausentes a extensão do cotovelo, punho e mão, bem como, ausência de sensibilidade abaixo do antebraço. Os portadores de lesão cervical C6 possuem mínima extensão de punho, acompanhada de sensibilidade parcial que se estende distalmente para a mão. Em lesão ao nível C7-T1 os pacientes têm preservado algum controle dos dedos, acompanhado de sensibilidade parcial da mão, o que resulta em impedimentos ou dificuldades na realização de atividades simples do cotidiano, como higiene pessoal, vestir-se, segurar objetos, alcançar talheres ou copos e levá-los até a boca, entre outros.

Entretanto, cada paciente avaliado apresentou um quadro clínico e habilidades específicas, que não permitiram a compartimentalização das suas características de acordo com o nível de lesão. Pois os resultados obtidos nas avaliações qualitativas indicaram que a maioria dos pacientes apresentou ganho neurológico e aumento no índice de independência funcional decorrentes do tratamento de seis meses com EENM. 
Ainda, a EENM promove alterações centrais e periféricas que favorecem o controle e a coordenação motora, através das ações sinergistas que conduzem à funcionalidade dos membros superiores e ao conseqüente aumento da independência nas AVDs.

Também foi possível a implementação de um sistema de EENM a partir da restauração do movimento de alcance, favorecendo o deslocamento do membro superior no espaço por meio de órtese robótica e neuroprótese, além da obtenção das medidas angulares da articulação do cotovelo e dos diversos tipos de preensão resturadas (APÊNDICE B), de acordo com o desejo dos pacientes, durante a execução de atividades lúdicas e de AVDs. 


\section{REFERÊNCIAS BIBLIOGRÁFICAS}

AMADIO, A.C. Fundamentos Biomecânicos para Análise do Movimento. São Paulo: Laboratório de Biomecânica/EEFUSP, 1996.

AMADIO, A.C.; BARBANTI, V.J. A Biodinâmica do Movimento e suas Relações Interdisciplinares. São Paulo; Editora Estação da Liberdade: Escola de Educação Física e Esporte da Universidade de São Paulo, 2000.

AMADIO, A. C., BAUMANN, W. Aspects of Methodology to Determine the Internal Forces of the Locomotor System. Brazilian Journal of Biomechanics. N.1: p. 7-14, 2000.

AISEN, M.L. et al. The effect of Robot-Assited Therapy and Rehabilitative Training on Motor Recovery Following Stroke. Archives of Neurology, V. 54, N. 4: p. 443-446, 1997.

ALLARD, P.; STOKES, I.A.F.; BLANCHI, J.P. Three-Dimensional Analysis of Human Movement. USA, Human Kinetics, 1995.

ALLON, G. et al. Eficacy of a Hybrid Upper Limb Neuromuscular Electrical Stimulation System in Lessening Selected Impairements and Dysfunction Consequent to Cerebral Damage. J. Neuro Rehab., V. 12, N. 2: p. 73-80, 1998 / Resumo.

ASANO, M. et al. Post-Traumatic Syringomyelia. Spine, V. 21, N. 12: p. 1446453, June, 1996.

BAJD, T. et al. Use of Functional Electrical Stimulation in the Lower Extremities of Incomplete Spinal Cord Injury Patients. Artificial Organs, V. 23, N. 5: p. 403-409, 1999.

BARBEAU, H. et al. Tapping into Spinal Circuits to Restore Motor Function. Brain Research Reviews, V. 30: p. 27-51, 1999. 
BARROS FILHO, T.E.P et al. Avaliação Padronizada nos Traumatismos Raquimedulares. Revista Brasileira de Ortopedia, V. 29, N. 3: p. 99-106, Março, 1994.

BARSTOW, T.J. et al. Changes in Gas Exchange Kinetics with Training in Patients with Spinal Cord Injury. Medicine and Science in Sports and Exercise, V. 28 N. 10: p. 1221-1228, 1996.

BAYDUR, A.; ADKINS, R.H.; MILIC-EMILI, J. Lung Mechanics in Individuals with Spinal cord Injury Level and Posture. J. Appl. Physiol., 90: p. 405-411, 2001.

BELANGER, E.; LEVI, A.DO. The Acute and Chronic Management of Spinal Cord Injury. J. American College of Surgeons, V. 190, N. 5: p. 589-604, May, 2000 .

BENJUYA, N.; KENNEY, S.B. Myoelectric Hand Orthosis. J. of Prosthetics and Orthotics, V.2, N. 2: p. 149-151, 1990a.

BENJUYA, N.; KENNEY, S.B. Hibrid Arm Orthosis. J. of Prosthetics and Orthotics, V.2, N. 2: p. 155-163, 1990 b.

BÉNONY, H. et al. Emotional Factors and Subjective Quality of Life in Subjects with Spinal Cord Injuries. Am. J. Phys. Med. Rehabil, V. 81, N. 6: p. 437-445, June, 2002.

BHADRA, N.; KILGORE, K.L. \& PECKHAM, P.H. Implanted Stimulators for Restoration of Function in Spinal Cord Injury. Medical Engineering \& Physics, V. 23: p.19-28, 2001.

BIJAK, M. et al. Functional and Biological Test of a 20 Channel Implantable Stimulator in Shepp in View of Functional Electrical Stimulation Walking for Spinal Cord Injury Persons. Artificial Organs, V. 25, N. 6: p. 467-474, 1999

BLOOMFIELD, S. Changes in Musculoskeletal Struture and Function with Prolonged Bed Rest. Med. Sci. Sports. Exerc., V. 29, N. 2: p. 197-206, Feb., 1997.

BRANDÃO, J.S. Desenvolvimento Psicomotor da Mão. Rio de Janeiro, RJ, Enelivros, 1984.

BUCHANAN, T.S. Evidence that Maximum Muscle Stress is not a Constant: differences in Specific Tension in Elbow Flexors and Extensors. Med. Eng. Phys., V. 17, N. 7: p. 529-536, 1995.

BÜHREN, V.; POTULSKI, M.; JAKSCHE, H. Chirurgische Versorgung bei Tetraplegie. Unfallchirurg, V. 102: p. 2-12, 1999. 
BURNS, A. Pain, Spasticity, and Bladder and Sexual Function After Spinal Cord Injury. Spine, V. 26, N. 24S: p. S161, Dec, 2001./suplement/

BURNS, A.S.; DITUNNO, J.F. Establishing Prognosis and Maximizing Functional Outcomes After Spinal Cord Injury. Spine, V. 26, N. 245: p. 51375145, 2001.

BURRIDGE, J.H.; LADOUCEUR, M. Clinical and Therapeutic Applications of Neuromuscular Stimulation - a Review of Current Use and Speculation into Future Developments. Disponível na Internet. http://feswww.fes.cwrv.edu/ifess/papers/papersBL.htm. [01 mar. 2002].

CALANCIE, B. Interlimb Reflexes Following Cervical Spinal Cord Injury in Man. Experimental Brain Research. V. 85: p. 458-469, 1991.

CALANCIE, B.; LUTTON, S.; BROTON, J.G. Central Nervous System Plasticity after Spinal Cord Injury in Man: Interlimb Reflexes and the Influence of Cutaneous Stimulation. Electroencephalography and Clinical Neurophysiology. V.101: p. 304-315, 1996.

CALANCIE, B.; MOLANO, M.R.; BROTON, J.G. Interlimb Reflexes and Synaptic Plasticity become Evident Months after Human Spinal Cord Injury. Brain. V.125: p.1150-1161, 2002.

CARVALHO, D.C.L.; CARVALHO, M.M.; CLIQUET Jr., A. Osteoporose por Desuso: Aplicação na Reabilitação do Lesado Medular. Acta Ortop. Bras., V. 9, N. 3: p. 34-43, 2001.

CASTRO, M.C.F.; CLIQUET Jr., A. A Low-Cost Instrumented Glove for Monitoring Forces During Object Manipulation. IEEE Transactions on Rehabilitation Engineering, V. 5: p. 140-147, 1997.

CHADWICK, E.K.J. \& NICOL, A.C. Elbow and Wrist Joint Contact Forces During Occupational Pick and Place Activities. J. of Biomechanics, V.33: p. 591-600, 2000.

CLIQUET Jr, A. A Comprehensive Sensorymotor Rehabilitation Programe for Spinal Cord Injured Patients Using Neuromuscular Electrical Stimulation. World Congress on Medical Physics and Biomedical Engineering, Sydney, Austrália. ANAIS, P.7/CD, 24-29 August, 2003.

CLIQUET Jr., A. Conexão Reativada. Revista Pesquisa FAPESP, N.80: p. 4851, 2002.

CLIQUET Jr., A. et al. Avanços Técnológicos nos Procedimentos Ortopédicos: Avaliações e Análises Biomecânicas. In: 34 CONGRESSO BRASILEIRO DE ORTOPEDIA E TRAUMATOLOGIA, São Paulo, 2002. Anais. São Paulo, 2002. 
CLIQUET Jr., A et al. Tendências em Biomecânica Ortopédica Aplicadas à Reabilitação. Acta Ortopédica Brasileira, V. 9, N. 3: p. 44-58, 2001

CLIQUET Jr., A. Man-Machine Systems for Restoring Movement to the Disabled. In: WORLD CONGRESS ON MEDICAL PHYSICS AND BIOMEDICAL ENGINEERING, Rio de Janeiro, 1994. Anais. Rio de Janeiro, 1994.

CLIQUET Jr., A.; BAXELANDALE, R.H.; ANDREWS, B.J. Paraplegic Locomotion and Its Metabolic Energy Expenditure. In ROSE, F.C.; JONES, R.; VRBOVÁ, G. Neuromuscular Stimulation: Basic Concepts and Clinical Implications. Vol 3, USA, Demos, 1989. p.273-274.

CLIQUET Jr., A; CASTRO, M.C.F. An Artificial Grasping Evaluation System for the Paralysed Hand. Medical and Biological Engineering and Computing. V. 38, N. 5: P. 275-281, 2000a.

CLIQUET Jr., A; CASTRO, M.C.F. Artificial Sensorymotor integration in spinal Cord Injured Subjects. Artificial Organs, V. 24, N. 9: p. 710-717, $2000 \mathrm{~b}$.

CRAGO, P.E. et al. An Elbow Extension Neuroprosthesis for Individuals whith Tetraplegia. IEEE Transactions of Reahabilitations Engineering, V. 6, N. 1: p. 16, 1998.

COSTA, P.H.L. da; VIEIRA, M.F. Revisitando Bernstein: Uma Linguagem para o Estudo da Coordenação de Movimentos. Brazilian Journal of Biomechanics. N.1: p. 55-62, 2000.

DAI, LI-YANG. Acute Central Cervical Cord Injury: the Effect of Age upon Prognosis. Injury, Int. J, Care Injured, V. 32: p. 195-199, 2001.

DALLMEIJER, A.J.; van der WOUDE, L.H.V.; HOLLANDER, A.P. \& van AS, H.H.J. Physical Performance Durimg Rehabilitation in Persons with Spinal Cord Injuries. Medicine \& Science in Sports \& Exercise, V31, N. 9: p. 13301335, 1999.

DALY, J.J. et al. Therapeutic Neural Effects of Electrical Stimulation. IEEE Transaction on Rehabilitation Engineering, V. 4, N. 4, Dec, 1996.

DANGELO, J.G.; FATTINI, C.A. Anatomia Básica dos Sistemas Orgânicos. São Paulo, SP, Atheneu,1984.

DAVIS, R. Twenty-Eight Years of Clinical Experience with Implantable Neuroprotheses for Various Applications. Artificial Organs, V. 26, N. 3:p. 280283, 2002. 
DEC, K.L.; SPARROW, K.J.; McKEAG, D.B. The Physically-Challenged Athlete: Medical Issues and Assessment. Sports Med., V. 29, N. 4: p.245-258, Apr, 2000.

de LIMA, G.F.; VAROTO, R.; PAOLILLO, A.R.; PAOLILLO F.R. CLIQUET,Jr.A. Restauração Artificial do Movimento de Membros Superiores de Tetraplégicos: Um Sistema Homem-Máquina. In: III Congresso Latino Americano de Órgãos Artificiais e Biomateriais, Campinas, SP, Julho de 2004. /in press/

DiMARCO, A.F. et al. Mechanical Contribution of Expiratory Muscles to Pressure Generation During Spinal Cord Stimulation. J. Appl. Physiol., V. 87, N. 4: p. 1433-1439, 1999.

DIETZ, V. Interaction Between Central Programs and Afferent Input in the Control of Posture and Locomotion. J. Biomechanics, V.29, N.7: p. 841-844, 1996.

DIETZ, V.; GOLLHOFER, A.; TRIPPEL, M. Regulation of Bipedal Stance: Dependency on "Load” Receptors. Experimental Brain Research, V. 89: p. 229231, 1992.

DUNE, J.W.; HEYE, N.; DUNE, S.L. Treatment of Chronic Limb Spasticity with Botulinum Toxin A. Journal of Neurology, Neurosurgery \& Psychiatry, V. 58, N. 2: p. 232-235, 1995.

EDGERTON, V.R. et al. How the Science and Engineering of Spaceflight Contribute to Understanding the Plasticity of Spinal Cord Injury. Acta Astronautica, V. 47, N. 1: p. 51-62, 2000.

ELOKDA, A.S.; NIELSEN, D.H.; SHIELDS, R.K. Effect of Functional Neuromuscular Stimulation on Postural Related Orthostatic Stress in Individuals with Acute Spinal Cord Injury. Journal of Rehabilitation Research and Development, V. 37, N. 5, Sep/Oct, 2000. Disponível na Internet http://www.vard.org/jour/37/5/elokd375.htm [14 fev. 2002].

ERTEKIN, C. et al. Motor Evoked Responses from the Thigh Muscles to the Stimulation of the Upper Limb Nerves in Pacients with late Poliomyelits. Clinical Neurophisiology, V. 133: p. 478-484, 2002.

ETTEMA, G.J.C.; STYLES, G.; KIPPERS, V. The Moment Arms of 23 Muscle Segments of the Upper Limb with varying and Forearm Positions: Implications for Motor Control. Human Movement Science, V. 17: p. 201-220, 1998.

FENG, C.J.; MAK, A.F.T. Three-Dimensional Motion Analysis of the Voluntary Elbow Moviment in Subjects with Spasticity. IEEE Transactions on Rehabilitation Engenneering, V. 5, N. 3: p. 253-262, 1997. 
FOUAD, K. et al. Treadmill Training in Incomplete Spinal Cord Injury Rats. Behavioural Brain Research, V. 115: p. 107-113, 2000.

FREEHAFER, A.A. Gaining Independence in Tetraplegia: Cleveland Technique. Clinical Orthopaedics \& Related Research, V. 355, p. 282-289, 1998.

GLASER, R.M. et al. The Physiology of Exercise for People with Spinal Cord Injury. Disponível na Internet http://www.vard.org/mono/sci/sciglase.htm [12 mar. 2002].

GREENWALD, D. et al. Current Surgical Therapy for Quadriplegia: Functional Electrical Stimulation. Plastic and Reconstructive Surgery, V. 109, N. 4: p. 1378-1385, 2002.

GRILL, W.M. et al. At the Interface: Emerging Clinical Applications of Electrical Stimulation: opportunities for restoration of function. Journal of Rehabilitation Research and Development, V.38, N. 6, Nov/Dec, 2001. Disponível na Internet http://www.vard.org/jour/38/6/grill386.htm $[14 \mathrm{fev}$. 2002].

GRONLEY, J.K. Electromyographic and Kinematc Analysis of the Shoulder During for Activities Daily Living in Men with C6 Tetraplegia. Journal of Rehabilitation Research and Development, V.37, N. 4, Jul/Aug, 2000. Disponível na Internet http://www.vard.org/jour/37/4/Gronl374.htm $[14 \mathrm{fev}$. 2002].

HANDA, Y. Current Topics in Clinical Functional Electrical Stimulation in Japan. J. Electromyography and Kinesiology, V. 7: p. 269-274, 1997.

HARTKOPP, A. et al. High Expression of MHC I in the Tibialis Anterior Muscle of a Paraplegic Patient. Muscle \& Nerve, V. 22: p. 1731-1737, 1999.

HEIDUSCHKA, P.; THANOS, S. Implantable Bioeletronic Interfaces for Lost Nerve Functions. Progress in Neurobiology, V. 55: p. 433-461, 1998.

HOBBY, J.; TAYLOR, P.N.; ESNOUF, J. Restauration of Tetraplegic Hand Function by Use of the Neurocontrol Freehand System. J. Hand Surgery, British and European, V. 26B, N.5: p. 459-464, 2001.

HOPMAN, M.T.E. et al. Blood Redistribution and Circulatory Responses to Submaximal Arm Exercise in Persons with Spinal Cord Injury. Scand. J. Reab. Med., V. 30: p. 167-174, 1998.

HUONKER, M., et al. Cardiovascular Differences between Sedentary and Wheelchair-Trained Subjects with Paraplegia. Med. Sci. Sports Exerc., V. 30 N. 4: p. 609-613, April, 1998. 
INSTITUTO BRASILEIRO DE GEOGRAFIA E ESTATÍSTICA - IBGE Censo 1991 e 2000. Disponível na Internet http://www.ibge.gov.br [9 de Maio, 2002].

INMANN, A.; HAUGLAND, M. An Instrumented Object for Evaluation of Lateral Hand Grasp During Functional Tasks. J. of Medical Engneering \& Techinology, V. 25, N. 5: p. 207-211, 2001.

IOANNIDES, A.A. et al. Brain Activation Sequences Following Electrical Limb Stimulation of Normal and Paraplegic Subjects. NeuroImage, V.16: p. 115-129, 2002.

ISELI, E., et al. Prognosis and recovery in Ischaemic and Traumatic Spinal Cord Injury: Clinical and Electrophysiological Evaluation. J. Neuol. Neurosurg. Psychiatry, V. 67: p. 567-571, 1999.

JU, M.S. et al. Performance of Elbow Tracking under Constant Torque Disturbance in Normotonic Stroke Patients and Normal Subjects. Clinical Biomechanics, V. 17: p. 640-649, 2002.

KARLSSON, A.K. et al. Regional Sympathetic Function in High Spinal Cord Injury During Mental Stress and Autonomic Dysreflexia. Brain, 121: p. 17111719, 1998.

KEITH, M.H. Neuroprostheses for the Upper Extremity. Microsurgery, V. 21: p. 256-263, 2001.

KELLER, T. et al. Grasping in Hight Lesioned Tetraplegic Subjects Using The EMG Controlled Neuroprosthesis. J. of NeuroRehabilitation, V. 10: p. 251-255, 1998.

KELLER, T. et al. Transcutaneous Functional Electrical Stimulador "Compex Motion”. Artificial Organs, V. 26, N. 3: p. 219-223, 2002.

KELLY, D.F.; BECKER, D.P. Advances in Management of Neurosurgical Trauma: USA and Canada. World Journal of Surgery, V. 25, N. 9: p. 1179-1185, Sep, 2001.

KERN, H. Functional Electrical Stimulation in Paraplegic Spastic Patients. Artificial Organs, V. 21, N. 3: p. 195-196, March, 1997.

KILGORE, K.L. et al. Neuroprothesis Consumers' Forum: Consumer Priorities for Research Directions. Journal of Rehabilitation Research and Development, V. 38, N. 6, Nov/Dec, 2001. Disponível na Internet http://www.vard.org/jour/38/6/kilgo386.htm. [14 fev. 2002]. 
KIRSCH, R.F. et al. Model-Based Development to Neuroprostheses for Restauring Proximal Arm Function. Journal of Rehabilitation Research and Development, V. 38, N. 6, Nov/Dec, 2001. Disponível na Internet http://www.vard.org/jour/38/6/kirsc386.htm. [14 fev. 2002].

KOJIMA N.; NAKAZAWA, K.; YANO, H. Effects of Limb Loading on the Lower-limb Electromyografic Activity During Orthotic Locomotion in a Paraplegic Patient. Neuroscience Letters, V. 274: p. 211-213, 1999.

LANKHORST, A.J. et al. Combined Treatment with $\alpha$ MSH and Methylprednisolone Fails to Improve Functional Recovery After Spinal Cord Injury in the Rat. Brain Research, V. 854: p. 334-340, 2000.

LATASH, M.L. Control of Human Movement. USA, Human Kinetics, 1993.

LATASH, M.L. Neurophysiological Basis of Movement. USA, Human Kinetics, 1998.

LATASH, M.L.; ARUIN, A.S.; ZATSIORSKY, V.M. The Basis of a Simple Synergy: Reconstruction of Joint Equilibrium Trajectories During Unrestrained Arm Moviments. Human Movement Science, V. 18: p. 3-30, 1999.

LEMAY, M.A.; CRAGO, P.E. A Dinamic Model for Simulating Movements of the Elbow, Forearm, and Wrist. J. Biomechanics, V. 29, N. 10:p. 1319-1330, 1996.

LEMAY, M.A.; CRAGO, P.E.; KEITH, M.W. Restauration of Pronosupination Control by FNS in Tetraplegia - Experimental and Biomechanics Evaluation of Feasibility. J. of Biomechanics, V. 29, N. 4: p. 435-442, 1996.

LEROUX, A.; FUNG, J.; BARBEAU, H. Adaptation of the Walking Pattern to Uphill Walking in Normal and Spinal-Cord Injured Subjects. Experimental Brain Research, V. 126: p. 359-368, 1999.

LJZERMAN, M.J. et al. The NESS Handmaster Orthosis: restauration of Hand Function in C5 and Stroke Patients by means of Electrical Stimulation. J. Rehabil Sciencs, V. 9, N. 3: 86-89, 1996 / Resumo /

LONG, C.; MASCIARELLI, V. An Electrophysiologic Splint for the Hand. Arch. Phys. Med., V. 44: p. 499-499, 1963.

MAKARAN, J.B. et al. The SMART® Wrist-Hand Orthosis (WHO) for Quadriplegic Patients. J. of Prosthetics and Orthotics, V. 5, N. 3: p. 73-76, 1993.

MAKSIMOVIC, R.; POPOVIC, M.B. Classification of Tetraplegics through Automatic Movement Evaluation. Medical Engineering \& Physical, V. 21: p. 313-327, 1999. 
MANNS, P.J.; CHAD, K.E. Components of Quality of Life for, Person with a Quaadriplegic and Paraplegic Spinal Cord Injury. Qualitative Health Research, V. 11, N. 6: p. 795-811, Nov, 2001.

MAYR, W. et al. Basic Design and Construction of the Vienna FES Implants: Existing Solutions and Prospects for New Generations of Implants. Medical Engineering \& Physics, V. 23: p. 53-60, 2001.

MELA, P.; VELTINK, P.H.; HUIJING, P.A. Excessive Reflexes in Spinal Cord Injury Triggered by Electrical Stimulation. Archives of Physiology and Biochemistry, V. 109, N. 4: p. 309-315, 2001.

MICERA, S. ET AL. A Hybrid Approach to EMG Pattern Analysis for Classification of Arm Movements Using Statistical and Fuzzy Techniques. Medical Engineering \& Physics V. 21: p. 303-311, 1999.

MIKULIS, D.J. et al. Adaptation in the Motor Cortex Following Cervical Spinal Cord Injury. Neurology, V. 58, p. 794-801, 2002.

MUCCIO, P.; ANDREWS, B.; MARSOLAIS, E.B. Eletronic Orthoses: Technology, Prototypes, and Practices. Journal of Prosthetics and Orthotics, V.1, N. 1: p. 3-17, 1989.

MURRAY, W.M.; BUCHANAN, T.S.; DELP, S.L. The Isometric Function Capacity of Muscles that cross the Elbow. J. Biomechanics, V. 33: p. 943-952, 2000.

MURRAY, W.M.; DELF, S.L.; BUCHANAN, T.S. Variation of Muscle Moment Arms with Elbow and Forearm Position. J. Biomechanics, V. 28, N. 5: p. 513525, 1995.

MUSA, I.M. The Role of Afferent Input in the Reduction of Spasticity: an Hipotheses. Physioterapy, V. 72, N. 4: p. 179-182.

NATHAN, R.H. Generation of Functional Arm Movements in C4 Quadriplegics by Neuromuscular Stimulation. In: ROSE, F.C.; JONES, R. \& VRBOVÁ, G. Neuromuscular Stimulation: Basic Concepts and Clinical Implications. V.3, USA, Demos, 1989. p.273-274.

ODA, S.; KIDA, N. Neuromuscular Fatigue During Maximal Concurrent Hand Grip and Elbow Flexion or Extension. J. Electromyography and Kinesiology, V.11: p. 281-289, 2001.

PAGLIARO, P.; ZAMPARO, P. Quantitative Evaluation of the Strech Reflex Before and After Hydro Kinesy Therapy in Patients Affected by Spastic Paresis. J. Electromyography and Kinesiology, N. 9: p. 141-148, 1999. 
PAOLILLO, A.R.; PAOLILLO, F.R.; CLIQUET Jr., A. É Possível Voltar a Andar Após a Lesão Medular? XVIII Congresso Brasileiro de Engenharia Biomédica, São José dos Campos, SP, p. 288, 9-12 de Setembro, 2002.

PEIXOTO, B.O.; CLIQUET Jr, A. Redução da Fadiga Muscular através da Estimulação Elétrica Neuromuscular em Pacientes Portadores de Lesão Medular. RBE - Caderno de Engenharia Biomédica, V. 12, N. 2: p. 21-46, Jul/Dez, 1996.

PFURTSCHELLER, et al. Brain Oscillations Control Hand Orthosis in a Tetraplegic. Neuroscience Latters, V. 292: p. 211-214, 2000.

POPOVIC, D.B. et al. Clinical Evaluation of the Bionc Glove. Arch. Phys. Med. Rehabil. V. 80: p. 299-304, 1999.

POPOVIC, D.B.; POPOVIC, M.B. Tuning of a Nonanalytical Hierarchical Control System for Reaching with FES. IEEE Transactions on Biomedical Engineering, V. 45, N. 2: p. 203-212, 1998.

POPOVIC, D.B.; POPOVIC, M.B.; SINKJAER, T. Neurorehabilitation of Upper Extremities in Humans with Sensory-Motor Impairement. Neuromodulation, V. 5, N. 1: p. 54-67, 2002.

POPOVIC, M.B. et al. Restitution of Reaching and Grasping Promoted by Functional Electrical Therapy. Artificial Organs, V.23, N. 3: p. 271-275, 2002.

POPOVIC, M.B.; POPOVIC, D.B. Cloning Biological Synergies Improves Control of Elbow Neuroprostheses. IEEE Enginnering in Medicine and Biology, V. 20, N. 1: p. 74-81, 2001.

POPOVIC, M.B.; POPOVIC, D.B.; TOMOVIC, R. Control of Arm Movement: Reaching Synergies for Neuroprostheses with Life-Like Control. J. of Automatic Control, V.12: p. 9-15, 2002.

POPOVIC, M.R.; POPOVIC, D.B.; KELLER, T. Neuroprostheses for Grasping. Neurological Research, V. 24, N. 5: p. 443-452, 2002.

POPOVIC, M.R. et al. Functional Electrical Stimulation for Grasping and Walking: Indications and Limitations. Spinal Cord, Jun de 2001. Disponível na Internet. http://www.utoronto.ca/ibbme/faculty/popovic-milos/publications. [25 nov. 2002].

POPOVIC, M.R. et al. Surface-Stimulation Technology for Grasping and Walking Neuroprostheses. IEEE Enginnering in Medicine and Biology, Jan/Fev de 2001. Disponível na Internet. http://www.utoronto.ca/ibbme/faculty/popovicmilos/publications. [25 nov. 2002]. 
POYNTON, A.R. et al. An Evaluation of The Factors Affecting Neurological Recovery Following Spinal Cord Injury. Injury, V. 28, N. 8: p. 545-548, 1997.

PROCHAZKA, A. et al. The Bionic Glove: An Electrical Stimulator Garment that Provides Controlled Grasp and Hand Opening in Quadripligia. Arch. Phys. Med. Rehabil. V. 78: p. 608-614, 1997.

RAHMAN, T. et al. A Body-Powered Functional Upper Limb Orthosis. Journal of Rehabilitation Research and Development, V. 37, N. 6, Sep/Oct, 2000. Disponível na Internet. http://www.vard.org/jour/00/37/6/rahma376.htm [27 out., 2001].

RAPADO, A. General Management of Vertebral Fractures. Bone, V.18, N. 3: p.191S-196S, 1996 / Suplemento /

REDE SARAH DE HOSPITAIS DO APARELHO LOCOMOTOR. Disponível na Internet http://www.sarah.br [3 julho, 2002].

ROGERS, S.M. Factors that Influence Exercise Tolerance. Disponível na Internet http://www.vard.org/mono/sci/sciroger.htm [12 mar. 2002].

ROSSINI, P.M.; PAURI, F. Neuromagnetic Integrated Methods Tracking Human Brain Mechanisms of Sensorimotor areas "plastic" Reorganization. Brain Research Reviews, V. 32: 131-154, 2000.

SALMONS, S. et al. ASIC or PIC? Implantable Stimulators Based on SemiCustom CMOS Technology or Low-Power Microcontroller Architecture. Medical Engineering \& Physics, V. 23: p. 37-43, 2001.

SAVITSKY, E.; VOTEY, S. Emergence Department Approach to Acute Thoracolumbar Spine Injury. J. of Emergence Medicine, V. 15, N. 1: p. 49-60, 1997.

SEKHON, L.H.S.; FEHLINGS, M.G. Epidemiology, Demographics, and Pathophysiology of Acute Spinal Cord Injury. Spine, V. 26, N. 24S: p. S2-S12, 2001.

SPINAL CORD INJURY. Disponível na Internet. http:॥www.spinalcord.uab.edu. [28 de Junho, 2002].

SEPÚlVEDA, F; CLIQUET Jr. A. Gait Restoration in a Spinal Cord Injured Subject Via Neuromuscular Electrical Stimulation Controlled by an Artificial Neural Network. The International Journal of Artificial Organs. V. 21, N.1: P. 49-62, 1998.

SHAPIRO, M.B.; ARUIN, A.S.; LATASH, M.L. Velocity-Dependent Activation of Postural Muscles in a Simple Two-Joint Synergy. Human Movement Science. V. 14: p. 351-369, 1995. 
SKÖLD, C. et al. Effects of Functional Electrical Stimulation Training for Six Months on Body Composition and Spasticity in Motor Complete Tetraplegic Spinal Cord Injury. J. Rehabil. Med., V. 34: p. 25-32, 2002.

SLACK, M.; BERBRAYER, D. A Myoelectrically Controlled Wrist-Hand Orthosis for Brachial Plexus Injury: A Case Study. J. of Prosthetics and Orthotics, V.4, N. 3: p. 171-174, 1992.

STEIN, R.B.; PECKHAM, P.H.; POPOVIC, D.P. Neural Prostheses: Replacing Motor Function After Disease or Disability. New York, Oxford university Press, 1992.

STERNAD, D.; DEAN, W.J.; SCHAAL, S. Interaction of Rhythmic and Discrete Pattern Generators in Single-Joint Movements. Human Movement Science, V. 19: p. 627-664.

TAOKA, Y.; OKAJIMA, K. Spinal Cord Injury in the Rat. Progress in Neurobiology, V. 56: p. 341-358, 1998.

THOMAS, C.K. Fatigue in Human Thenar Muscle Paralysed by Spinal Cord Injury. J. Electromyography and Kinesiology, V. 7, N1, p. 15-26, 1997.

THOMAS, C.K. et al. Muscle Weakness, Paralysis, and Atrophy after Human Cervical Spinal Cord Injury. Experimental Neurology, V. 148: p. 414-423, 1997.

THOUMIE, P. et al. Restoration of Functional Gait in Paraplegic Patients with the RGO-II Hybrid Orthosis. A Multicenter Controlled Study. II: Physiological Evaluation. Paraplegia, V. 33: p. 654-659, 1995.

TREMBLAY, M. Going Back to Civvy Street: a Historical Account of the Impact of the Everest and Jennings Wheelchair for Canadian World War II Veterans with Spinal Cord Injury. Disability \& Society, V. 11, N. 2: p. 149-169, 1996.

TROMBLY, C. A. Terapia Ocupacional para a Disfunção Física.. São Paulo, SP, Santos, 1989.

TROYK, P.R.; DONALDSON, N. de N. Implantable FES Stimulation Systems: What is Needed? Neuromodulation, V. 4, N. 4: p. 196-204, 2001.

UCHIYAMA, T.; BESSHO, T.; AKAZAWA, K. Static Torque-Angle Relation of Human Elbow Joint Estimated with Artificial Neural Network Technique. J. Biomechanics, V. 31: p. 545-554, 1998.

van der HELM, F.C.T.; VEEGER, H.E.J. Quasi-estatic Analysis of Muscle Forces in the Shoulder Mechanism During Wheelchair Propulsion. J. of Biomechanics, V. 29, N. 1: p. 39-52, 1996. 
van der SLUIS, C.K. et al. Long-Term Phisical, Psychological and Social Consequences of Severe Injuries. Injury: International Journal of the Care of the Injured, V.29, N.4: p.281-285, May, 1998.

VOLPE, B.T. et al. A Novel approach to Stroke Reabilitation: Robot-Aided Sensori-Motor Stimulation. Neurology, V. 54, N. 10: 1938-1944, 2000.

VOSSIUS, G. Comparsion of FES of the Upper Extremities by Means of Surface and of Implanted Electrodes. In: $2^{\text {nd }}$ VIENNA INTERNATIONAL WORKSHOP ON FUNCTIONAL ELECTROSTIMULATION, Vienna, 1986. Anais. Vienna, University of Vienna, 1986. .

WHELAN, P.J. Control of Locomotion in the Decerebrate Cat. Progress in Neurobiology, V. 49: p. 481-515, 1996.

WICKELGREN, I. Teaching the Spinal Cord to Walk. Science Magazine, V. 279, N. 5349: p. 319-321, Jan, 1998.

WIERZBICKA, M.M.; WIEGNER, A.W. Orthosis for Improvement of Arm Function in C5/C6 Tetraplegia. J. of Prosthetics and Orthotics, V.8, N. 3: p. 8692, 1996.

WINTER, D.A. Biomechanics and Motor Control of Human Movement. 2 2a ed., New York, Wiley Inter-Science, 1990.

YANAGI, T. et al. Agonist Contractions Against Electrically Stimulated Antagonists. Arch Phys Med Rehabil, V.84, p. 843-848, 2003.

YOCK, D.H., Magnetic Resonance Imaging of CNS Disease, New York, Mosby, 1995. 


\section{Apêndice A}

\section{O ESTUDO PILOTO COM O SISTEMA QUALISYS}

O estudo piloto incluiu, além de avaliações com o Eletrogoniômetro, avaliações com o Sistema Optoeletrônico Qualisys de Captura Tridimensional de movimentos. Este sistema inclui 6 Unidades de Captura do Movimento (MCU Motion Capture Unit), que podem operar numa taxa de aquisição de até $240 \mathrm{~Hz}$, possui emissores luminosos na faixa de infravermelho (LEDs), trabalhando em regime pulsado. Durante a captura, pulsos de luz são emitidos iluminando os marcadores reflexivos colocados sobre os pontos anatômicos pré-definidos correspondente às articulações. Cada MCU capta uma imagem e transmite ao hardware dedicado ao processamento de imagens, que define as coordenadas bidimensionais dos marcadores reflexivos e transfere os dados para o microcomputador. Com os dados das câmeras, pode-se calcular as coordenadas tridimensionais de cada marcador definindo a variação de posição das articulações durante o movimento. O hardware dedicado de cada MCU, acelera a etapa de análise a ser realizada no microcomputador hospedeiro.

O sistema permite uma grande flexibilidade em sua configuração, podendo ser utilizado de 2 a 6 câmeras para a captura do movimento.

Para esta pesquisa, foram utilizadas 2 câmeras, formando um ângulo de $90^{\circ}$ ao lado direito do paciente, posicionado próximo a uma mesa, na postura sentada e com o antebraço na posição neutra sobre a mesa, de acordo com o protocolo de Feng e Mak (1997). 
A calibração do sistema é dada pelas coordenadas de referências:

eixo $\mathbf{X} \rightarrow$ médio-lateral

eixo $\mathbf{Y} \rightarrow$ antero-posterior

eixo $\mathbf{Z} \rightarrow$ próximo-distal

Para mensuração em 3-D, o sistema deve ser calibrado dinamicamente, assim o sistema de referência foi colocado nos limites do volume da área a ser calibrada, posicionando as câmeras de modo a cobrir todo o volume, para isso foi utilizado um corpo de prova com dois marcadores varrendo todo volume, com movimentos na direção dos três eixos, indicando a linearidade e a ortogonalidade do espaço tridimensional medido pelo sistema.

Depois que o sistema foi devidamente calibrado, inicia-se o processo de captura da imagem. Com as informações adquiridas pelas câmeras em relação ao movimento dos marcadores reflexivos, fixados no indivíduo, inicia-se a reconstrução 3-D, utilizando-se o software Q-Trac.

Foram utilizados marcadores reflexivos esféricos de 13 mm de diâmetro colocados nos pontos anatômicos: borda do acrômio direito, epicôndilo lateral do úmero direito, região medial do carpo direito.
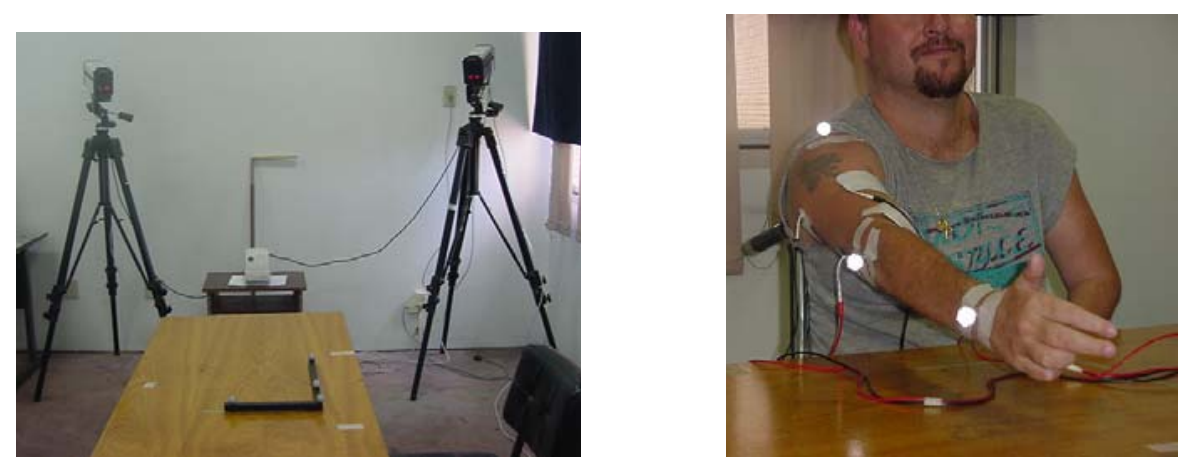

FIGURA 29 - Calibração do Sistema Qualisys (a) e procedimento experimental (b).

O paciente realizou 10 tentativas dos movimentos de flexão-extensão do cotovelo do membro superior dominante (direito), sem Estimulação Elétrica e mais 10 tentativas, com Estimulação Elétrica Neuro-Muscular dos músculos bíceps e 
tríceps, utilizando Estimulador portátil. A variável cinemática avaliada foi a medida angular.

Os resultados, da avaliação do paciente 1 , mostraram valores de variação angular, sem Estimulação Elétrica, entre $120^{\circ}$ e $130^{\circ}$ durante a flexão do cotovelo, enquanto a extensão ocorreu entre $25^{\circ}$ e $35^{\circ}$, com maior variabilidade (Figura 30-a). Quando submetido a Estimulação, o pico máximo do ângulo de flexão foi de $135^{\circ} \mathrm{e}$ o pico mínimo de extensão foi de $10^{\circ}$, apresentando maior repetibilidade (Figura 30b).

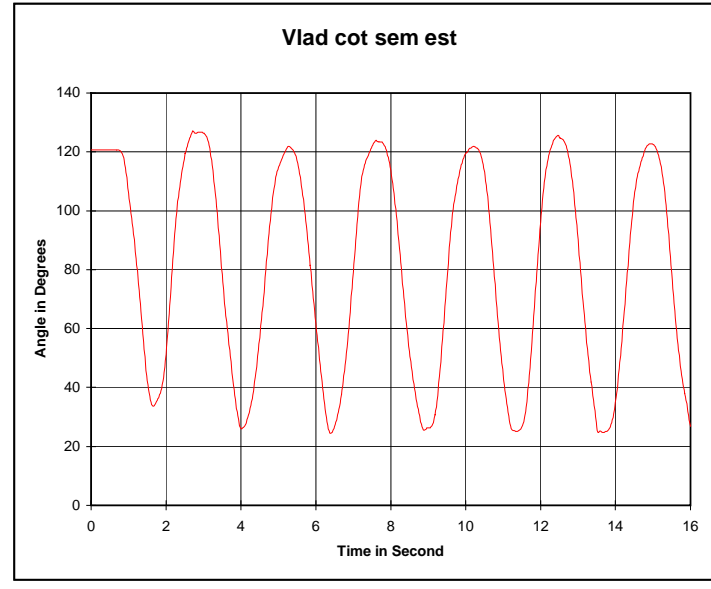

(a)

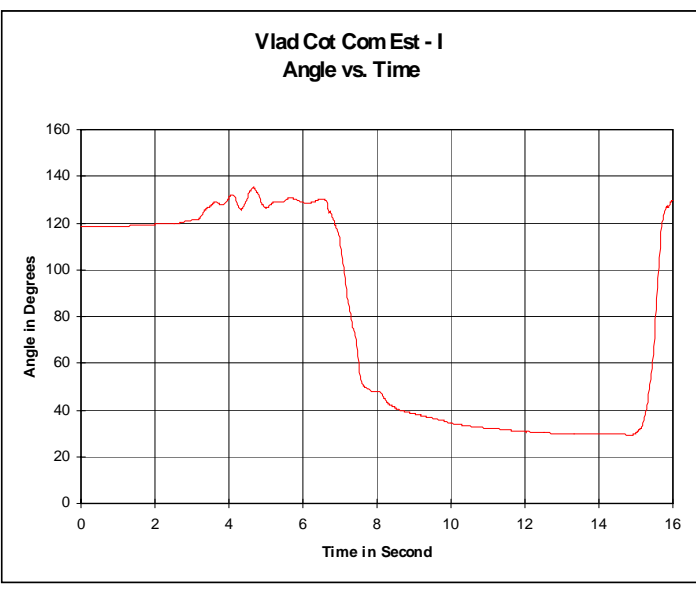

(b)

FIGURA 30 - Variação angular vs. tempo durante a flexão e extensão do cotovelo do paciente 1 sem Estimulação Elétrica (a) e com EENM (b), utilizando o Sistema Qualisys.

As diferenças obtidas nos resultados das avaliações do paciente 1 com 0 Sistema Qualisys e com o Eletrogoniômetro (FIGURA 20 e 30) ocorreram devido ao a modificação do Protocolo utilizado, ou seja, com o Sistema Qualisys seguiu-se o procedimento realizado por diversos autores, entre eles: Shapiro, Aruin e Latash (1995), Latash, Aruin e Zatsiorsky (1999) e Feng e Mak (1997), no qual o movimento de flexão/extensão ocorreu com o cotovelo apoiado sobre a mesa, que 
limita a extensão. Entretanto, com o uso da EENM ocorria a extensão completa e o cotovelo do paciente 1 não permanecia sobre a mesa. Portanto houve a necessidade do Protocolo ser realizado sem o apoio, ainda os autores citados enfatizaram a flexão, e esta pesquisa inclui também a avaliação da extensão. A partir desta conclusão, os testes com Eletrogoniômetro foram realizados sem o apoio do cotovelo sobre a mesa.

O Sistema Qualisys possibilita a análise 3-D, com visualização dos movimentos articulares. Além da variação angular, pode-se obter outras variáveis como velocidade angular, aceleração angular, momento e torque que não foram incluídos nesta pesquisa.

O Eletrogoniômetro, também permite a análise dinâmica do movimento, porém com restrição das variáveis biomecânicas a serem analisadas.

Com o Sistema Qualisys foram registrados movimentos compensatórios. Já durante os testes com Eletrogoniômetro, os movimentos compensatórios foram observados por inspeção visual. Este fato não foi fator de decisão para escolha da metodologia, uma vez que o teste não foi realizado com restrição do movimento de tronco e ombro, para assemelhar-se o máximo possível ao cotidiano.

O estudo piloto mostrou que as avaliações utilizando o Eletrogoniômetro e o Sistema Qualisys puderam quantificar a medida angular da articulação do cotovelo dos pacientes tetraplégicos.

Portanto, para conclusão desta pesquisa, optou-se pela utilização do Eletrogoniômetro por ser uma avaliação monoarticular realizada no plano sagital, apresentar sistema de referência relativo e permitir a análise dinâmica do movimento. 


\section{Apêndice B}

\section{RESTAURAÇÃO DE PREENSÕES, MOVIMENTOS DE ALCANCE E DESLOCAMENTO DO MEMBRO SUPERIOR NO ESPAÇO DURANTE ATIVIDADES DE VIDA DIÁRIA}

Para realização das atividades de vida diária foram realizadas as preensões em pinça, disco, lateral e palmar.

A restauração das preensões foram determinadas a partir de dados obtidos na literatura ou empiricamente, testando os pontos motores e nervos do membro superior.

Visando a redução da quantidade de eletrodos e portabilidade do sistema, foi utilizado um estimulador portátil de 2 canais.

Os parâmetros de Estimulação utilizados foram: tipo de onda monofásica bipolar, freqüência de $25 \mathrm{~Hz}$, duração de pulso de $300 \mu$ s e amplitude de 0 a $150 \mathrm{~V}$, ajustável de acordo com a necessidade do paciente para determinar a força de preensão, controlada por potenciômetro e sistema acionado por chave. 
Para a preensão em pinça entre o primeiro e segundo dedos, foram estimulados o primeiro dorsal interósseo e adutor do polegar, que possibilitaram as atividades lúdica, de escrita, pintura e segurar uma moeda.

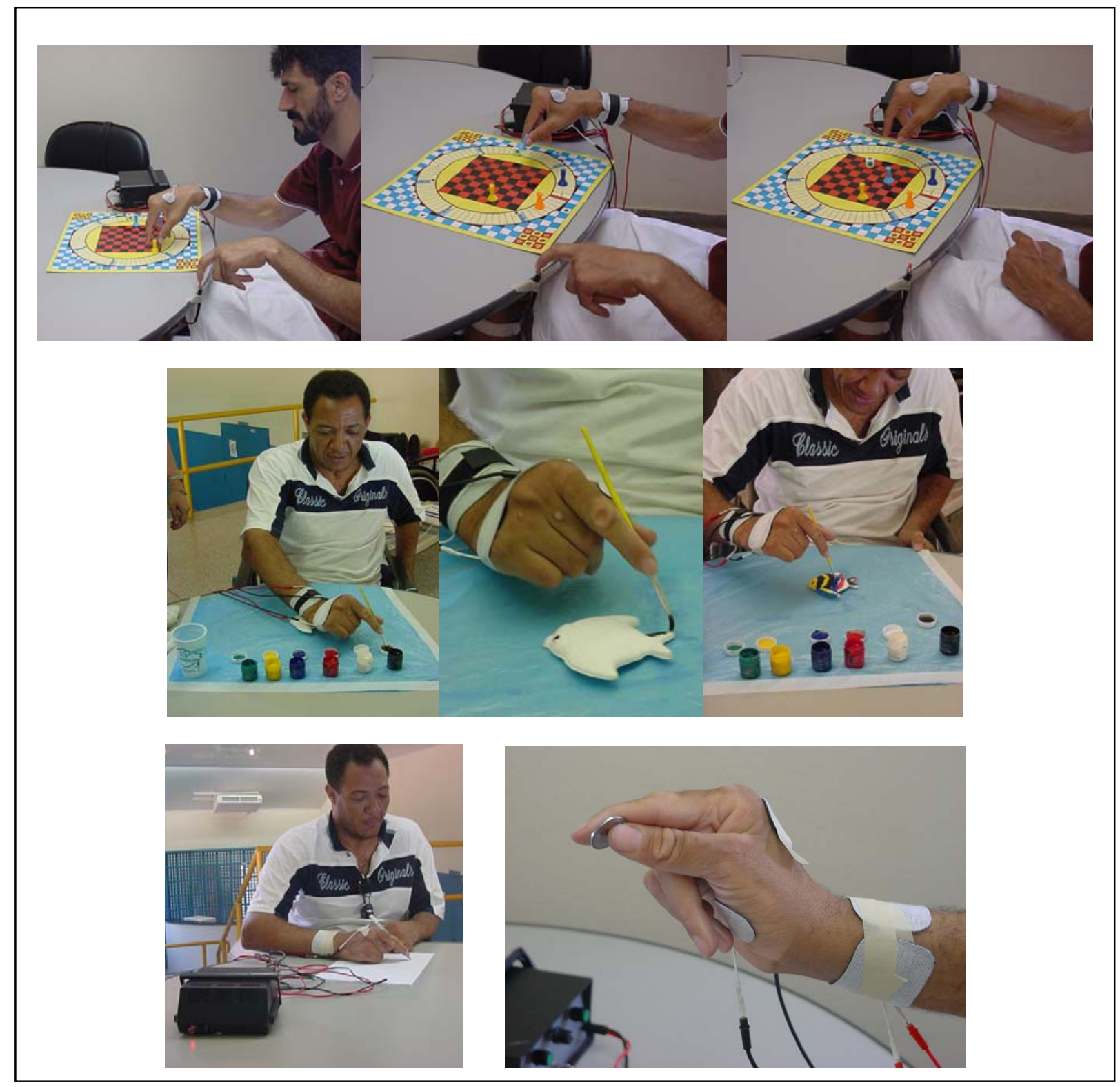

FIGURA 31 - Restauração da preensão em pinça durante as atividades funcionais. 
Para o movimento de preensão em disco, foram estimulados os lumbricais e flexor dos punhos, que possibilitam segurar uma tampa de frasco para mantimentos e um CD.

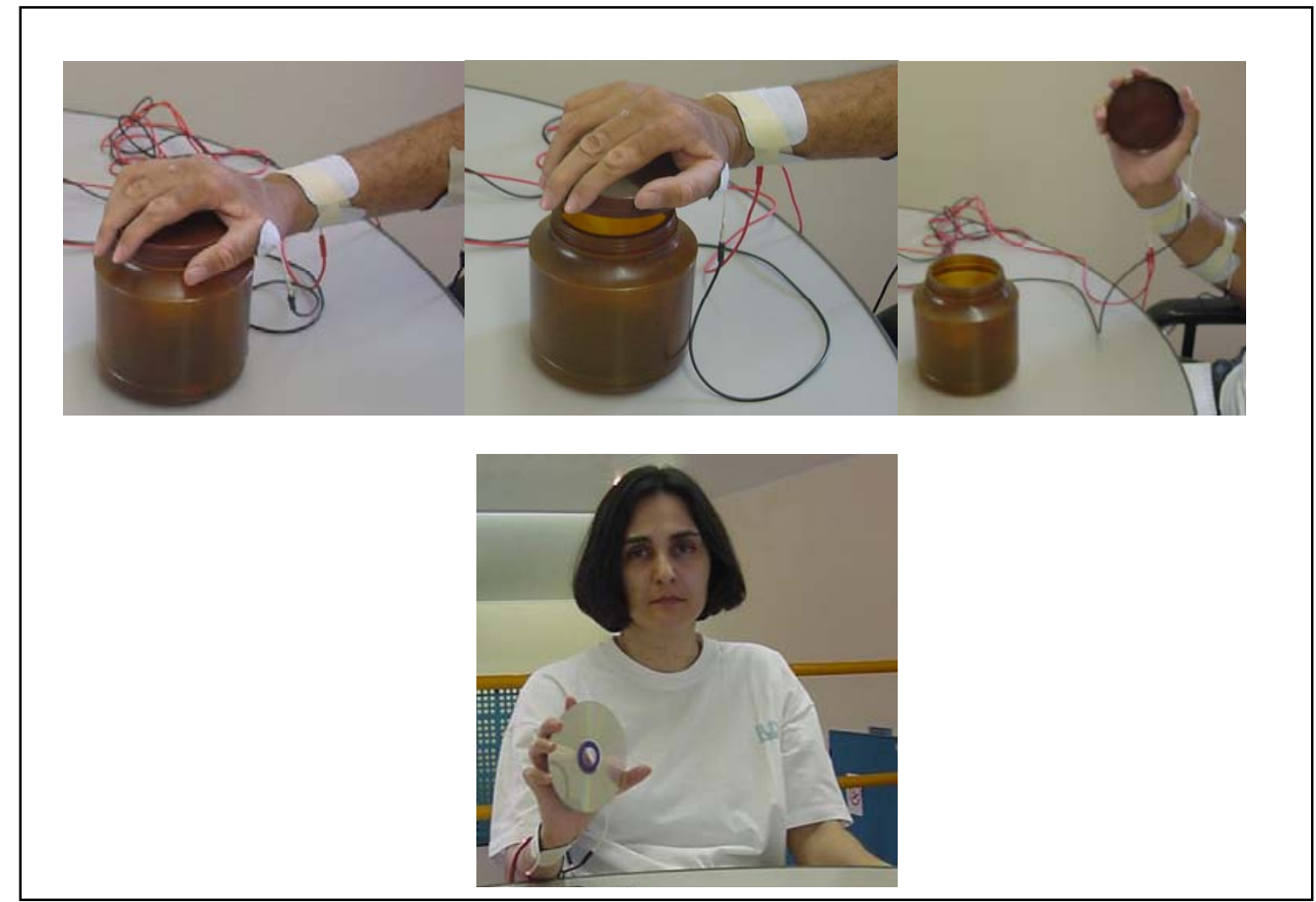

FIGURA 32 - Restauração da preensão em disco durante as atividades funcionais.

Para realização da preensão lateral, foram estimulados o flexor dos dedos e adutor do polegar, que possibilitam segurar talheres e escova de dentes.

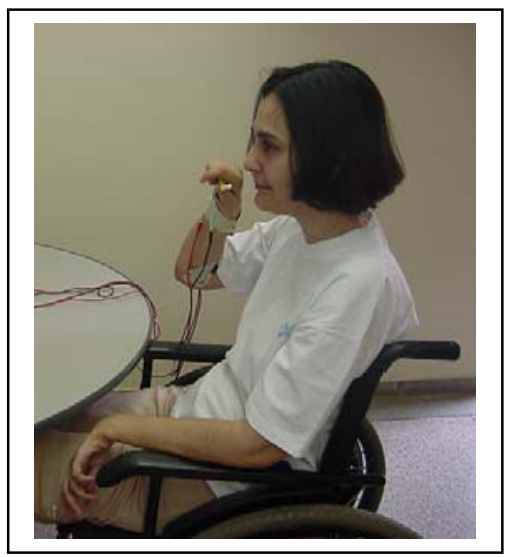

FIGURA 33 - Restauração da preensão lateral durante as atividades funcionais. 
Para preensão palmar foram estimulados os lumbricais e abdutor do polegar, que possibilitam segurar copos, telefone celular, secador e escova de cabelo.

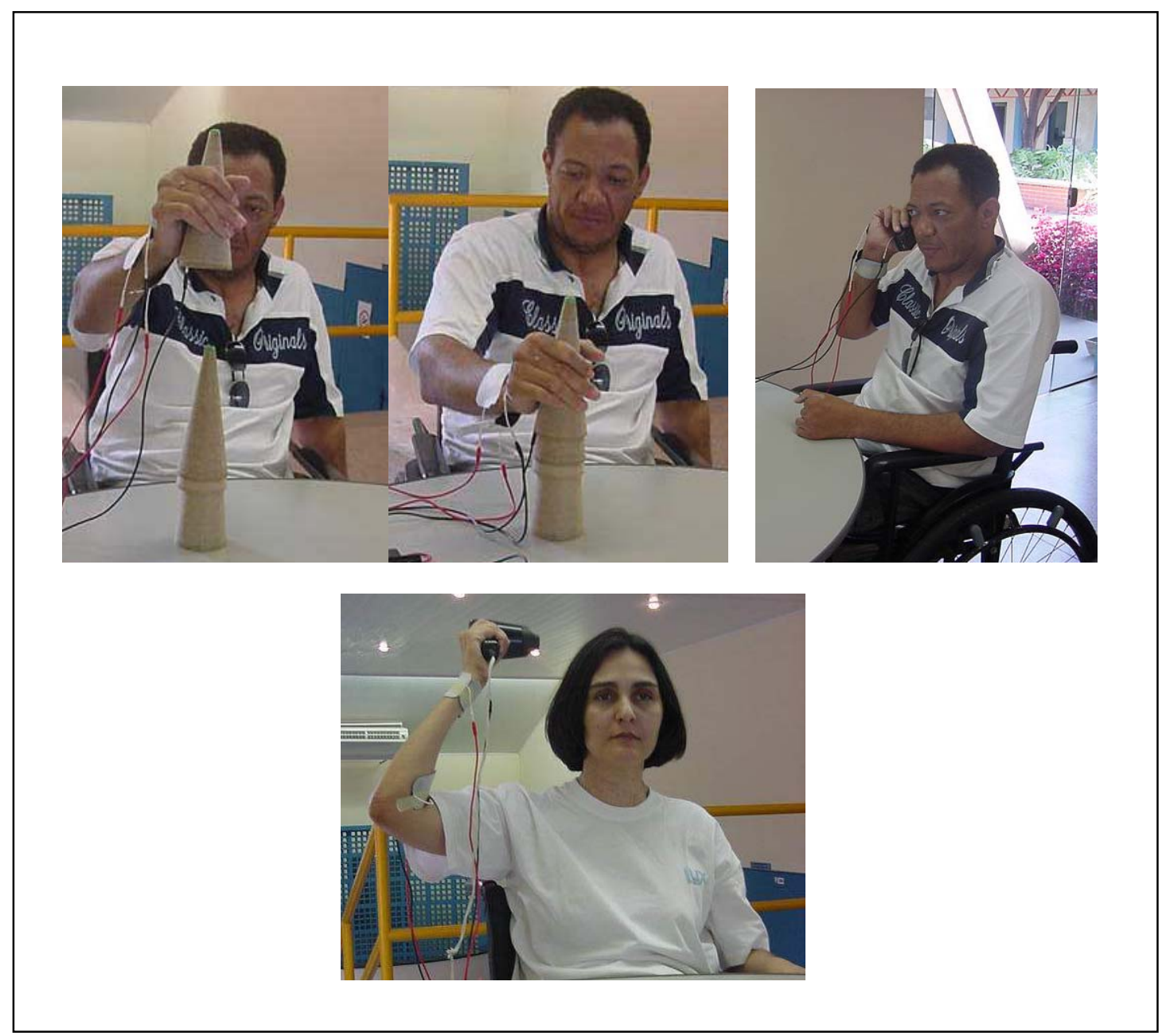

FIGURA 34 - Restauração da preensão palmar durante as atividades funcionais.

Observou-se, que durante a execução das atividades propostas, os pacientes demonstraram maior satisfação e motivação nas atividades lúdicas e de pintura, que favoreceram o aumento da auto-estima, iniciativa, criatividade, auto-expressão, organização de pensamento, orientação espaço-temporal, memória, bem como dos processos cognitivos e da socialização. Outro aspecto relevante constatado, foi a coordenação motora fina e óculo-manual, gerada pelo ato de pegar as peças do jogo, através da preensão em pinça que foi acionada por botão, pelo membro contralateral, caracterizando uma atividade bimanual, que também ocorreu durante a realização da 
pintura em gesso, no qual houve o auxilio do outro membro para o posicionamento adequado do pincel, importante para o encontro dos membros superiores na linha média do corpo, favorecendo o desenvolvimento do esquema/imagem corporal e a integração sensório-motora.

Estes aspectos são importantes, uma vez que encontram-se reduzidos ou ausentes na maioria dos portadores de lesão no sistema nervoso central (TROMBLY, 1989).

A reaprendizagem sensório-motora é obtida pela repetitibilidade de movimentos dos membros superiores, ativados artificialmente, que geram input central e podem ser combinados com movimentos voluntários, conduzindo à reorganização cortical e aumento do ganho de função. Durante a realização de AVDs, utilizando Estimulação Elétrica e manipulação de objetos, houve aumento do número de movimentos realizados com êxito e redução do tempo na execução das atividades (POPOVIC, D.B.; POPOVIC, M.B. \& SINKJAER, 2002); (POPOVIC, M.B.; POPOVIC, D.B. \& TOMOVIC, 2002); (POPOVIC, M.B. et al., 2002). Ainda, várias sessões diárias de prática, melhoram a velocidade e precisão nas tarefas motoras complexas, como as seqüências de movimentos rápidos (ROSSINI \& PAURI, 2000).

Portanto, se houver maior acometimento dos membros superiores de indivíduos tetraplégicos, torna-se necessária a restauração artificial dos movimentos do cotovelo para a realização das AVDs, por meio do uso de órteses mecânicas e/ou das seqüências de Estimulação Elétrica, que incluam o ato de alcançar e o deslocamento do membro superior no espaço. 


\section{Apêndice C}

\section{REFLEXOS INTERMEMBROS EM TETRAPLEGIA}

Para verificar se houve a presença de reflexos intermembros (reflexo de interconexão entre os membros superiores e inferiores em tetraplégicos) foi utilizada a EENM dos nervos fibulares dos membros inferiores direito e esquerdo, alternadamente (durante 15 minutos) e obtida a atividade muscular dos membros superiores em repouso através de eletromiografia (EMG). Os sinais mioelétricos dos membros superiores (flexores do punho direito e esquerdo; extensores do punho direito e esquerdo; abdutor do polegar direito e esquerdo; adutor do dedo mínimo direito e esquerdo) foram captados por meio de eletrodos de superfície ativos diferenciais com ganho de 20 vezes (PA602 da empresa Linx Tecnologia Eletrônica LTDA), em seguida o sinal foi amplificado mais 50 vezes em uma placa condicionadora de sinais (MCS 1000-V2 da Linx) totalizando um ganho de 1000 vezes, nesta placa os sinais passaram ainda por filtros passa alta de $20 \mathrm{~Hz}$ e passa baixa de $500 \mathrm{~Hz}$. Este sinal foi então digitalizado por uma placa conversora analógico/digital de 12 bits (CAD 1256 também da Linx) a uma taxa de amostragem de $4000 \mathrm{~Hz}$. O software de aquisição de dados foi o AqDados versão 5.0 confeccionado pela mesma empresa. Foram obtidos sinais mioelétricos pelo período de um minuto antes de iniciar a EENM e durante a EENM (depois de transcorridos 5 minutos de estimulação). O procedimento experimental pode ser visualizado na Figura 35-a. 
Alguns dos pacientes tetraplégicos que fazem parte do Programa de EENM apresentaram atividade mioelétrica dos membros superiores durante a EENM dos membros inferiores e pode ser exemplificada pela resposta do paciente 4, como mostra a Figura 35-b.

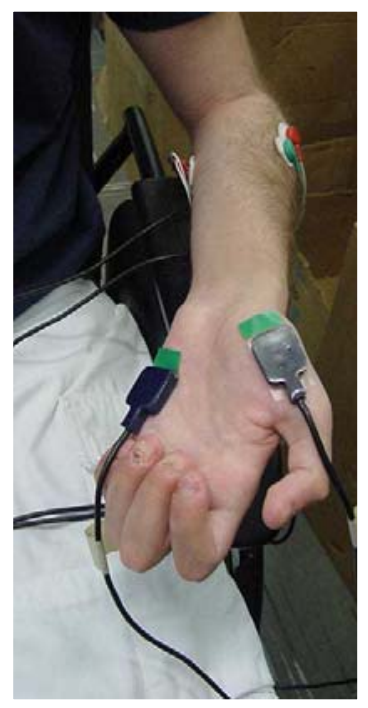

(a)
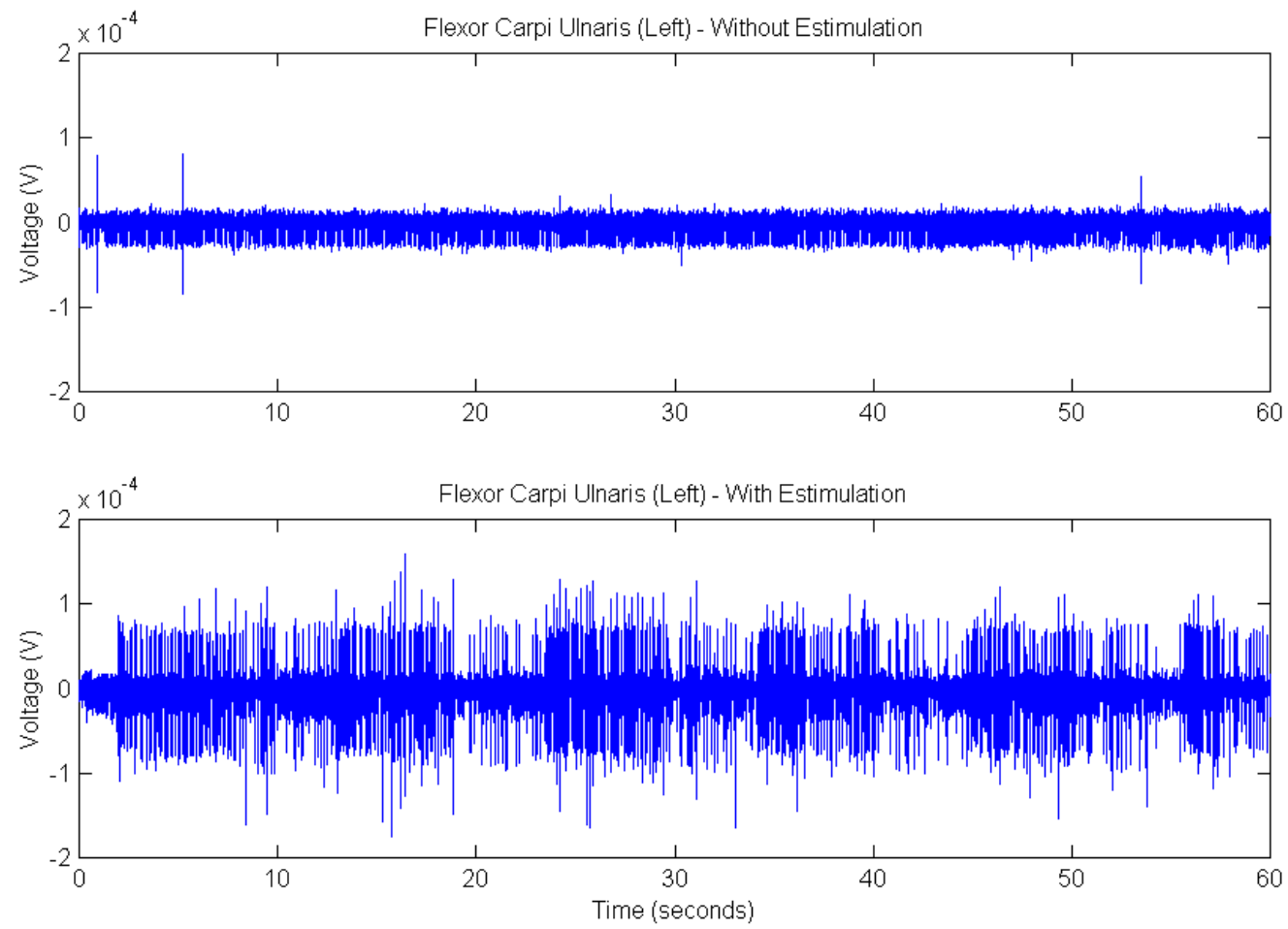

(b)

FIGURA 35: Procedimento experimental em neurofisiologia (a) e atividade muscular do grupo flexor do punho esquerdo do paciente 4 sem e com a EENM (b). 
A atividade muscular nos membros superiores do paciente 4 indica possivelmente a presença de reflexos intermembros. Estes reflexos consistem em respostas motoras nos músculos distais dos membros superiores evocadas por estimulação de nervos periféricos mistos dos membros inferiores (CALANCIE 1991); (CALANCIE; LUTTON \& BROTON, 1996). Estas respostas evocadas podem ser ipslateral, contralateral ou ambos em cada paciente com lesão medular (CALANCIE, MOLANO \& BROTON, 2002); (ERTEKIN et al., 2002). A presença do reflexo intermembros pode ser decorrente de dois fatores:

1) os circuitos interneurais que são pré-existentes e inativos sob condições comuns (sinapses latentes) podem tornar-se funcionais após a lesão neural, ou

2) a presença de novas conexões sinápticas entre as fibras aferentes da extremidade inferior e os motoneurônios- $\alpha$ que inervam os músculos distais dos membros superiores.

Entretanto, os dados obtidos na literatura fundamentam a segunda hipótese, ou seja, ocorre uma reorganização medular caudal ao nível da lesão, com desenvolvimento de novas conexões sinápticas, sugerindo uma possível regeneração da medula (CALANCIE; LUTTON \& BROTON, 1996); (CALANCIE, MOLANO \& BROTON, 2002). Portanto, sugere-se que os resultados obtidos da atividade mioelétrica dos membros superiores deste tetraplégico - reflexo intermembros indicam reorganização dos reflexos, aumento da excitabilidade neural e possível recuperação da função medular, decorrentes dos efeitos terapêuticos do Programa de Estimulação Elétrica Neuromuscular. 
ANEXO A 


\section{Unidade de Reabilitação do Aparelho Locomotor \\ Programa de Estimulação Elétrica Neuromuscular \\ Departamento de Ortopedia e Traumatologia - FCM/UNICAMP}

\section{Termo de Consentimento Pós - Informação}

Eu, portador do RG $n^{\circ}$.

$\mathrm{HC} \mathrm{n}^{\circ}$ , residente à

$\mathrm{N}^{\mathrm{o}}$. Bairro cidade de

Estado Telefone $\mathrm{n}^{\circ}$. $0 \mathrm{xx}$ ,nascido aos 1 ,declaro que contatei a Unidade de Reabilitação do Aparelho Locomotor com o intuito de solicitar minha participação no Programa de Estimulação Elétrica Neuromuscular. Nesta Unidade fui devidamente informado(a) sobre o seguinte:

$1^{\circ}$ ) que a estimulação elétrica neuromuscular é um procedimento não invasivo, realizado externamente na pele e, deste modo, não tem efeitos colaterais e não traz qualquer risco para integridade física do lesado medular;

$2^{\circ}$ ) que o objetivo geral do programa é a busca pela restauração dos movimentos dos membros paralisados e a prevenção e/ou redução da osteoporose;

$3^{\circ}$ ) que pesquisadores pós-graduandos desenvolvem projetos de pesquisa específicos dentro do Programa de Estimulação Elétrica Neuromuscular, coordenados pelo Prof. Dr. Alberto Cliquet Jr., e estou devidamente informado(a), segundo as normas e exigências do Comitê de Ética em pesquisa da FCM/UNICAMP que faço parte de um destes projetos;

$4^{\circ}$ ) que poderei, a qualquer momento, retirar-me do programa, sem que com isso venha a prejudicarme nos demais atendimentos do HC/UNICAMP.

Por fim, comprometo-me a informar a equipe sobre todo e qualquer tipo de procedimentos (e/ou tratamentos) externos, concomitantes à estimulação elétrica neuromuscular que são ou que venham a ser realizados no futuro. de de 200

Assinatura ou Impressão digital do paciente
Prof. Dr. Alberto Cliquet Jr.

(Coordenador do Programa)

Assinatura da Testemunha

RG: 
ANEXO B 


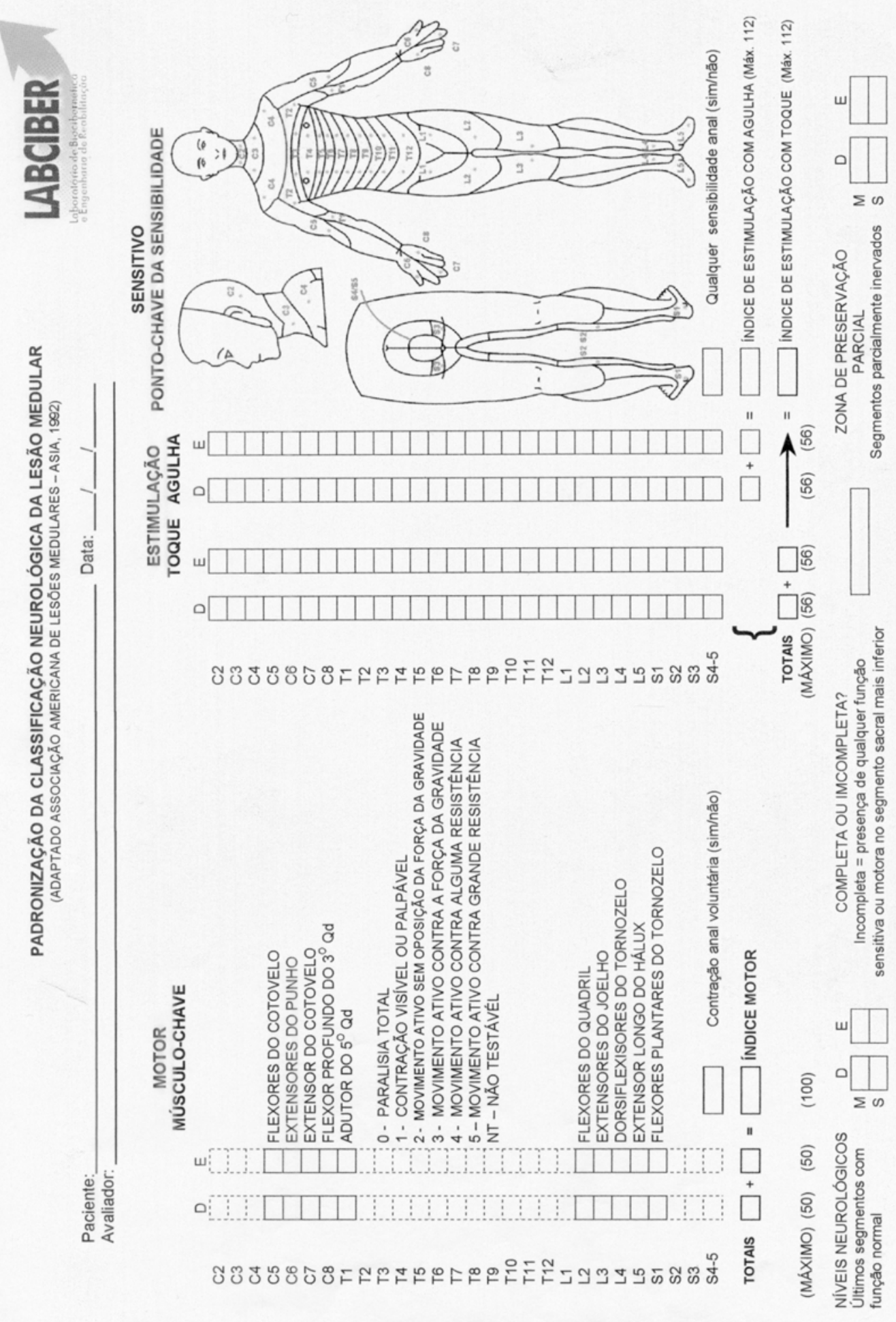




\section{PADRONIZAÇÃO DA CLASSIFICAÇÃO NEUROLÓGICA DA LESÃO MEDULAR \\ (Associação Americana de Lesões Medulares) \\ ÍNDICE DE INDEPENDÊNCIA FUNCIONAL}

Nome:

Data:

Examinador:

\section{CUIDADOS PESSOAIS}
a) alimentação:
b) cuidados com aparência:
c) banhos:
d) vestir parte superior do corpo:
e) vestir parte inferior do corpo:
f) asseio:

\section{CONTROLE DE ESFÍNCTERES}

g) controle vesical:

h) controle de esfíncter anal:

\section{MOBILIDADE/TRANSFERÊNCIA}

i) cama, cadeira, cadeira de rodas:

j) banheiro:

k) banheira, chuveiro:

\section{LOCOMOÇÃO}

l) caminhar, cadeira de rodas:

m) escada:

V. COMUNICAÇÃO

n) compreensão:

o) expressão:

\section{COGNIÇÃO SOCIAL}

p) interação social:

q) solução de problemas:

r) memória: 


\section{NÍVEIS}

\section{COM ASSISTÊNCIA}

\section{DEPENDÊNCIA COMPLETA}

1. Assistência total: indivíduo emprega nessa atividade de 0 a $25 \%$ do esforço necessário

2. Assistência máxima: indivíduo emprega nessa atividade de 25 a $50 \%$ do esforço necessário

\section{DEPENDÊNCIA MODIFICADA}

3. Assistência moderada: indivíduo requer mais que contato físico e emprega nessa atividade de 50 a 75\% do esforço necessário

4. Assistência mínima: com mínimo de contato: indivíduo não requer mais que contato físico e emprega nessa atividade $75 \%$ ou mais do esforço necessário

5. Supervisão: não requer assistência física, porém necessita de estímulos e disposição

\section{SEM ASSISTÊNCIA}

\section{INDEPENDÊNCIA}

6. Independência modificada (aparelhada): a atividade requer apoio assistencial e/ou não um tempo maior para sua execução e/ou se realiza de forma segura

7. Completa independência (imediata, com segurança): a atividade é feita de forma segura, sem modificação, sem órtese ou apoio assistencial e em tempo relativamente razoável 